\title{
FERRITE MATERIALS FOR PHOTOASSISTED ENVIRONMENTAL AND SOLAR FUELS APPLICATIONS
}

\author{
Patricia Garcia-Muñoz, ${ }^{1 *}$ Fernando Fresno ${ }^{2}$, Víctor A. de la Peña O'Shea ${ }^{2}$, Nicolas Keller ${ }^{1}$ \\ ${ }^{1}$ Institut de Chimie et Procédés pour l'Energie, I'Environnement et la Santé (ICPEES), CNRS/University \\ of Strasbourg, 25 rue Becquerel, Strasbourg, France. \\ ${ }^{2}$ Photoactivated Processes Unit, IMDEA Energy Institute, Móstoles, 28935, Madrid, Spain \\ * garciamunoz@unistra.fr \\ P. Garcia-Muñoz ORCID: 0000-0001-6157-7952 \\ F. Fresno ORCID: 0000-0001-6622-6721 \\ V. A. de la Peña O'Shea ORCID: 0000-0001-5762-4787 \\ N. Keller ORCID: 0000-0003-1965-2730
}

\section{ABSTRACT}

Ferrites are a large class of oxides containing $\mathrm{Fe}^{3+}$ and at least another metal cation that have been investigated for and applied to a wide variety of fields ranging from mature technologies like circuitry, permanent magnets, magnetic recording and microwave devices to the most recent developments in areas like bioimaging, gas sensing, and photocatalysis. In the last respect, although ferrites have been less studied than other types of semiconductors, they present interesting properties such as visible light absorption, tuneable optoelectronic properties and high chemical and photochemical stability. The versatility of their chemical composition and of their crystallographic structure opened a playground for developing new catalysts with enhanced efficiency. This article reviews the recent development of the application of ferrites to photoassisted processes for environmental remediation and for the synthesis of solar fuels. Applications in the photocatalytic degradation of pollutants in water and air, photo-Fenton, and solar fuels production, via photocatalytic and photoelectrochemical water splitting and $\mathrm{CO}_{2}$ reduction, are reviewed paying special attention to the relationships between the physico-chemical characteristics of the ferrite materials and their photo-activated performance. 
KEYWORDS: ferrite; photocatalyst; heterojunction; water treatment; air detoxification; solar fuels

\section{Ferrites: structure, synthesis and properties}

\subsection{Structure of ferrites}

Ferrites - with an ethymology from the latin word 'ferrum' meaning iron - are a large class of oxides containing $\mathrm{Fe}^{3+}$ and at least another metal cation that have been investigated and applied as powder, films or ceramic bodies for the last 50 years. They are classified according to their crystal structure and the way the oxygen anions are arranged around the metal cations, as spinel, garnet, magnetoplumbite and orthoferrite. While spinel and garnet ferrites both crystallize within a cubic structure, magnetoplumbites and orthoferrites crystallize within a hexagonal and orthorhombic structure, respectively.

\subsubsection{Spinel ferrites}

Spinel ferrites are compounds with a general chemical formula $\mathrm{MFe}_{2} \mathrm{O}_{4}$, where $\mathrm{M}$ refers to a divalent metal cation, and that crystallize in a crystallographic structure isomorph with that of the naturally-occurring mineral spinel $\mathrm{MgAl}_{2} \mathrm{O}_{4} \quad\left(\mathrm{AB}_{2} \mathrm{O}_{4}\right.$ as general composition). They crystallize in a cubic symmetry structure containing eight formula units $A[B]_{2} \mathrm{O}_{4}$, with a rigid sub-lattice of 32 closely packed oxygen anions giving rise to 64 tetrahedral (A)-type and 32 octahedral [B]-type interstitial sites partially occupied by $24 \mathrm{M}^{2+}$ and $\mathrm{Fe}^{3+}$ metal cations (Figure 1). Depending on the synthetic conditions, tetragonal unit cells can be obtained as well [1]. In the spinel ferrites, the electrical neutrality is maintained by $\mathrm{M}^{2+}$ and $\mathrm{Fe}^{3+}$ cations occupying both tetrahedral and octahedral interstitial sites. The interstitial fourfold and sixfold sites have $r_{t}$ and $r_{o}$ radii in the $0.055 \mathrm{~nm}<r_{t}<0.067 \mathrm{~nm}$ and $0.070 \mathrm{~nm}<r_{0}<0.075 \mathrm{~nm}$ range, so that they can be occupied by many transition metal cations with $\mathrm{d}^{0}$ to $\mathrm{d}^{10}$ electronic configurations. 


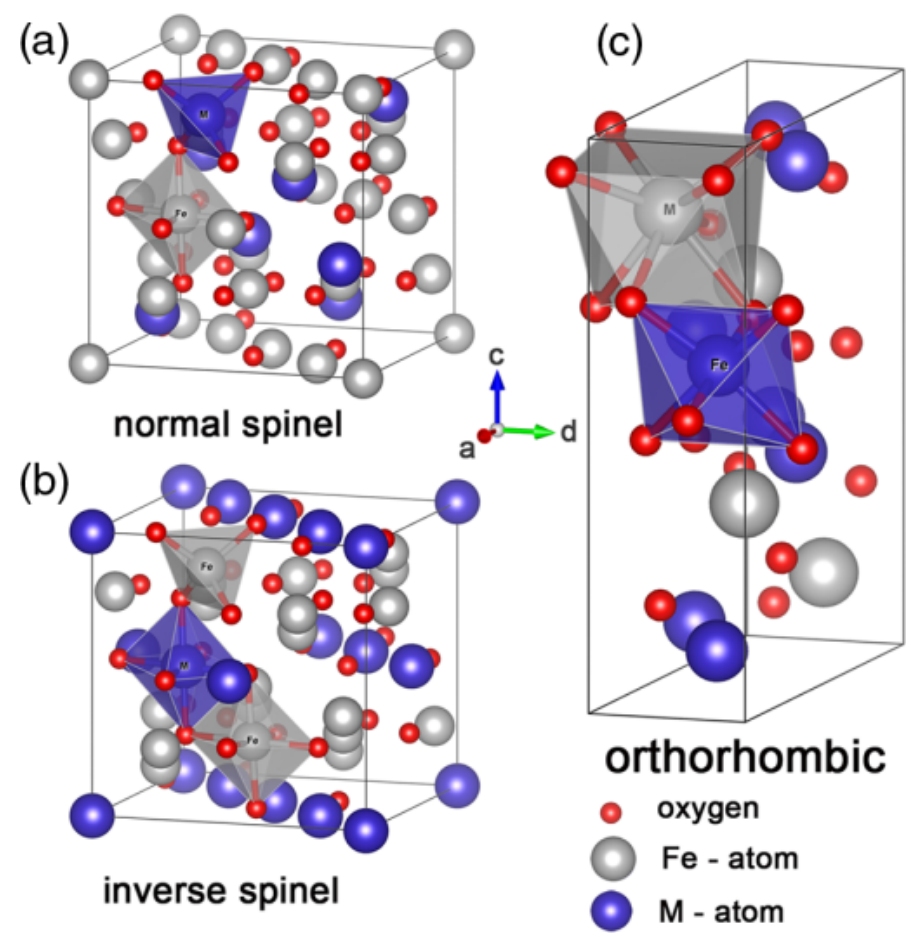

Figure 1. Crystallographic structure of $\mathrm{AB}_{2} \mathrm{O}_{4}$ spinel ferrites schematizing the different crystallographic sites: (a) normal spinel, (b) inverse spinel, and (c) orthorhombic. Reproduced with permission from ref. [2] Copyright SPIE

The octahedral vs. tetrahedral site occupation - and therefore the spinel ferrite structure - is reported to be driven by the electrostatic contribution to the lattice energy, the cation radii, the cation charge and the crystal field effect. The reader can refer to the work of Sickafus et al.[2]. Following the $\mathrm{M}^{2+}$ and $\mathrm{Fe}^{3+}$ metal cation balance between both tetrahedral and octahedral sites, the spinel ferrites are categorized as:

- normal spinels $\left(\mathrm{M}^{2+}\right)^{T d}\left[\mathrm{Fe}^{3+}\right]_{2}{ }_{2} \mathrm{O}_{4}$, in which the smaller divalent $\mathrm{M}^{2+}$ cations occupy only the tetrahedral A-sites and the trivalent $\mathrm{Fe}^{3+}$ cations occupy the octahedral B-sites. Eg. Zn- or $\mathrm{Cd}-\mathrm{Fe}_{2} \mathrm{O}_{4}$.

- $\quad$ inverse spinels $\left(\mathrm{Fe}^{3+}\right)^{T d}\left[\mathrm{M}^{2+} \mathrm{Fe}^{3+}\right]^{\mathrm{Oh}} \mathrm{O}_{4}$ in which the divalent $\mathrm{M}^{2+}$ cations are located in the octahedral B-sites, while the trivalent $\mathrm{Fe}^{3+}$ cations are equally distributed between both tetrahedral A-sites and octahedral B-sites. Eg. Mg-, Co-, $\mathrm{Cu}_{-}, \mathrm{Ni}-$, NiCo-, CuMn- or $\mathrm{MgCu}-\mathrm{Fe}_{2} \mathrm{O}_{4}$. 
- $\quad$ mixed spinels $\left(\mathrm{M}_{\mathrm{x}}^{2+} \mathrm{Fe}_{\mathrm{y}}^{3+}\right)^{T d}\left[\mathrm{M}_{1-\mathrm{x}}^{2+} \mathrm{Fe}_{2-\mathrm{y}}^{3+}\right]^{\mathrm{Oh}} \mathrm{O}_{4}$, in which both the divalent $\mathrm{M}^{2+}$ and trivalent $\mathrm{Fe}^{3+}$ cations are distributed between both tetrahedral A-sites and octahedral B-sites. e. g. NiZn-, MgZn-, ZnMn-, MnNi-, CuZn- or NiCuZn-Fe $\mathrm{O}_{4}$.

Some spinel ferrites, such as $\mathrm{MgFe}_{2} \mathrm{O}_{4}, \mathrm{CaFe}_{2} \mathrm{O}_{4}$ and $\mathrm{BaFe}_{2} \mathrm{O}_{4}$, are also reported to crystallize as orthorhombic phases [3-5] (Fig 1c).

\subsubsection{Garnet ferrites}

Garnets are ferrites with a general chemical formula $\mathrm{M}_{3} \mathrm{Fe}_{5} \mathrm{O}_{12}$, where $\mathrm{M}$ is a rare-earth cation. They crystallize in the structure of the $X_{3} Y_{2}\left(\mathrm{SiO}_{4}\right)_{3}$ silicate mineral garnet, in which the $X$ and $Y$ sites are usually occupied by divalent $\left(\mathrm{Ca}^{2+}, \mathrm{Mg}^{2+}, \mathrm{Fe}^{2+}\right)$ and trivalent $\left(\mathrm{Al}^{3+}, \mathrm{Fe}^{3+}, \mathrm{Cr}^{3+}\right)$ cations, respectively, while the $\left(\mathrm{SiO}_{4}\right)^{4-}$ units are providing a tetrahedral framework [6]. They crystallize in the cubic system, within a relatively complex structure based on a unit cell composed of eight formula units. Three kinds of cations sites coexist within this structure, and the cation distribution is usually expressed as $\left\{\mathrm{M}_{3}\right\}\left(\mathrm{Fe}_{3}\right)\left[\mathrm{Fe}_{2}\right] \mathrm{O}_{12}$. The $\mathrm{M}$ rare-earth cations occupy the largest dodecahedral (eightfold) sites, while the $\mathrm{Fe}^{3+}$ cations distribute among both tetrahedral (fourfold) and octahedral (sixfold) sites. By contrast to the spinel structure, the oxygen sublattice is better described as a polyhedral arrangement rather than as a closepacked one.

\subsubsection{Magnetoplumbite ferrites}

Magnetoplumbites are synthetic ferrites first prepared at Philips Lab in the 50s, and mainly sharing a general chemical formula $\mathrm{M}^{2+} \mathrm{Fe}_{12} \mathrm{O}_{19}$, where $\mathrm{M}^{2+}$ can be $\mathrm{Ba}^{2+}, \mathrm{Pb}^{2+}, \mathrm{Sr}^{2+}$ or $\mathrm{Ca}^{2+}$. Although they are labelled also as hexaferrites, they crystallize in a hexagonal or rhombohedral symmetry structure. In addition to the $\mathrm{MFe}_{12} \mathrm{O}_{19}$ form (labelled as $\mathrm{M}$ type ferrite, Figure 2), they can be categorized within five other groups, consisting in $\mathrm{M}_{1-4} \mathrm{Me}_{2} \mathrm{Fe}_{12}$ ${ }_{36} \mathrm{O}_{22-60}$ type ferrites. While $\mathrm{M}^{2+}$ is considered as a large divalent cation, $\mathrm{Me}^{2+}$ represents usually a smaller divalent first-row transition metal cation such as $\mathrm{Co}^{2+}, \mathrm{Fe}^{2+}, \mathrm{Zn}^{2+}$ or $\mathrm{Ni}^{2+}$. They are consequently categorized as Z-type $\left(\mathrm{Ba}_{3} \mathrm{Me}_{2} \mathrm{Fe}_{24} \mathrm{O}_{41}\right)$, Y-type $\left(\mathrm{Ba}_{2} \mathrm{Me}_{2} \mathrm{Fe}_{12} \mathrm{O}_{22}\right)$, X-type 
$\left(\mathrm{Ba}_{2} \mathrm{Me}_{2} \mathrm{Fe}_{28} \mathrm{O}_{46}\right), \mathrm{W}$-type ferrites $\left(\mathrm{BaMe}_{2} \mathrm{Fe}_{16} \mathrm{O}_{27}\right)$, and $\mathrm{U}$-type $\left(\mathrm{Ba}_{4} \mathrm{Me}_{2} \mathrm{Fe}_{36} \mathrm{O}_{60}\right)$ ferrites [7]. The most studied magnetoplumbites are ferrites containing $\mathrm{Ba}$ and $\mathrm{Co}$ as divalent cations, but a large range of cation-substituted hexaferrites are investigated, especially $M, W, Z$ and $Y$ ferrites containing $\mathrm{Sr}, \mathrm{Zn}, \mathrm{Ni}$ and $\mathrm{Mg}$. Hexaferrites can also form many solid solutions, and partial substitution with trivalent or tetravalent cations can be performed. The reader can refer to the review of Pullar for in-depth analysis [7].
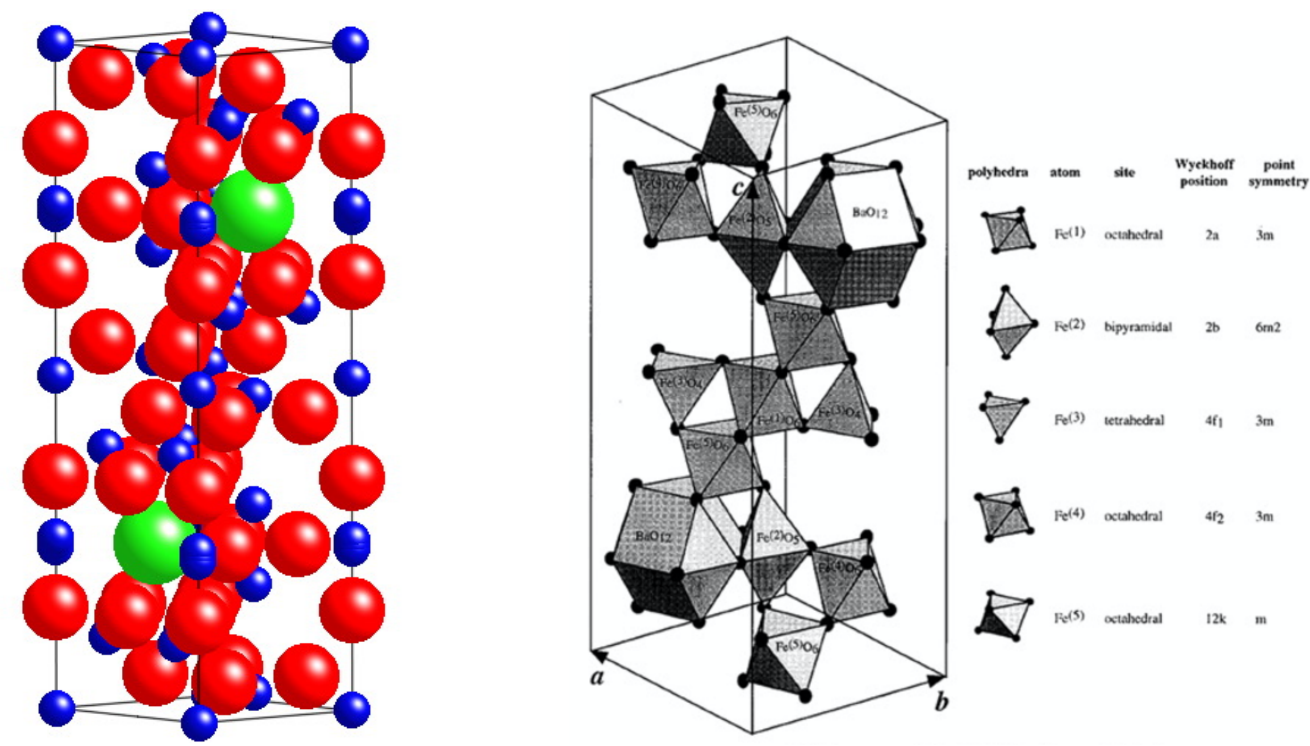

Figure 2. (left) Perspective view [8] and (right) polyhedra of the unit cell in the case of the Mferrite structure $\left(\mathrm{BaFe}_{12} \mathrm{O}_{19}\right)$ (Fe blue, $\mathrm{Ba}$ green, $\mathrm{O}$ red). Reproduced with permission from ref. [9] Copyright Elsevier and Wiley.

\subsubsection{Orthoferrites}

Orthoferrites are ferrites with a general chemical formula $\mathrm{MFeO}_{3}$, where $\mathrm{M}$ is very often a rare-earth cation, an alkaline or an alkaline earth metal cation. They crystallize in a distorted perovskite structure with an orthorhombic symmetry and $\mathrm{ABO}_{3}$ formula unit, in which $\mathrm{FeO}_{6}$ as a rotary tilted $\mathrm{BO}_{6}$ element fills the empty space left around the $\mathrm{A}$ cation (Figure 3 ). In this structure, the Fe cations occupy octahedral sites and are sixfold coordinated to oxygen anions, 
while the larger $\mathrm{M}$ cation is twelvefold coordinated to anions. While the ideal perovskite-type structure displays a cubic symmetry with a unit cell composed of four formula units in which the atoms are touching one another, the deviation from the ideal perovskite structure to give pseudo-cubic - mainly orthorhombic - symmetry has been rationalized by Goldschmidt [10]. He introduced a tolerance factor $t$ applicable at room temperature to the empirical ionic radii and materializing the stability and the distortion of the crystal structure within the following range:

$$
0.75<t=\frac{\left(r_{A}+r_{O}\right)}{\sqrt{2}\left(r_{B}+r_{O}\right)}<1
$$

For instance, lanthanum orthoferrite $\mathrm{LaFeO}_{3}$ shows a high Goldschmidt tolerance factor of 0.954, indicating that the distorted structure maintains a high level of symmetry, while the Yttrium orthoferrite $\mathrm{YFeO}_{3}$ structure displays a far lower symmetry with a lower tolerance factor of $0.855[11]$.

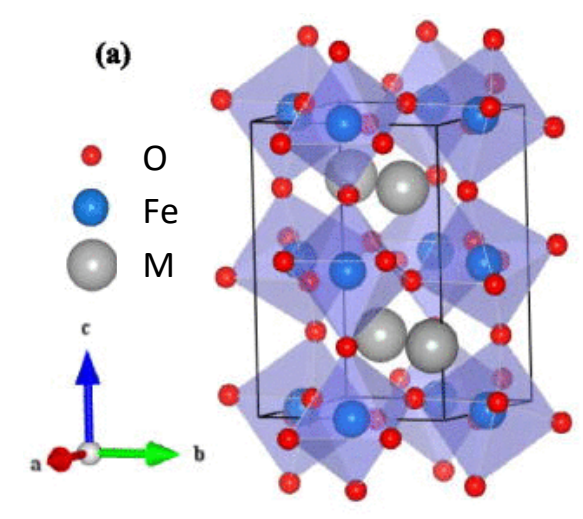

Figure 3. Crystallographic structure of $\mathrm{MFeO}_{3}$ orthoferrites with distorted perovskite structure (orthorhombic crystal symmetry). Adapted and reproduced with permission from ref. [12]. Copyright AIP Publishing.

\subsection{Preparation methods}

Progress in the synthesis of orthoferrites and spinel ferrites has been driven in the last decades by the technological interest aroused by the ferrite materials in various interdisciplinary application fields and by that derived from their tunable magnetic properties. Whether they 
are categorized as bottom-up or top-down approaches, or as chemical or physical methods, a large variety of preparation methods have been investigated for synthesizing ferrite nanoparticles. Among them, co-precipitation, sol-gel methods, thermal methods and solidstate reactions remain the most popular strategies implemented for elaborating catalysts for heterogeneous photo-Fenton or photocatalysis, whereas a large (non-exhaustive) panel of methods such as sonochemical, microemulsion, reverse micelle, electrospinning, polyol, electrochemical, (auto)combustion, vapor deposition, laser ablation or flame-spray pyrolysis methods has been also reported (Figures 4 and 5) [13-16].

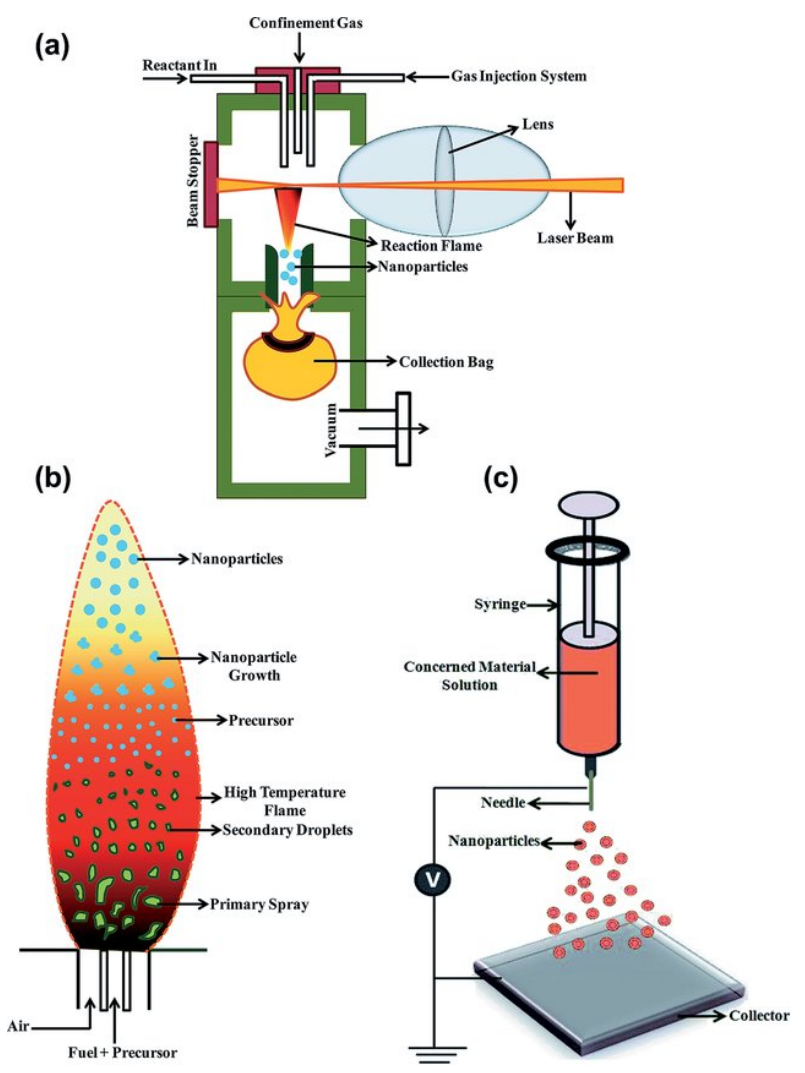

Figure 4. Schematic diagrams of some selected less conventional synthesis methods (a) laser pyrolysis, that uses a laser for the decomposition of materials by heating gas-phase reactants in an oxygen-poor environment, (b) flame spray pyrolysis, that is the latest of the flame aerosol technologies, and consists in a one-step combustion process with self-sustaining flame where less volatile precursors are in liquid form, with significantly higher combustion enthalpy 
( $>50 \%$ of total energy of combustion), usually in an organic solvent ; and (c) electrospraying technique, that is a technique similar to electrospinning with the exception that it forms nanoparticles rather than nanofibers. Reproduced with permission from ref. [17]. Copyright Royal Society of Chemistry.

\section{(a)}

(b)

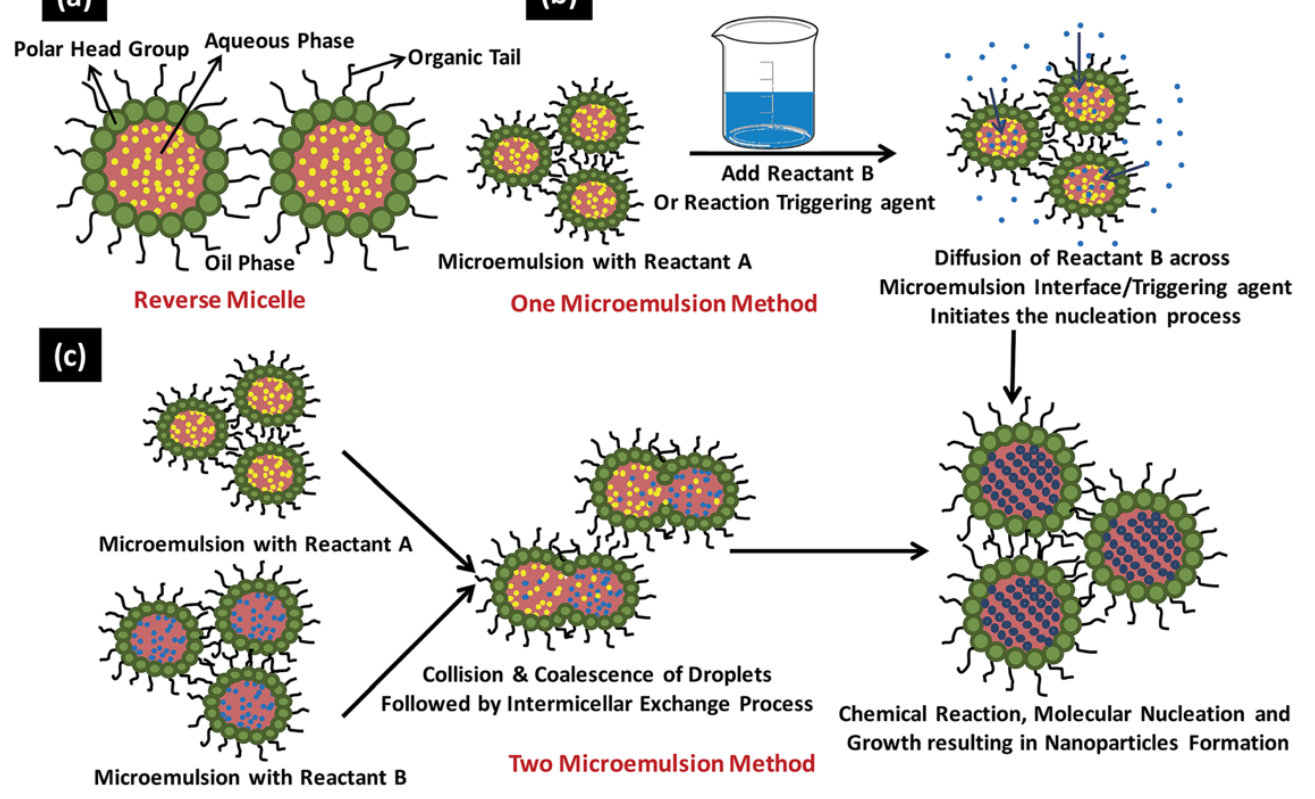

Figure 5. Schematic diagrams depicting microemulsion-based syntheses : (a) typical reverse micelle system, that is a water-in-oil microemulsion where the polar head groups of the surfactants creating the aqueous core reside towards the inside, whereas the organic tails of the surfactant molecules are directed towards the outside; (b) one-microemulsion synthesis method, and (c) two-microemulsion synthesis method in which the microemulsions carrying the separate reactants are mixed together in the appropriate ratio. Reproduced with permission from ref. [17]. Copyright Royal Society of Chemistry.

For applications in photocatalysis or photo-Fenton processes, the specific surface area exposed, the crystallinity as well as the possibility to tune the intrinsic properties of the ferrites (such as the surface redox properties, the band-gap values or the light absorption profile) are 
the main criteria to be considered for selecting the synthesis method. The cationic or anionic mono- or bi-substitution within the defined structure of the ferrites is an elegant and powerful way to tailor those properties. Further, as far as the catalysts need to operate in a manner consistent with the constraints of industrial implementation, whether it concerns liquid or gas phase applications, the synthesis method should allow the ferrite catalyst to be immobilized on macroscopic supports. In addition, since most of the methods require a thermal treatment for increasing the crystallinity of the ferrite materials, the methods enabling a lower temperature to be achieved has to be preferred for not impacting too strongly on the specific surface area. Therefore, the chemical syntheses in solution remain the preparation methods of choice, among which co-precipitation, sol-gel methods and thermal methods are the most popular ones.

\subsubsection{Co-precipitation method}

The co-precipitation is a very common and fast synthesis method consisting in favoring the simultaneous precipitation of insoluble or low solubility products formed under high supersaturation conditions, from aqueous solutions of metal precursors, through $\mathrm{pH}$ adjustment and use of precipitating agents. The overall process in solution consists in nucleation, growth, coarsening and/or agglomeration processes that are highly difficult to uncouple, while a final thermal treatment is needed for decomposing the intermediate precipitate into the usable ferrite as well as for crystallizing the oxide. The co-precipitation method has been successfully used for synthesizing a large variety of spinel ferrites [18-23] or orthoferrites, mono-, bi -or non-substituted.

\subsubsection{Sol-gel methods}

The sol-gel method is a versatile approach in which a metal alkoxide solution undergoes hydrolysis and condensation polymerization reactions, with the formation of a sol and subsequent cross-linking to form a gel. It requires usually a final heat treatment for removing volatile byproducts and crystallizing the ferrite material. It takes advantage of a relatively low annealing temperature compared to solid state reactions for maintaining a relatively high 
surface area. It globally benefits from its simplicity, low implementation costs and tuneability for preparing a large range of spinel ferrites [24-28] and orthoferrite structures [29-33] with controlled composition, structure and morphology. One can note that the sol-gel method combined with combustion was used for preparing $\mathrm{BaFe}_{12} \mathrm{O}_{19}$ and $\mathrm{CoFe}_{12} \mathrm{O}_{19}$ hexaferrites (magnetoplumbite structure) [26, 34].

Pechini developed a modified sol-gel method for materials which do not have favorable hydrolysis equilibria, and in which the metallic ions undergo complexation through the addition of bi-or tri-dentate organic chelating agents $[35,36]$. The method builds on the principles of sol-gel chemistry involving small-molecule chelating ligands that in the initial step form a solution of metal/chelate complexes. It takes this further to convert the mixture into a covalent polymer network to entrap the metal ions. The use of chelating agents allows stable complexes to be formed with a large variety of metals, and to get rid of the requirement that the metal has to form stable hydroxo species. The underlying strategy of the method lies in the delay of the thermal decomposition of the organic matrix in order to afford more control over the growing ceramic phase. While citric acid is the most popular chelating agent (i.e. citrate method), it can be also replaced by ethylenediaminetetraacetic acid (EDTA), which has the advantage of chelating most metals and, with four carboxylate groups, it is easily cross-linked to form a gel. When ethylene glycol is used in association with citric acid, the key-reaction is the transesterification between citrate and ethylene glycol (Figure 6). The metal salt dissolved in water with citric acid and ethylene glycol forms a homogeneous precursor solution containing the metal-citrate chelate complexes, while the heat-induced polyesterification between the citrate and ethylene glycol creates an extended covalent network. The method requires a final calcination step for combusting the organic matrix and forming the oxide. It became very popular for synthesizing ferrite materials, notably due to its ability to form a polymeric precursor where two or more metals may be dispersed homogeneously throughout the network [37, 38].

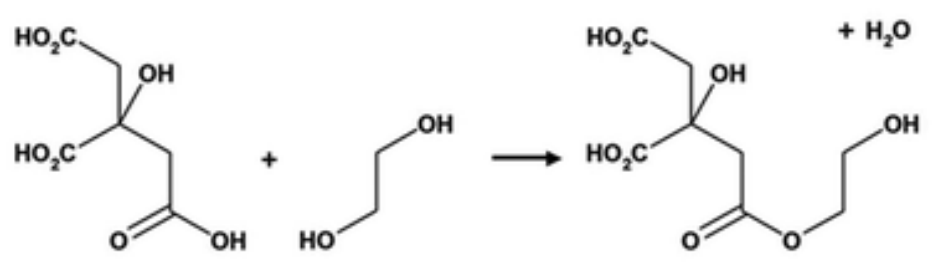




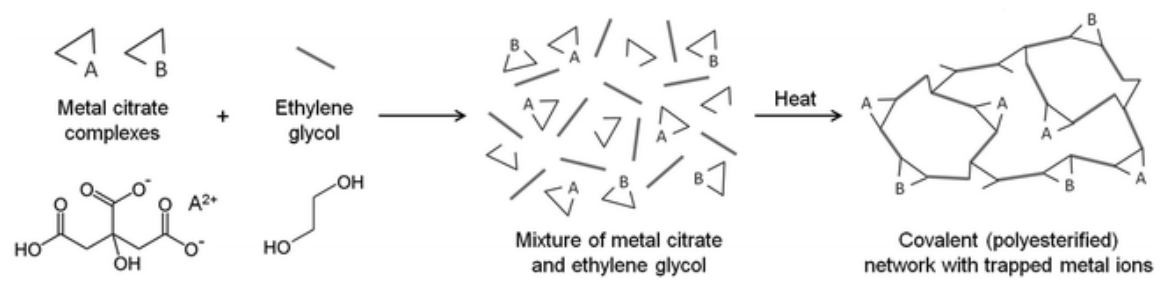

Figure 6. (top) Transesterification reaction occurring between citric acid and ethylene glycol in a typical Pechini process; (bottom) Proposed schematic of the process of making metal/organic gels. Reproduced with permission from ref. [39]. Copyright Royal Society of Chemistry.

\subsubsection{Thermal methods}

The thermal methods are mainly based on thermal decomposition [40], as well as on hydrothermal [41-44], solvothermal and microwave-assisted methods. While the thermal decomposition consists in the simple decomposition of precursors, organic solvents and surfactants during heat treatment to get the ferrite, the other methods are driven by the need to lower the temperature used for crystallization in order for the ferrite to maintain a suitable specific surface area. Hydrothermal and solvothermal usually differ in terms of solvent, aqueous vs. non-aqueous, respectively, in which the soluble metal salts are dissolved. Temperature, pressure, synthesis duration as well as choice of solvent, of precursors and of additional surfactant, are the main synthesis parameters impacting on the physico-chemical properties of the ferrites $[13,14,45,46]$. While the temperature can be as high as $500{ }^{\circ} \mathrm{C}$ for the thermal decomposition method, it can be decreased to the $100-200{ }^{\circ} \mathrm{C}$ range for solvothermal, hydrothermal and microwave-assisted methods. However, although the microwave-assisted syntheses allow shorter reaction durations to be achieved, they suffer usually from low synthesis yields.

\subsubsection{Solid-state reaction methods}


Besides the bottom-up chemical syntheses in solution above-reported, the solid-state reaction methods are a suitable top-down approach consisting in treating solid precursors at high temperature, usually oxides or carbonates, for inducing solid-solid diffusion, with a further stabilization/crystallization of the ferrite defined structure. $\mathrm{CoFe}_{2} \mathrm{O}_{4}, \mathrm{CuFe}_{2} \mathrm{O}_{4}, \mathrm{NiFe}_{2} \mathrm{O}_{4}$ and $\mathrm{Ni}_{1-x} \mathrm{Mn}_{x} \mathrm{Fe}_{2} \mathrm{O}_{4}$ spinel ferrites have notably been synthesized [47-50]. However, the obtained ferrites usually suffer from low specific surface area when compared to chemical synthesis in solution. Therefore, the mechanical milling method has been implemented as a high-energy collision top-down approach method using planetary ball mill, high-energy shaker or tumbler mill for inducing proper conditions in which solid state chemical reactions can take place, mostly through mechanical activation or mechano-chemistry. However, while the method is low-cost and time-saving with easy up-scaling, it suffers notably from strong contamination problems during prolonged milling, non-stoichiometrical structure, nonuniform size distribution and low crystallinity.

Further, many more or less complex and versatile bottom-up or top-down methods have been implemented for preparing ferrite materials, alone or as part of the main popular methods above-described. Without being exhaustive, one can list notably microemulsion, flame spray pyrolysis, auto-combustion, vapour deposition, liquid exchange, self-reactive quenching, or electrospinning. The reader can refer to the reviews of Kefeni et al. [13] and Tatarchuk et al. [24], or directly to the original research cited therein.

Finally, it is worth noting that the optimal physico-chemical properties that the ferrite materials need to exhibit are highly depending on their application fields, so that putting into perspective the advantage vs disadvantage of the different preparation methods remain in many cases inappropriate.

\subsection{Ferrite properties}

Ferrites are globally considered as being thermally and chemically stable in aqueous systems [45], and the Pourbaix diagrams indicate that most of the ferrites are stable in most of the alkaline or near-neutral media used in photoelectrochemical cells [9]. However, they are reported to suffer from corrosion in acidic media [51, 52]. Independently of the 
crystallographic structure, the mono- or bi-substitution of the cations within the ferrite materials is known to affect many of their physico-chemical properties, among others, the resistivity (conductivity), the optical properties (reflectivity), the band-gap energy, the energy position of both valence and conduction bands, or the $\mathrm{p} / \mathrm{n}$-type behaviour [9]. Therefore, the controlled cationic single- or multi-substitution in the ferrite network, whether A- or B-sites are concerned, became an elegant, versatile and promising way to tune both bulk and surface physico-chemical properties of the ferrite-based photocatalysts used for environmental (water and air depollution) and solar fuel applications.

The specific surface area exposed by the ferrite materials is strongly depending on the preparation method. However, the ferrite catalysts globally exhibit low to medium specific surface area $\left(<100 \mathrm{~m}^{2} / \mathrm{g}\right)$, in contrast to lab-made or commercially available titania photocatalysts, that can reach high surface areas within the $200-350 \mathrm{~m}^{2} / \mathrm{g}$ range thanks to the implementation of adequate synthesis approaches. Without being obviously exhaustive, Table 1 gathers some selected spinel ferrites and orthoferrites, substituted or not, with their specific surface area, crystallite size and isoelectrical point being reported in relationship with their preparation method and final calcination temperature. It points out to which extent the synthesis method impacts on some properties of the materials. It has to be mentioned that maintaining a relatively low or moderate calcination temperature does not necessarily prevent failing to obtain high specific surface area ferrites, while, by contrast, it may result in materials with low crystallinity and therefore with a low photoactivity due to a high recombination rate.

Most of the ferrite materials are semiconductors and take advantage of being capable to absorb a part of visible light due to a band gap of about $2 \mathrm{eV}$ (corresponding to wavelengths lower than $621 \mathrm{~nm}$ ). This contrasts with the very popular anatase $\mathrm{TiO}_{2}$ reference material, whose band gap of $3.2 \mathrm{eV}$ allows only the absorption of UV light, corresponding to wavelengths lower than $388 \mathrm{~nm}$. Most of them display energy positions of both valence and conduction bands suitable for either the oxidation of water, the reduction of protons and/or the generation of active hydroxyl radicals from water and the reduction of dioxygen into the superoxide radical, as necessary for environmental and water splitting applications. Figure 7 gathers the band positions of the most popular ferrite materials with $\mathrm{AB}_{2} \mathrm{O}_{4}$ spinel structure. 
Similarly to its influence on the reactivity in thermal catalysis $[53,54]$, the chemical nature of the substituted metals and the magnitude of the mono- and bi-substitution ratios is known to influence some of the physico-chemical properties directly affecting the reactivity in photocatalysis, such as the optical properties via the band gap energy and the material reflectivity, the conductivity [55-57], as well as the n/p-type behavior of the semiconductor $[58,59]$.

The $p$ or $n$ nature of the spinel ferrite influences the positions of both conduction and valence bands, and consequently the band gap value as well. This can be evidenced in the case of the $\mathrm{MgFe}_{2} \mathrm{O}_{4}$ spinel ferrite, with a conduction band for the $p$-ferrite being $1.8 \mathrm{eV}$ more cathodic compared to its $n$-counterpart, and band gap being smaller from ca. $0.3 \mathrm{eV}$. for the $p$-ferrite. By contrast, the $\mathrm{p}$ - or $\mathrm{n}$ - nature of the $\mathrm{ZnFe}_{2} \mathrm{O}_{4}$ ferrite has been reported to only affect the band position, for the $p$-ferrite being $c a .1 .2 \mathrm{eV}$ more cathodic compared to its $n$ counterpart.

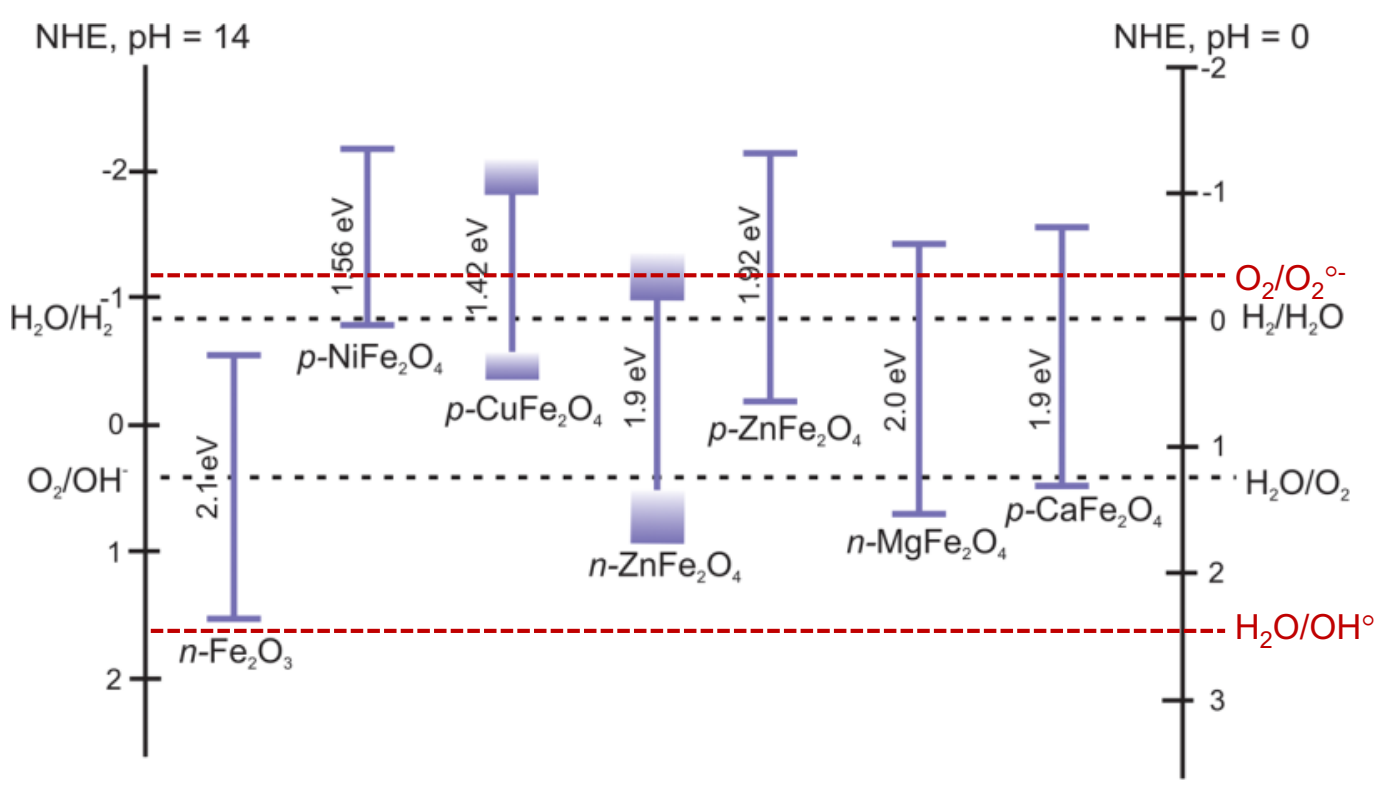

Figure 7. Band positions of the most popular spinel ferrites in contact with aqueous solution referenced to normal hydrogen electrode $(\mathrm{RHE})$ (right $\mathrm{pH}=10$ and left $\mathrm{pH}=14$ ) relative to the standard potentials for the oxidation and reduction of water, as well as for the reduction of dioxygen into the superoxide radical and the oxidation of water into the hydroxyl radical. Adapted from [9]. 
Growing interest has been paid to $\mathrm{ABO}_{3}$ transition-metal oxide orthoferrites thanks to a small band gap (2.0-2.7 eV), that allows the catalyst to be activated by visible light, and that results from the relative location of valence and conduction bands, mainly constituted of strongly mixed $e_{g}$ states of Fe $3 d$ and $\mathrm{O} 2 p$ states, and of the $t_{2 g}$ states of Fe $3 d$, respectively. For instance, $\mathrm{LaFeO}_{3}$, one of the most common and promising perovskite-like ferrite catalyst, is usually reported with a band gap between 2.0 and $2.6 \mathrm{eV}$, depending on the synthesis method and their resulting physico-chemical properties $[37,83]$. Ansari et al. used $\mathrm{CoFe}_{12} \mathrm{O}_{19}$ hexaferrites as photocatalyst with a $3 \mathrm{eV}$ band-gap [34]. By contrast Zielinska et al. graphically estimated the band-gap of the $\mathrm{BaFe}_{12} \mathrm{O}_{19}$ semiconductors material at $1.0 \mathrm{eV}$ [26].

\subsection{Towards more efficient ferrite-based photocatalytic materials}

Ferrite semiconductor-based photocatalysis and photoelectrochemistry have attracted attention because of the ability of the ferrite materials to absorb and consequently use visible light - and therefore to directly convert the solar energy - for performing surface redox reactions allowing environmental remediation to be implemented and solar fuels to be synthesized. During the photocatalytic process, the recombination of the photogenerated electron-hole pairs plays a highly negative role. Thus, similarly to the wide bandgap semiconductor $\mathrm{TiO}_{2}$, considered as the most frequently used semi-conductor photocatalyst under UV-A light, the photocatalytic efficiency of the ferrites is usually defined by the abundance and stability of the photo-generated charges (electron and holes). Therefore, efforts have been devoted to extending the life time of such charge carriers, i.e. to slowing down their recombination rate. Many approaches have been investigated for that purpose, including the modification of the shape of the nanoparticles or of their chemical compositions through the design and fabrication of semiconductor heterostructures, hybrid nanocomposites, doped-nanostructures or more globally multi-phase materials.

The design of semiconductor heterojunctions is a general and very promising strategy for elaborating ferrite-based photocatalysts with improved efficiency, whether the reactions concern environmental applications (water and air depollution) or the solar fuel field for the energy-related applications ( $\mathrm{CO}_{2}$ conversion or $\mathrm{H}_{2}$ production). Basically, a heterojunction can 
in general be schematically described as the interface between two different semiconductors with unequal band structure, that can result in band alignments $[60,61]$. In the recent years, most of the studies were devoted to the creation of controlled heterojunctions with anatase $\mathrm{TiO}_{2}$ of different morphologies absorbing UV-A light, or with the smaller gap graphitic $\mathrm{g}-\mathrm{C}_{3} \mathrm{~N}_{4}$ semiconductor absorbing visible light, as well as to the design of visible light responsive ferrite/ferrite interface heterojunctions. Whatever the configuration investigated, the heterojunction strategy was mainly implemented for use as photocatalysts and photoelectrodes for energy applications. Details are given in the further corresponding sections.

In some cases like for conventional Z-scheme heterojunctions, there is not physical contact between both systems, the charges migrating through donor/acceptor pairs [62]. Depending on the band gaps and on the relative position of the valence and conduction bands of both semiconductors, the engineering of ferrite-based heterojunctions aims (i) at separating spatially the photogenerated charges for extending the charge carrier life time thanks to efficient semi-conductor/semi-conductor interfacial charge transfers, and/or (ii) at using the ferrite semiconductor as solid visible light absorption/harvesting system for the photosensitization of wider band gap semiconductors (ie. $\mathrm{TiO}_{2}$ ).

The reader can refer to the critical reviews of Low et al. [63] and Jang et al. [64] that extensively depicted and systematically discussed the basic principles of various heterojunction photocatalysts, namely conventional heterojunctions of type I-II-III depending on the relative positions of both bandgaps, $p-n$ heterojunctions, direct Z-Scheme heterojunctions (including solid-state Z-scheme) as well as graphene-based heterojunctions.

The elaboration of metal-ferrite semiconductor junctions is another strategy followed by different research groups reported in the next sections of this review. The supported metals consists usually in nanoscale metal islands on the semiconductor. The junction forms an electric field that facilitates the separation the photogenerated electrons and holes $[65,66]$, together with the formation of local space charge separation zones at the interphase. Beside a role for enhancing the lifetime of the charge carries, the supported metallic nanoparticles act as well as co-catalyst in different innovative ferrite-based systems used as photocatalysts or photoelectrodes for hydrogen production and $\mathrm{CO}_{2}$ reduction (see section 3 ). 
The association of ferrites nanoparticles with adsorbent materials such as montmorillonite or palygorskite clays is also reported in the field of environmental remediation for trying to take advantage of the synergistic effect of adsorption and catalysis (section 2).

Finally, the cationic doping of ferrite - usually depicted as partially substituted ferrites - is a very promising approach investigated by many research groups for improving the efficiency of the ferrite photocatalysts and photoelectrodes, and reported in the next sections. Indeed, whatever the crystallographic structures of the catalysts, the composition versatility of the ferrites - eg. as $A_{1-x} A^{\prime}{ }_{x} B_{1-y} B^{\prime}{ }_{y} O_{3 \pm \delta}$ or $A_{1-x} A^{\prime}{ }_{x} B_{2-y} B^{\prime}{ }_{y} O_{4 \pm \delta}$ in the case of orthoferites or spinel ferrites, respectively- is a great advantage for modifying many bulk and surface physicochemical properties of the ferrites, including their textural, structural or electronic properties, and as a result for tuning the redox and catalytic ability of the ferrites through A-and/or B-site cationic partial substitution.

The objective of improving the efficiency of the ferrite-based photocatalysts and photoelectrodes requires investigating charge trapping and recombination as well as understanding the factors affecting the related processes. Furthermore, deeper understanding of the relationship between the physico-chemical properties of the ferritebased systems and the catalytic behavior and efficiency indicators under visible or solar light is absolutely necessary. Especially, understanding the physico-chemical phenomena taking place in the bulk, and at the surface and the interfaces of the multi-component systems, is of high interest, as well as understanding the catalytic mechanism(s) taking place on such systems, and how the material design can orientate the efficiency indicators. 
Table 1. Selected spinel ferrites and orthoferrites with their specific surface area, crystallite size and isoelectrical point following their preparation method and final calcination temperature

\begin{tabular}{|c|c|c|c|c|c|}
\hline Ferrites & $\begin{array}{l}\text { Specific } \\
\text { surface area } \\
\left(\mathrm{m}^{2} / \mathrm{g}\right)\end{array}$ & $\begin{array}{l}\text { Crystallite } \\
\text { size }(\mathrm{nm})\end{array}$ & $\begin{array}{l}\text { Isoelectric } \\
\text { Point }\end{array}$ & Preparation method (calcination temperature) & References \\
\hline $\mathrm{CuFe}_{2} \mathrm{O}_{4}$ & $48-69$ & $30-110^{b}$ & 7.3 & $\begin{array}{l}\text { Combination of acid leaching, chemical exchange, } \\
\text { and ferrite process from Printed Circuit Board } \\
\text { sludge }\end{array}$ & $\begin{array}{l}\text { Tu et al. (2013), Tu } \\
\text { Etal. (2012) and Tu } \\
\text { et al. (2014) [67-69] }\end{array}$ \\
\hline $\mathrm{CuFe}_{2} \mathrm{O}_{4}$ & 70 & $72^{\mathrm{a}}$ & - & Micro-emulsion $\left(650^{\circ} \mathrm{C}\right)$ & $\begin{array}{l}\text { Rehman et al. } \\
(2015)[70]\end{array}$ \\
\hline $\mathrm{CoFe}_{2} \mathrm{O}_{4}$ & 149 & $20-30^{c}$ & 8.1 & Hydrothermal $\left(100^{\circ} \mathrm{C}\right)$ & $\begin{array}{l}\text { Sun et al (2019) } \\
{[71]}\end{array}$ \\
\hline $\mathrm{CoFe}_{2} \mathrm{O}_{4}$ & 202 & $10-20^{c}$ & 8.0 & Hydrothermal $\left(100^{\circ} \mathrm{C}\right)$ & $\begin{array}{l}\text { Sun et al (2019) } \\
{[71]}\end{array}$ \\
\hline $\mathrm{Co}_{0.6} \mathrm{Fe}_{0.4} \mathrm{Fe}_{2} \mathrm{O}_{4}$ & 97 & $14^{c}$ & 2.9 & Thermal decomposition $\left(400^{\circ} \mathrm{C}\right)$ & $\begin{array}{l}\text { Duan et al. (2015) } \\
\text { [72] }\end{array}$ \\
\hline $\mathrm{MnFe}_{2} \mathrm{O}_{4}$ & 48 & $50-80^{c}$ & 6 & Hydrothermal $\left(100^{\circ} \mathrm{C}\right)$ & $\begin{array}{l}\text { Sun et al. (2015) } \\
{[71]}\end{array}$ \\
\hline $\mathrm{ZnFe}_{2} \mathrm{O}_{4}$ hollow fibers & 132 & 50 & 6.5 & Sol-gel using kapok fibers as bio-template $\left(700^{\circ} \mathrm{C}\right)$ & Li et al. (2015) [73] \\
\hline $\mathrm{MgFe}_{2} \mathrm{O}_{4}$ & 54 & $25-35^{c}$ & 11 & Co-precipitation $\left(500^{\circ} \mathrm{C}\right)$ & $\begin{array}{l}\text { Srivastava et al. } \\
(2015)[74]\end{array}$ \\
\hline $\mathrm{MnFe}_{2} \mathrm{O}_{4}$ & $3-156$ & $200-290^{b}$ & 6.6 & Co-precipitation $\left(400^{\circ} \mathrm{C}\right)$ & $\begin{array}{l}\text { Yang et al. (2014) } \\
\text { [75] }\end{array}$ \\
\hline
\end{tabular}




\begin{tabular}{|c|c|c|c|c|c|}
\hline $\mathrm{MnFe}_{2} \mathrm{O}_{4}$ & 138 & $30-50^{c}$ & 7.5 & Co-precipitation & $\begin{array}{l}\text { Zhang et al. (2010) } \\
\text { [76] }\end{array}$ \\
\hline $\mathrm{CaFe}_{2} \mathrm{O}_{4}$ & $5-42$ & $15-30^{c}$ & 4.7 & Sol-gel in presence of citric acid $\left(200-800^{\circ} \mathrm{C}\right)$ & An et al. (2015) [77] \\
\hline $\mathrm{Ni}_{0.6} \mathrm{Fe}_{0.4} \mathrm{Fe}_{2} \mathrm{O}_{4}$ & 114 & $15^{\mathrm{c}}$ & 4.1 & Micro-emulsion $\left(400^{\circ} \mathrm{C}\right)$ & $\begin{array}{l}\text { Zeng et al. (2014) } \\
\text { [78] }\end{array}$ \\
\hline $\mathrm{Ni}_{0.5} \mathrm{Zn}_{0.45} \mathrm{Fe}_{2} \mathrm{O}_{4}$ & 70 & $15-18^{a}$ & - & Sol combustion $\left(400^{\circ} \mathrm{C}\right)$ & Liu et al. (2015) [79] \\
\hline $\mathrm{BiFeO}_{3}$ & 8 & $80-120$ & - & Pechini (citric acid) sol-gel $\left(500^{\circ} \mathrm{C}\right)$ & $\begin{array}{l}\text { Gao et al. (2007) } \\
{[80]}\end{array}$ \\
\hline $\mathrm{LaFeO}_{3}$ & $21-49$ & $1-22^{a}$ & - & Pechini (citric acid) sol-gel $\left(500-1000^{\circ} \mathrm{C}\right)$ & Li et al. (2007) [81] \\
\hline $\mathrm{LaFeO}_{3}$ dendrites & 68 & $84^{a}$ & - & Hydrothermal $\left(800^{\circ} \mathrm{C}\right)$ & $\begin{array}{l}\text { Thirumalairajan et } \\
\text { al. (2013) [82] }\end{array}$ \\
\hline $\mathrm{LaFeO}_{3}$ & $4-11$ & $27-46^{a}$ & - & Citric acid assisted sol-gel $\left(700-900^{\circ} \mathrm{C}\right)$ & $\begin{array}{l}\text { Ismael et al. (2019) } \\
\text { [83] }\end{array}$ \\
\hline $\mathrm{LaFeO}_{3}$ & $6-25$ & $24-104^{a}$ & - & Sol-gel autocombustion $\left(500-900^{\circ}\right)$ & $\begin{array}{l}\text { Parida et al. (2010) } \\
\text { [84] }\end{array}$ \\
\hline $\mathrm{LaFe}_{0.95} \mathrm{Mn}_{0.05} \mathrm{O}_{3}$ & 20 & 22 & - & Citric sol-gel method $\left(600^{\circ} \mathrm{C}\right)$ & $\begin{array}{l}\text { Gong et al. (2019) } \\
\text { [85] }\end{array}$ \\
\hline $\mathrm{LaFe}_{0.95} \mathrm{Ni}_{0.05} \mathrm{O}_{3}$ & 21 & 22 & - & Citric sol-gel method $\left(600^{\circ} \mathrm{C}\right)$ & $\begin{array}{l}\text { Gong et al. (2019) } \\
\text { [85] }\end{array}$ \\
\hline $\begin{array}{l}\mathrm{La}_{1-x} \mathrm{Ti}_{1 x} \mathrm{FeO}_{3} \\
(0<x<0.2)\end{array}$ & $8-40$ & $14-23^{a}$ & - & Pechini (citric acid) sol-gel $\left(800^{\circ} \mathrm{C}\right)$ & $\begin{array}{l}\text { Garcia-Muñoz et al. } \\
\text { (2019) [37] }\end{array}$ \\
\hline
\end{tabular}

$a, b$ and $c$ correspond to crystallite sizes derived from XRD, SEM and TEM analysis, respectively. 


\section{Ferrite photocatalysts for environmental applications: water detoxification and air depollution}

\subsection{Introduction}

Photocatalysis as an Advanced Oxidation Process has been applied for water treatment and for air depollution. These processes are based on the formation of highly oxidative species that can convert recalcitrant organic pollutants into mineral compounds, i.e. $\mathrm{CO}_{2}, \mathrm{H}_{2} \mathrm{O}$ and mineral acids. Among the catalysts that can be employed are found the ferrites. The main properties of those materials are their high stability and the good mobility of the oxygen in the network and so the facility to form vacancies and to stabilize metals with non-usual oxidation states $[13,16]$. In this scenario, ferrites have been employed in both fields (water and air treatment), taking advantage of their activation by visible light to generate the species that carry out the photocatalytic process [45]. The catalytic applications for environmental remediation in which ferrites result relevant include not only their use as photocatalysts, but also, as catalyst in intensified processes by simultaneously applying single processes with the purpose of obtaining a higher efficiency by reducing the inherent drawbacks of each single treatment. [31, 37].

\subsection{Ferrite photocatalysts for water detoxification}

There are several works dealing with the use of ferrite catalysts for the treatment of water by photocatalysis (Table 2). The first ones were reported in 2015 by Zaharieva et al. [86] and Mahto et al. [87]. In the first case, the authors synthesized $\mathrm{Cu}_{0.25} \mathrm{Fe}_{2.75} \mathrm{O}_{4}$ by a co-precipitation method with a further thermal treatment and applied it for the degradation of malachite green. They obtained better activity than the reference $\mathrm{TiO}_{2}-\mathrm{P} 25$. In the second one, $\mathrm{Fe}_{3} \mathrm{O}_{4}$, $\mathrm{MnFe}_{2} \mathrm{O}_{4}$ and $\mathrm{ZnFe}_{2} \mathrm{O}_{4}$, obtained by co-precipitation too, were employed to degrade azo dyes in aqueous solution. Materials were functionalized by citric acid in order to get an improvement in the photoactivity. 
Recently, other methods, as mentioned in the section 1, have been employed for the synthesis of ferrites such as combustion route, electrospinning and sol-gel [34, 88, 89]. Ansari et al. synthesized a cobalt hexaferrite, $\mathrm{CoFe}_{12} \mathrm{O}_{19}$, by sol-gel method and using a natural agent as reducing agent: maltose and fructose. In order to increase the activity, the nanoparticles were supported on carbon nanotubes or graphene sheets. The effect of the reducing agent as well as the calcination temperature was evaluated. The band gap value of $3.0 \mathrm{eV}$ let their use in the photocatalytic degradation of methyl orange under visible light. The authors obtained $75 \%$ of methyl orange degradation in 50 min of reaction as well as a higher activity when the ferrite was supported due to an improved charge separation and a lower charge recombination.

$\mathrm{CaFe}_{2} \mathrm{O}_{4}$, with spinel structure, was obtained by electrospinning by El-Rafei's group [88]. The material showed a good magnetization, a key-parameter in water treatment for a recovery purpose, as well as photoactivity under simulated sunlight. The study was focused on the effect of heat-treatment temperature and showing the needed of higher than $800^{\circ} \mathrm{C}$ treatment to get a well-formed ferrite phase.

The last technique employed for the synthesis of ferrite as photocatalysts for water treatment has been the autocombustion route performed by Patil et al [89]. In this case, the authors got $\mathrm{ZnFe}_{2} \mathrm{O}_{4}$ by using sugar cane as fuel. The resulted material showed a band gap value of $2.8 \mathrm{eV}$ and was used for two objectives. On one hand, as photocatalyst for dye removal and, on the other hand, for antibacterial purposes. The data indicated that a complete removal of mixed dyes after 150 min was reached as well as good inhibition of Escherichia Coli, Staphylococcus Aureus and Pseudomonas Aeruginosa. $\mathrm{ZnFe}_{2} \mathrm{O}_{4}$ showed good reusability over 4 cycles minimum.

However, the perovskite specific surface areas are usually quite low, and, in most cases, the activity can be limited by this parameter. In order to increase the activity, they have been immobilized on different supports like montmorillonite and active carbon. A few works have been developed in this sense. It is worth highlighting the works of Peng et al. [29] and Roonasi et al. [90]. In the former, $\mathrm{LaFeO}_{3}$ was deposited on montmorillonite and employed to oxidize Rhodamine B in water [29]. The composite photoactivity was higher than that of pristine $\mathrm{LaFeO}_{3}$, which was associated to the adsorption onto the surface. They got a complete degradation of Rhodamine $B$ in 75 min, but the main drawback was that the TOC evolution 
was not followed during the time-course of the photoreactions. Roonasi et al. [90] supported barium ferrite on active carbon for the discoloration of dyes in water. When comparing the unsupported ferrite with the supported one, data showed that the photoactivity improved when adding an the active carbon due to a synergetic effect.

Other strategies have been developed to improve the activity too. Among them, coupling semiconductors in heterojunctions has gained importance. In this frame, it is worth highlighting the employment of $\mathrm{LaFeO}_{3} / \mathrm{SnS}_{2}, \mathrm{LaFeO}_{3} / \mathrm{AgBr}, \mathrm{BiFeO}_{3} / \mathrm{BiOl}$ and $\mathrm{Ag}_{3} \mathrm{PO}_{4}-\mathrm{CoFe}_{2} \mathrm{O}_{4}-$ GO, the latest with a double improvement by the addition of an adsorbent. In the first case, $\mathrm{LaFeO}_{3}$ was obtained by a hydrothermal method and well-dispersed in $\mathrm{SnS}_{2}$ nanosheets [41]. Better activity than pristine $\mathrm{LaFeO}_{3}$ was observed for tetracycline oxidation. In parallel, Song et al. [91] obtained a $\mathrm{LaFeO}_{3} / \mathrm{AgBr}$ composite, used for Rhodamine $\mathrm{B}$ removal. They got a faster movement of charges with the $10 \% \mathrm{LaFeO}_{3} / \mathrm{AgBr}$. In these two cases, the enhancement of the photoactivity could be ascribed to the prevalence of Z-scheme mechanism of charges transfer. The synthesis of $\mathrm{a} \mathrm{BiFeO}_{3} / \mathrm{BiOl}$ composite by wet impregnation was carried out by Malathi et al. [92]. The authors designed a photocatalyst that resulted to be quite active and stable after several runs. The $2 \% \mathrm{BiFeO}_{3} / \mathrm{BiOl}$ got the maximum activity for a complete Rhodamine B depletion within the first $60 \mathrm{~min}$ of reaction and after 3 sequential cycles of reaction. The good activity was related to the efficient charge separation of photoinduced hole-electron pairs by transferring the electrons from $\mathrm{BiOl}$ to $\mathrm{BiFeO}_{3}$ surface [92]. Finally, the last work with composites was performed by Zielinska et al. [26]. In this case, the role of ferrites was to provide a magnetic core to a $\mathrm{TiO}_{2} / \mathrm{SiO}_{2}$ coated material for a recovery purpose after application. Figure 8 shows the HAADF images of the catalyst as example.

The last recently reported strategy deals with the partial substitution of cations in the ferrite structure. There are a few works that have developed this method until now. Jamil et al. synthesized a $\mathrm{BaFe}_{1-\mathrm{x}} \mathrm{Cu}_{x} \mathrm{O}_{3-\delta}$ material [38], the group of Rashmi et al. $\mathrm{ZnSm}_{x} \mathrm{Fe}_{2-\mathrm{x}} \mathrm{O}_{4}$ [21] and recently Garcia-Muñoz et al. obtained a $\mathrm{La}_{1-x} \mathrm{TixFeO}_{3}$ ferrite by sol-gel method [37].

A Pechini synthesis of $\mathrm{BaFe}_{1-\mathrm{x}} \mathrm{Cu}_{\mathrm{x}} \mathrm{O}_{3-\delta}$ catalyst led to a material rich in oxygen vacancies that was successfully employed for the abatement of atrazine in aqueous solution. The best photoactive catalysts resulted in $\mathrm{BaFe}_{0.95} \mathrm{Cu}_{0.05} \mathrm{O}_{3-\delta}$ sample which provoked a $90 \%$ of atrazine removal (in 180 min of reaction) that resulted not only from the vacancies created during 
synthesis but also from the higher surface area [38]. In contrast, $\mathrm{ZnSm}_{x} \mathrm{Fe}_{2-\mathrm{x}} \mathrm{O}_{4}$ nanoparticles were synthesised by co-precipitation method. In this case, the insertion of $\mathrm{Sm}^{3+}$ ions in the $\mathrm{ZnFe}_{2} \mathrm{O}_{4}$ spinel matrix shows an increase in lattice parameter and crystallite size leading to an extension of the light absorption spectrum toward the visible range as Sm content increases up to $x=1.5$ with narrow band gap $(1.42 \mathrm{eV})$. This fact reduced the recombination of electron and holes improving the degradation of Methyl Orange [21]. A modified Pechini method was used for the synthesis of $\mathrm{Ti}$ modified $\mathrm{LaFeO}_{3}$ catalysts [37]. The best performance was reached by adding a $10 \%$ of nominal $\mathrm{TiO}_{2}$ to the synthesis. However, a scarce activity was seen for $4-$ $\mathrm{Cl}$-Phenol depletion, whether solar light or visible light was used as activation source, what led to the implementation of other strategies that will be studied in the next part of this review.
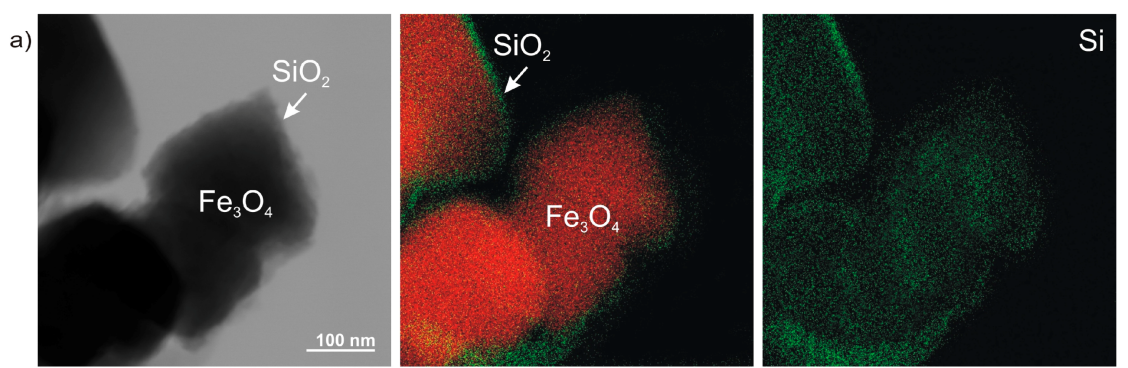

b)
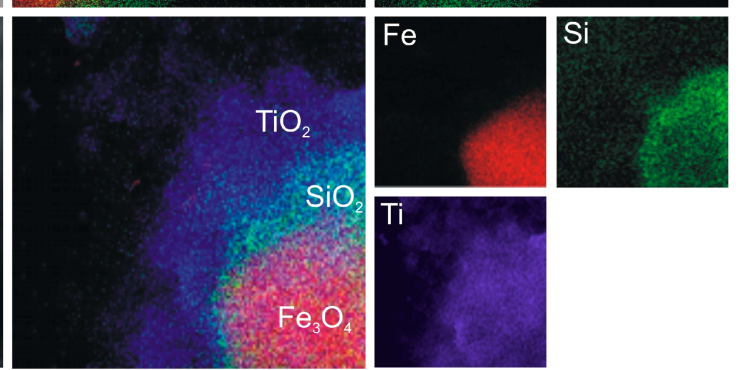

Figure 8. $\mathrm{HAADF}$ images of $\mathrm{Fe}_{3} \mathrm{O}_{4} / \mathrm{SiO}_{2}(\mathrm{a})$ and $\mathrm{Fe}_{3} \mathrm{O}_{4} / \mathrm{SiO}_{2} / \mathrm{TiO}_{2}$ (b) combined with mappings of $\mathrm{Fe}_{3} \mathrm{O}_{4}, \mathrm{SiO}_{2}$ and $\mathrm{TiO}_{2}$ (blue is $\mathrm{Ti}$, red is $\mathrm{Fe}$ and green $\mathrm{Si}$ ). Reproduced with permission from [26]. Copyright MDPI. 
Table 2. Summary of ferrite materials used as photocatalyst for water treatment.

\begin{tabular}{|c|c|c|c|c|c|c|}
\hline Catalyst & Method of synthesis & Pollutant & Conversion & Advantages & Disadvantages & Reference \\
\hline $\mathrm{ZnSm}_{x} \mathrm{Fe}_{2-\mathrm{x}} \mathrm{O}_{4}$ & Co-precipitation & Methyl orange & $\begin{array}{lll}92 \% & \mathrm{MO} & (80 \\
\mathrm{min}) & & \end{array}$ & & & $\begin{array}{l}\text { Rashmi et al. } \\
{[21]}\end{array}$ \\
\hline $\mathrm{CuS} / \mathrm{BiFeO}_{3}$ & Two-step & Alachlor & $\begin{array}{l}90 \% \text { alachlor } \\
\text { removed }(60 \\
\text { min) }\end{array}$ & & & Bhoi et al. [93] \\
\hline $\mathrm{LaFeO}_{3} / \mathrm{SnS}_{2}$ & Hydrothermal method & Tetracycline & & $\begin{array}{l}\text { better rates with } \\
10 \% \quad \mathrm{LaFeO}_{3} ; \quad \mathrm{Z} \\
\text { scheme }\end{array}$ & & Luo et al. [94] \\
\hline $\mathrm{LaFeO}_{3} / \mathrm{AgBr}$ & Precipitation & $\begin{array}{l}\text { Dye, methyl } \\
\text { orange }\end{array}$ & & $\begin{array}{l}\text { better } \\
\text { photoactivity }\end{array}$ & $\begin{array}{l}\text { no complete } \\
\text { degradation }\end{array}$ & Song et al. [91] \\
\hline $\mathrm{LaFeO}_{3} /$ montmorillonite & Assembling sol-gel & Rhodamine B & $\begin{array}{l}100 \% \\
\text { Rhodamine } \\
\text { removed }(75 \\
\text { min) }\end{array}$ & & & Peng et al. [29] \\
\hline $\mathrm{ZnFe}_{2} \mathrm{O}_{4} / \mathrm{PMS}$ & Soft chemical process & Orange II & $\begin{array}{l}\text { total removal } \\
(90 \mathrm{~min})\end{array}$ & & & Zhu et al [95] \\
\hline $\mathrm{TiO}_{2} / \mathrm{CoFe}_{2} \mathrm{O}_{4}$ & $\begin{array}{l}\text { Two-Spinneret } \\
\text { Electrospinning }\end{array}$ & Phenol & $\begin{array}{l}20 \% \text { phenol } \\
\text { removed }(210 \\
\text { min) }\end{array}$ & & & Li et al. [96] \\
\hline
\end{tabular}




\begin{tabular}{|c|c|c|c|c|c|}
\hline $\mathrm{Zn}_{\mathrm{x}} \mathrm{Fe}_{3-\mathrm{x}} \mathrm{O}_{4}$ & soft chemical route & $\begin{array}{l}\text { dye Acid Blue } \\
\text { 113; } \\
\text { desinfection }\end{array}$ & & $\begin{array}{l}92 \% \text { of dye } \\
\text { removal } \\
\text { synergetic effect } \\
\text { with } \mathrm{H}_{2} \mathrm{O}_{2}\end{array}$ & $\begin{array}{l}\text { Mandal et al. } \\
{[97]}\end{array}$ \\
\hline $\mathrm{TiO}_{2} @ \mathrm{Mn}$-Zn ferrite & $\begin{array}{l}\text { sol-gel hydrolysis } \\
\text { precipitation. }\end{array}$ & Methylene Blue & $\begin{array}{l}\text { complete } \\
\text { removal }(360 \\
\text { min) }\end{array}$ & & $\begin{array}{l}\text { Chin-Chen et } \\
\text { al. [98] }\end{array}$ \\
\hline $\mathrm{BiFeO}_{3} /$ Ozone & $\begin{array}{l}\text { Thermal } \\
\text { decomposition }\end{array}$ & oxalic acid & $\begin{array}{l}80 \% \\
\text { degradation } \\
(60 \mathrm{~min})\end{array}$ & $\begin{array}{l}\text { improved } \\
\text { mineralization by } \\
\text { processes } \\
\text { combination }\end{array}$ & Liao et al. [40] \\
\hline $\mathrm{Cu}_{0.25} \mathrm{Fe}_{2.75} \mathrm{O}_{4}$ & $\begin{array}{l}\text { co-precipitation, } \\
\text { mechanochemical } \\
\text { and/or thermal } \\
\text { treatment. }\end{array}$ & $\begin{array}{l}\text { Malachite } \\
\text { Green }\end{array}$ & & $\begin{array}{l}\text { better activity } \\
\text { than } \mathrm{P} 25 \mathrm{TiO}_{2}\end{array}$ & $\begin{array}{l}\text { Zaharieva et } \\
\text { al. [86] }\end{array}$ \\
\hline La doped $\mathrm{BiFeO}_{3}$ & sol-gel method & Phenol removal & $\begin{array}{l}\text { complete } \\
\text { phenolic } \\
\text { removal with } \\
15 \% \text { La }(180 \\
\text { min) }\end{array}$ & & $\begin{array}{l}\text { Meng et al. } \\
{[99]}\end{array}$ \\
\hline $\mathrm{CaFe}_{2} \mathrm{O}_{4}$ & electrospinning & TPA & & & $\begin{array}{l}\text { El-Rafei et al. } \\
{[88]}\end{array}$ \\
\hline $\mathrm{Ag} / \mathrm{AgCl} / \mathrm{ZnFe}_{2} \mathrm{O}_{4}$ & Hydrothermal method & $\begin{array}{l}\text { bisphenol A; } \\
\text { Rhodamine B }\end{array}$ & $\begin{array}{l}85 \% \text { removal } \\
\text { bisphenol }(120 \\
\text { min); } 100 \%\end{array}$ & $\begin{array}{l}\text { enhanced } \\
\text { electron-hole pair } \\
\text { separation } \\
\text { efficiency and }\end{array}$ & Liu et al. [42] \\
\hline
\end{tabular}




\begin{tabular}{|c|c|c|c|c|c|}
\hline & & & $\begin{array}{l}\text { Rhodamine (70 } \\
\text { min) }\end{array}$ & & \\
\hline $\mathrm{ZnO} / \mathrm{ZnFe}_{2} \mathrm{O}_{4}$ & $\begin{array}{l}\text { Zn-Fe mixed metal } \\
\text { organic framework }\end{array}$ & $\begin{array}{l}\text { Rhodamine B } \\
\text { and methylene } \\
\text { Blue }\end{array}$ & & $\begin{array}{l}\text { higher } \\
\text { photodegradation } \\
\text { efficiency }\end{array}$ & Xu et al. [100] \\
\hline $\mathrm{ZnFe}_{2} \mathrm{O}_{4}$ nanoparticles & combustion route & $\begin{array}{l}\text { dyes; } \\
\text { antibacterial }\end{array}$ & $\begin{array}{l}\text { total removal } \\
\text { of mixed dyes } \\
(150 \mathrm{~min})\end{array}$ & $\begin{array}{l}\text { good reusability } \\
\text { over } 4 \text { cycles }\end{array}$ & Patil et al. [89] \\
\hline $\begin{array}{l}\text { Barium ferrite/activated } \\
\text { carbon composite }\end{array}$ & Sol-gel & dyes & $\begin{array}{l}\text { complete } \\
\text { discoloration } \\
\text { (30 min) }\end{array}$ & Visible light & $\begin{array}{l}\text { Roonasi et al. } \\
{[90]}\end{array}$ \\
\hline $\begin{array}{l}\mathrm{Fe}_{3} \mathrm{O}_{4} / \mathrm{SiO}_{2} / \mathrm{TiO}_{2} ; \\
\mathrm{CoFe}_{2} \mathrm{O}_{4} / \mathrm{SiO}_{2} / \mathrm{TiO}_{2} ; \\
\mathrm{BaFe}_{12} \mathrm{O}_{19} / \mathrm{SiO}_{2} / \mathrm{TiO}_{2}\end{array}$ & Sol-gel combustion & $\begin{array}{l}\text { phenol; } \\
\text { carbamazepine }\end{array}$ & $\begin{array}{l}\text { no loss of } \\
\text { activity when } \\
\text { incorporated } \\
\text { ferrites; } \\
\text { magnetic } \\
\text { separation }\end{array}$ & $\begin{array}{l}\text { reusability during } \\
4 \text { cycles }\end{array}$ & Zielinska [26] \\
\hline $\begin{array}{l}\mathrm{CuFe}_{2} \mathrm{O}_{4} / \mathrm{g}-\mathrm{C}_{3} \mathrm{~N}_{4} \\
\text { heterojunctions } \\
\text { nanocomposite/PMS }\end{array}$ & Sol-gel combustion & $\begin{array}{l}\text { Propranolol } \\
\text { (pharmaceutical } \\
\text { compound) }\end{array}$ & $\begin{array}{l}\text { PMS enhances } \\
\text { the activity }\end{array}$ & & Li et al. [101] \\
\hline $\mathrm{BiFeO}_{3}$ & thermolysis & doxorubicin & $\begin{array}{l}79 \% \text { pollutant } \\
\text { removal }(180 \\
\text { min) }\end{array}$ & & $\begin{array}{l}\text { Dumitru et al. } \\
\text { [102] }\end{array}$ \\
\hline $\mathrm{Ag}_{3} \mathrm{PO}_{4}-\mathrm{CoFe}_{2} \mathrm{O}_{4}-\mathrm{GO}$ & Hydrothermal & methylene blue & & $\begin{array}{l}\text { stability after } 6 \\
\text { cycles of reaction }\end{array}$ & Liu et al. [43] \\
\hline
\end{tabular}




\begin{tabular}{|c|c|c|c|c|c|}
\hline $\mathrm{CoFe}_{12} \mathrm{O}_{19}$ & sol-gel method & methyl orange & $\begin{array}{lr}75 \% & \text { of } \\
\text { degradation } & \text { in } \\
\text { presence } & \text { of } \\
\text { graphene } & (50 \\
\text { min) } & \end{array}$ & $\begin{array}{l}\text { higher surface } \\
\text { area, charges } \\
\text { separation and } \\
\text { lower } \\
\text { recombination of } \\
\text { charges }\end{array}$ & $\begin{array}{l}\text { Ansari et al. } \\
{[34]}\end{array}$ \\
\hline $\begin{array}{l}\mathrm{Co}_{0.5} \mathrm{Zn}_{0.25} \mathrm{M}_{0.25} \mathrm{Fe}_{2} \mathrm{O}_{4} \\
\mathrm{TiO}_{2}\end{array}$ & $\begin{array}{l}\text { co- } \\
\text { precipitation, hydrolisis } \\
\text { and thermal treatment }\end{array}$ & $\begin{array}{l}\text { methyl orange } \\
\text { and methylene } \\
\text { blue }\end{array}$ & & & \\
\hline $\mathrm{BaFe}_{1-\mathrm{x}} \mathrm{Cu}_{x} \mathrm{O}_{3-\delta}$ & Peccini method & atrazine & $\begin{array}{l}90 \% \\
\text { degradation } \\
(120 \mathrm{~min})\end{array}$ & $\begin{array}{l}\text { Best activity at } \mathrm{pH} \\
11 \text {; higher surface } \\
\text { area and more } \\
\text { oxygen vacancy }\end{array}$ & $\begin{array}{lll}\text { Jamil et al. } \\
{[103]}\end{array}$ \\
\hline $\begin{array}{l}\mathrm{MFe}_{2} \mathrm{O}_{4} \text {, where } \mathrm{M}=\mathrm{Fe} \text {, } \\
\mathrm{Mn}, \mathrm{Co})\end{array}$ & $\begin{array}{l}\text { chemical co- } \\
\text { precipitation }\end{array}$ & azo dyes & & $\begin{array}{l}\text { citric acid } \\
\text { functionalization } \\
\text { improves the } \\
\text { photocatalytic } \\
\text { activity }\end{array}$ & $\begin{array}{l}\text { Pereira et al. } \\
\text { [23] }\end{array}$ \\
\hline
\end{tabular}




\subsection{Ferrite photocatalysts for air depollution}

In contrast to water treatment, in the scope of air depollution, only a few works have been recently detailed, all of them treating $\mathrm{NO}_{x}$ (Table 3). The requirement of immobilizing ferrites onto supports improves the dispersion (avoiding agglomeration of particles) of those kind of catalysts characterized by relatively small values of surface area. Therefore, more complex further studies are needed.

Only two works with pure single ferrite have been published up to now, to the best of our knowledge. Agdham et al. [104] reported the synthesis of $\mathrm{BiFeO}_{3}$ by a sol-gel procedure. The resulted material showed a band gap value of $2.1 \mathrm{eV}$, and it was employed for the removal of $\mathrm{NO}_{x}$ under UV light though. The authors got $36 \%$ conversion by using a reusable catalyst.

Other strategies have also been applied in the air treatment. Xiazhang's group developed the immobilization of several ferritic composites onto a palygorskite support [32, 33]. The first immobilized ferrite was $\mathrm{LaFeO}_{3}$ where Ni was replacing Fe inside the perovskite structure; and the second was a ternary material composed of N-CQDots (Nitrogen-Doped Carbon Quantum dots) and of $\mathrm{PrFeO}_{3}$ acting as consistent structure to be further supported. In the first case, the $\mathrm{LaFe}_{1-\mathrm{x}} \mathrm{Ni}_{x} \mathrm{O}_{3}$ structure was conditioned by the fraction of $\mathrm{Ni}$ added to the synthesis. While ratios below 0.4 gave rise pure $\mathrm{LaFe}_{1-\mathrm{x}} \mathrm{Nix}_{\mathrm{X}} \mathrm{O}_{3}$, when $\mathrm{x}>0.4$ the material resulted in $\mathrm{a}$ heterojunction due to the co-precipitation of some $\mathrm{LaNiO}_{3}$. However, it must be said that $90 \%$ conversion was obtained when employing a ferrite with $x=0.5$ [32]. In the second case, the ternary composite with a $5 \%$ of CQDs (Carbon Quantum dots) $/ \mathrm{PrFeO}_{3}$ got $93 \%$ conversion with a total selectivity to $\mathrm{N}_{2}$ (Figure 9). The good results obtained are associated to the formed Zscheme that not only enhanced the separation of charges, but also promoted the absorption of visible light [33]. 

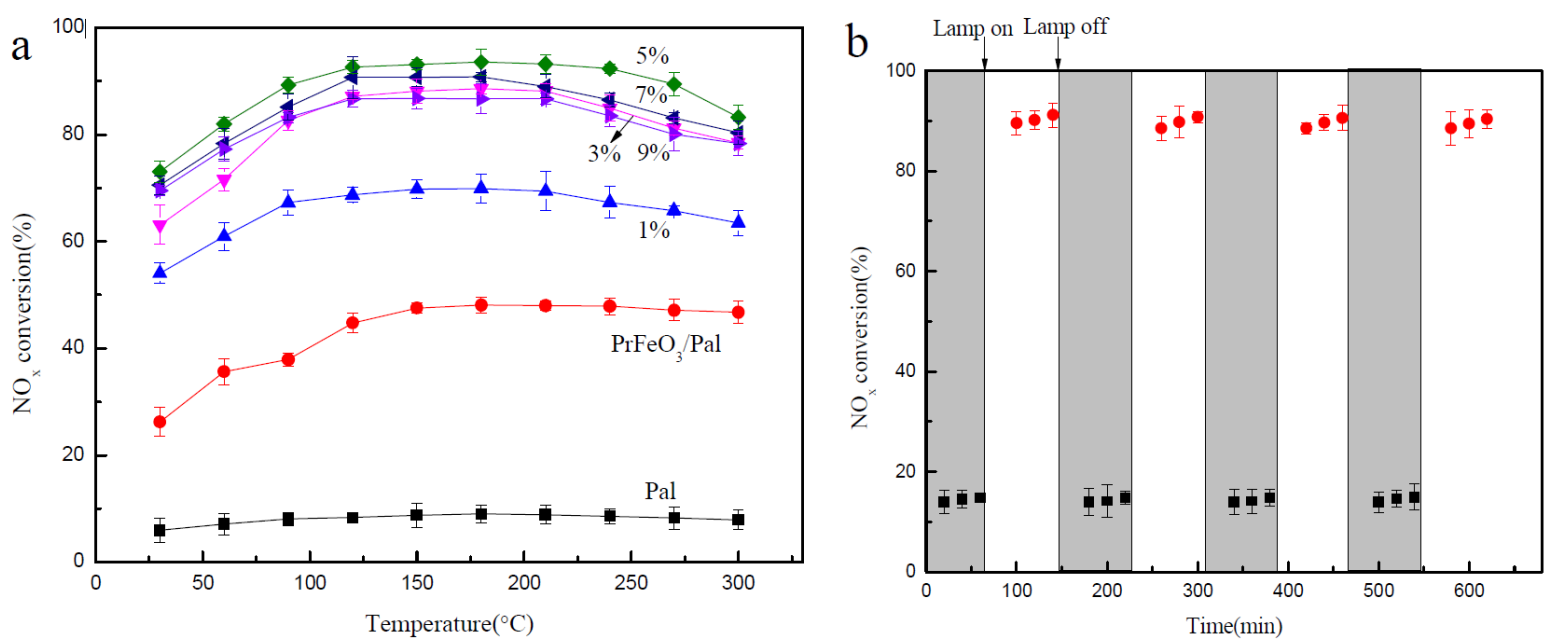

Figure 9. $\mathrm{NO}_{\mathrm{x}}$ conversion of $\mathrm{N}-\mathrm{CQDs} / \mathrm{PrFeO}_{3} /$ Palygorskite with various amounts of $\mathrm{N}-\mathrm{CQDs}(\mathrm{a})$ and $5 \mathrm{wt} \% \mathrm{~N}-\mathrm{CQDs} / \mathrm{PrFeO}_{3} / \mathrm{Pal}$ during several lamp-on/off tests (b). reproduced with permission from ref. [33]. Copyright ACS. 
Table 3. Summary of ferrite catalysts for air detoxification.

\begin{tabular}{|l|l|l|l|l|l|l|}
\hline Catalyst & $\begin{array}{l}\text { Method of } \\
\text { synthesis }\end{array}$ & Pollutant & Conversion & Advantages & Disadvantages & Reference \\
\hline $\mathrm{BiFeO}_{3}$ & $\begin{array}{l}\text { sol-gel } \\
\text { autocombustion }\end{array}$ & $\mathrm{NO}$ & $36 \%$ & & UV light & Rahimi et al.[104] \\
\hline $\mathrm{LaFe}_{1-\mathrm{XNi} \mathrm{NO}_{3} / \text { palygorskite }}$ & sol-gel & $\mathrm{NO}$ & $>90 \%$ & Visible light & $\begin{array}{l}\text { Xiazhang Li et al. } \\
{[32]}\end{array}$ \\
\hline $\mathrm{CQDS} / \mathrm{PrFeO}_{3} /$ Palygorskite & $\begin{array}{l}\text { Sol-gel } \\
\text { impregnation }\end{array}$ & $\mathrm{NO}$ & & & Xiazhang Li et al. \\
{$[33]$}
\end{tabular}




\subsection{Combination of ferrite photocatalysts and other oxidizing agents}

To take advantage of the redox surface properties of ferrite materials and to improve the reactivity, the ferrite catalysts started to be employed simultaneously as Fenton catalysts, with the addition of $\mathrm{H}_{2} \mathrm{O}_{2}$ as oxidizing agent, under light irradiation [22, 30, 93, 105, 106]. In this approach, materials with different compositions have been used for this purpose, like $\mathrm{LaFeO}_{3}$, $\mathrm{CoFe}_{2} \mathrm{O}_{4}$, mesoporous $\mathrm{CuFe}_{2} \mathrm{O}_{4}, \mathrm{NiFeMO}_{4}(\mathrm{M}=\mathrm{La}, \mathrm{Sm}, \mathrm{Gd}, \mathrm{Dy}), \mathrm{CuS} / \mathrm{BiFeO}_{3}$.

By adding $\mathrm{H}_{2} \mathrm{O}_{2}$, a larger variety of pollutants have been degraded than in the case of pure photocatalysis using ferrites (Table 4). In the first case, Sannino et al. [30] employed $\mathrm{LaFeO}_{3}$ for the removal of acetic acid. Only $60 \%$ depletion in $300 \mathrm{~min}$ was obtained for the best case. Then $\mathrm{CoFe}_{2} \mathrm{O}_{4}$ ferrite was used to oxidize methylene blue, with almost complete oxidation in $75 \mathrm{~min}$ of reaction [22]. Gao et al. [105] employed mesoporous $\mathrm{CuFe}_{2} \mathrm{O}_{4}$ ferrite for the elimination of sulphonamides in water. The antibiotic conversion was $31 \%$ within 180 min while no mineralization data was available. Samoila et al. [106] evidenced differences between pristine $\mathrm{NiFeO}_{4}$ and $\mathrm{NiFeO}_{4}$ substituted with $\mathrm{La}^{3+}, \mathrm{Sm}^{3+}, \mathrm{Gd}^{3+}$ or $\mathrm{Dy}^{3+}$ cations. The undoped material got $30 \%$ of Orange II azo-dye decolorization vs. around $90 \%$ in 30 min with the La-substituted catalyst. Recently, a mixed strategy has been the employment of a cocatalyst with $\mathrm{H}_{2} \mathrm{O}_{2}$ [93]. Concretely, the heterojunction $\mathrm{CuS} / \mathrm{BiFeO}_{3}$ for alachlor degradation. The combined mechanism in presence of $\mathrm{H}_{2} \mathrm{O}_{2}$ led to $90 \%$ of pesticide removal in $1 \mathrm{~h}$ of reaction.

Several efforts have been made to intensify the reactivity of ferrite materials in water in simultaneous application of AOPs processes. In this sense, the addition of $\mathrm{H}_{2} \mathrm{O}_{2}$ to the reaction media was not enough to improve substantially the activity. Lately, the research has been moved towards the material modification taking into account the composition of a ferrite and its ability to exchange A or B cation and so to tune its catalytic properties. In this scenario, recently the last trend has been the doping of the materials with transition metals $[31,44,97$, $107,108] . \mathrm{Zn}_{\mathrm{x}} \mathrm{Fe}_{3-\mathrm{x}} \mathrm{O}_{4}$ materials were synthesized by a soft chemical route by Mandal et al [97]. This magnetic catalyst was employed for the degradation of Acid Blue 113 and also for an antimicrobial purpose. The pristine and modified ferrites showed very good photoactivity when $\mathrm{H}_{2} \mathrm{O}_{2}$ was added in the reaction media. The ferrites were quite stable after 8 cycles of reaction and its magnetic properties allow recovery after each sequential run. Simultaneously, 
Soltani et al. [31] obtained $\mathrm{BiFeO}_{3}$ substituted by barium via sol-gel method. The ratio of substitution of $\mathrm{Bi}_{1-x} \mathrm{BaxFeO}_{3}$ was between 0.03 and 0.12. The experimental results indicate that the increase of $\mathrm{Ba}$ until $12 \%$ affected the redox cycle and provoked oxygen vacancies that significantly enhanced the toluene degradation under pure visible light.

In 2018, Cu-doped $\mathrm{LaFeO}_{3}$ has been obtained by Phan et al. [107]. The catalysts were employed for a dye decoloration, in this case Methyl Orange. The best reactivity resulted from the catalyst with $15 \%$ of copper. The authors attributed this improvement to the fact that it generates much more $\mathrm{HO}^{\circ}$ than pristine $\mathrm{LaFeO}_{3}$. This behavior was associated to an enhancement of the $\mathrm{H}_{2} \mathrm{O}_{2}$ decomposition by the two metals, $\mathrm{Cu}$ and $\mathrm{Fe}$, which provoke additional reactions, as well as to an improvement of the availability of $\mathrm{Fe}(\mathrm{II})$ at the surface. The greater generation of $\mathrm{HO}^{\circ}$ was corroborated by ESR technique. In the same way, Co-doped $\mathrm{MgFe}_{2} \mathrm{O}_{4}$ was synthesized from saprolite laterite ore [44]. The low addition of Co ( 1\%) greatly improved the activity. $97 \%$ of the dye was abated and $68 \%$ of TOC mineralized after $180 \mathrm{~min}$. The authors pointed out a synergistic effect between photocatalysis and heterogeneous photo-Fenton mechanism with this stable catalyst. The measurement of the iron leached to the solution showed that the activity was associated to the surface iron of the catalyst and not to iron in homogeneous solution. Besides this, the ferrite lost $10 \%$ of activity during its reuse. Recently, Yang Li et al. [108] has obtained a metal-doped zinc ferrite material by a modified microwave hydrothermal method. The authors compared synthesis using metals in wastewater and also using chemical precursors. The catalytic test showed that the doped material synthesized by using metals contained in wastewater was highly more active than the one using chemical precursors. Also, the substituted ferrite exhibited better efficiency than the pristine $\mathrm{ZnFe}_{2} \mathrm{O}_{4}$. The authors postulated that $\mathrm{HO}^{\circ}$ are formed through photogenerated $\mathrm{h}^{+}$and $\mathrm{H}_{2} \mathrm{O}_{2}$ decomposition by $\mathrm{Fe}^{3+}$ and $\mathrm{Mn}^{3+}$ on the catalyst surface. After the first cycle of reaction, $95 \%$ of Congo red was depleted within $3 \mathrm{~h}$ of reaction which let to $60 \%$ of TOC conversion. After the third cycle of reaction, $75 \%$ of decoloration was reached indicating a slight loss of activity of the material.

Finally, the $\mathrm{La}_{1-\mathrm{x}} \mathrm{TixFeO}_{3}$ material synthesized through a modified Pechini sol-gel method by Garcia-Munoz et al. [37] was employed as a combined photocatalyst and heterogeneous photo-Fenton catalyst without any homogeneous contribution (Figure 10). The authors 
demonstrated that the strategy combining both AOPs within a single dual catalyst allowed La ${ }_{1-}$ ${ }_{x} \mathrm{Ti}_{x} \mathrm{FeO}_{3}$ to simultaneously take advantage from the higher reaction rate of the photo-assisted heterogeneous Fenton process and of the higher mineralization yield of photocatalysis. This Ti-substituted $\mathrm{LaFeO}_{3}$ dual catalyst was reported to be very active in water treatment, by reaching complete mineralization and total pollutant removal with higher efficiencies than via single AOPs, whether the process operates under UV-A light, simulated solar light or pure visible light $(\lambda>420 \mathrm{~nm})$. The dual catalyst operates with pure heterogeneous surface reactions with an increase in the catalyst robustness by more than two orders of magnitude compared to the unsubstituted ferrite. This was symbolized by the absence of any Fe release and by the stability of catalytic performance with test cycles with no loss of activity [109].
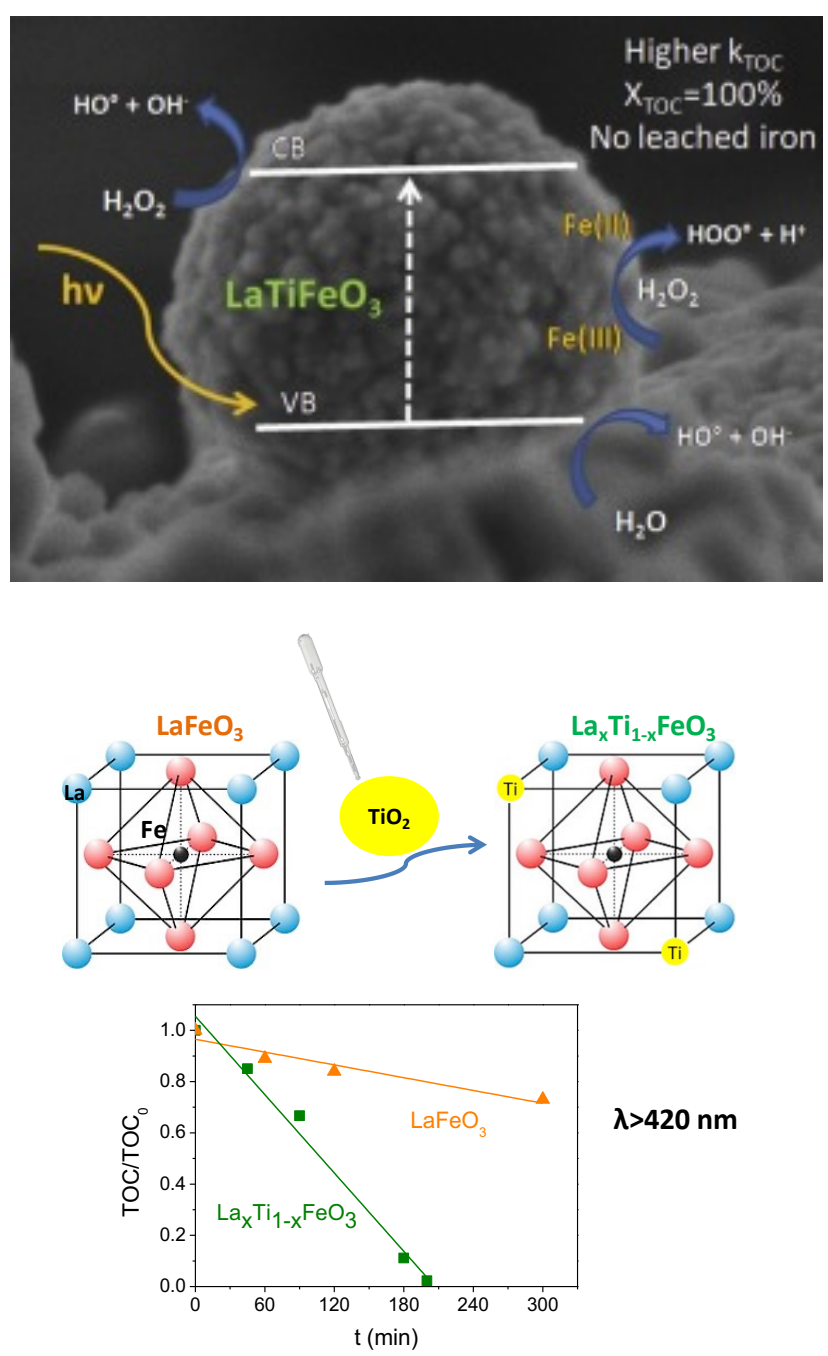

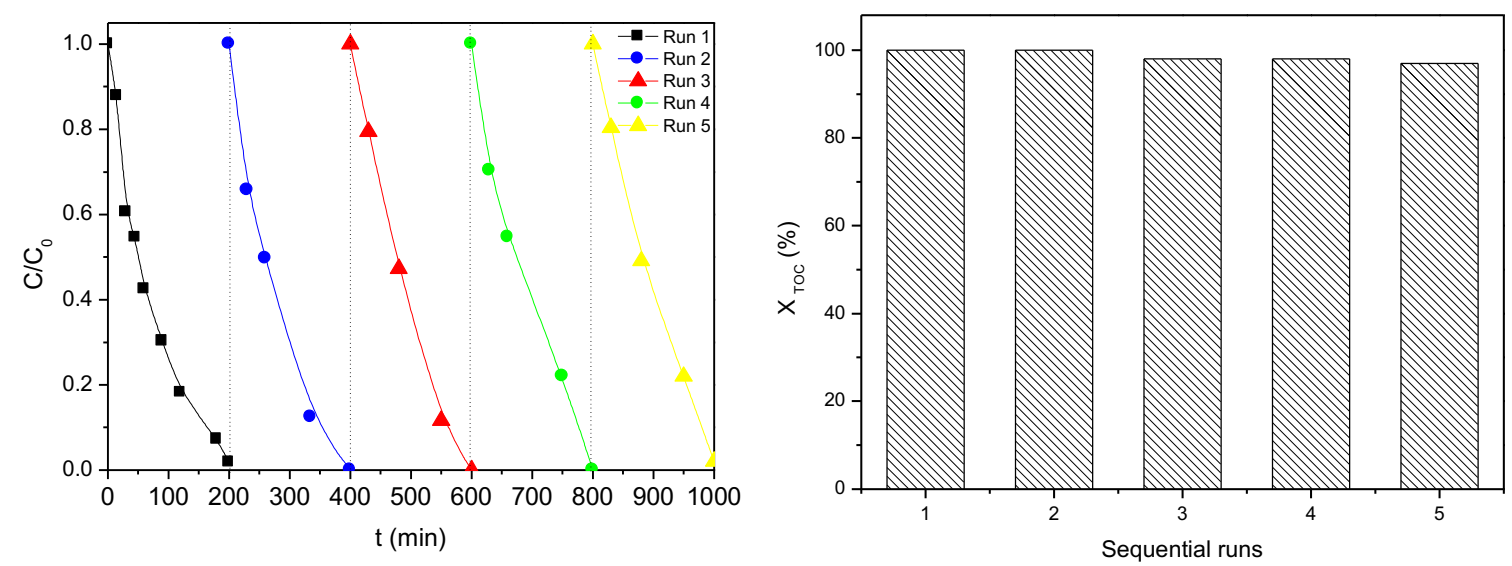

Figure 10. (A) Scheme of the mechanism of reaction of the combined $\mathrm{H}_{2} \mathrm{O}_{2}$ /photocatalytic process. Reproduced with permission of [37]. (B) Partial Ti $\rightarrow$ La cationic substitution in the $\mathrm{LaFeO}_{3}$ network and the resulting strong TOC removal rate improvement under pure visible light $(\lambda>420 \mathrm{~nm})$. Reproduced with permission of [109]. Copyright Elsevier.

Reusability tests with 5 consecutive runs performed on the $\mathrm{La}_{1-\mathrm{x}} \mathrm{Tix}_{\mathrm{X}} \mathrm{FeO}_{3}$ dual catalyst in the system $\mathrm{H}_{2} \mathrm{O}_{2}$ /visible light: (C) Evolution of the relative 4-Chlorophenol concentration and (D) TOC mineralization degree obtained after $210 \mathrm{~min}$ of test. Operating conditions: [4-ClPhenol $]_{0}=25 \mathrm{mg} / \mathrm{L} ;\left[\mathrm{H}_{2} \mathrm{O}_{2}\right]_{0}=125 \mathrm{mg} / \mathrm{L} ; \mathrm{T}=25^{\circ} \mathrm{C} ;$ [cat] $=0.5 \mathrm{~g} / \mathrm{L} ;(\lambda>420 \mathrm{~nm})$. Reproduced with permission of [109]. Copyright Elsevier. 
Table 4. Summary of ferrite catalysts employed in simultaneous application of oxidation systems.

\begin{tabular}{|c|c|c|c|c|c|c|}
\hline Catalyst & $\begin{array}{l}\text { Method of } \\
\text { synthesis }\end{array}$ & Pollutant & Conversion & Advantages & Disadvantages & Reference \\
\hline $\mathrm{Cu}$ doped $\mathrm{LaFeO}_{3}$ & Hydrothermal & Methyl orange & $\begin{array}{l}90 \% \text { MO with } \\
15 \% \mathrm{Cu}(60 \mathrm{~min})\end{array}$ & Visible light & No TOC data & Phan et al. [110] \\
\hline $\mathrm{LaFeO}_{3}$ & Sol-gel & Acetic acid & $\begin{array}{l}60 \% \text { TOC with } \mathrm{Fe} \\
\text { substitution }(300 \\
\text { min) }\end{array}$ & $\begin{array}{l}\text { Higher effective } \\
\text { use of } \mathrm{H}_{2} \mathrm{O}_{2}\end{array}$ & & Sannino et al. [30] \\
\hline $\mathrm{CoFe}_{2} \mathrm{O}_{4}$ & Co-precipitation & Methylene Blue & $\begin{array}{l}98.6-99.3 \% \quad \mathrm{MB} \\
(75 \mathrm{~min})\end{array}$ & & & $\begin{array}{l}\text { Vinosha et al. } \\
{[111]}\end{array}$ \\
\hline $\mathrm{Co}-\mathrm{MgFe}_{2} \mathrm{O}_{4}$ & Hydrothermal & Rhodamine B & $\begin{array}{l}95 \% \text { Rhodamine } \\
\text { B; TOC }>85 \% \text { (180 } \\
\text { min) }\end{array}$ & Visible light & & Diao et al. [44] \\
\hline $\begin{array}{l}\text { mesoporous } \\
\mathrm{CuFe}_{2} \mathrm{O} 4\end{array}$ & $\begin{array}{l}\text { Synthesis } \\
\text { including } \\
\text { template }\end{array}$ & Sulfonamide & $31 \%$ TOC (40 min) & Good reusability & no mineralization & Gao et al. [112] \\
\hline $\begin{array}{l}\mathrm{NiFeMO}_{4} \quad(\mathrm{M}=\mathrm{La}, \\
\mathrm{Sm}, \mathrm{Gd}, \mathrm{Dy})\end{array}$ & $\begin{array}{l}\text { Sol-gel } \\
\text { autocombustión }\end{array}$ & Dyes, orange II & $\begin{array}{l}30 \% \quad \text { undoped } \\
\text { material; } 90 \% \text { La } \\
\text { doped (30 min) }\end{array}$ & & No TOC data & $\begin{array}{l}\text { Samoila et al. } \\
\text { [113] }\end{array}$ \\
\hline$(\mathrm{Ba}, \mathrm{Bi}) \mathrm{FeO}_{3}$ & Sol-gel & Toluene & $\begin{array}{l}\text { Total } \\
\text { degradation; } \\
\text { 85\%TOC (40 min) }\end{array}$ & Visible light & & Soltani et al. [31] \\
\hline
\end{tabular}




\begin{tabular}{|c|c|c|c|c|c|c|}
\hline $\mathrm{Ni}_{x} \mathrm{Zn}_{1-\mathrm{x}} \mathrm{Fe}_{2} \mathrm{O}_{4}$ & $\begin{array}{l}\text { Sol-gel } \\
\text { autocombustion }\end{array}$ & 4-Cl-Phenol & $\begin{array}{l}\text { Total } \\
\text { degradation; 99\% } \\
\text { TOC (120 min) }\end{array}$ & Stable after 5 runs & & Kurian et al. [27] \\
\hline $\mathrm{CuS} / \mathrm{BiFeO}_{3}$ & Two-step & Alachlor & $\begin{array}{ll}90 \% & \text { alachlor } \\
\text { removed }(60 \mathrm{~min})\end{array}$ & High stability & & Bhoi et al. [93] \\
\hline $\mathrm{Zn}_{x} \mathrm{Fe}_{3-\mathrm{x}} \mathrm{O}_{4}$ & $\begin{array}{l}\text { Soft chemical } \\
\text { route }\end{array}$ & $\begin{array}{l}\text { dye Acid Blue 113; } \\
\text { desinfection }\end{array}$ & & $\begin{array}{l}92 \% \text { of dye } \\
\text { removal } \\
\text { synergetic effect } \\
\text { with } \mathrm{H}_{2} \mathrm{O}_{2}\end{array}$ & & Mandal et al. [97] \\
\hline $\begin{array}{l}\text { metal-doped zinc } \\
\text { ferrite } \\
\text { nanosphere }\end{array}$ & 2 step method & Congo red & $\begin{array}{l}96 \% \text { removal of } \\
\text { dye in } 3 \mathrm{~h}(180 \\
\text { min) }\end{array}$ & $\begin{array}{l}60 \% \text { TOC } \\
\text { depletion }\end{array}$ & $\begin{array}{l}\text { loss of activity } \\
\text { with cycles of use }\end{array}$ & Yang Li et al. [108] \\
\hline $\mathrm{La}_{1-\mathrm{x}} \mathrm{Ti}_{x} \mathrm{FeO}_{3}$ & Pechini sol-gel & 4-Cl-Phenol & $\begin{array}{lr}100 \% & 4-C P \\
\text { removal } & \text { under } \\
\text { different } & \text { light } \\
\text { spectra } & \end{array}$ & $\begin{array}{lr}100 \% & \text { TOC } \\
\text { removal } & (120 \mathrm{~min})\end{array}$ & & $\begin{array}{l}\text { Garcia-Munoz et } \\
\text { al. }[37,109]\end{array}$ \\
\hline
\end{tabular}




\section{Ferrite-based photocatalysts and photoelectrodes for energy applications: hydrogen production and $\mathrm{CO}_{2}$ reduction}

\subsection{Introduction}

Energy applications of photocatalysis, mainly $\mathrm{CO}_{2}$ reduction and hydrogen production by water splitting or photoreforming, are technologically less developed than environmental ones (viz. pollutant degradation), although their scientific interest has increasingly grown in the last decades as a result of their appealing possibilities in a hopefully not-so-long-term circular economy based on solar energy [114].

The production of hydrogen from renewable feedstock and energy sources is crucial for its implementation as a clean energy vector in a future non-carbon-based energy system [115]. Photocatalysis and photoelectrochemistry offer the possibility of directly converting sunlight into chemical energy by splitting the water molecule into hydrogen and oxygen, making use at the surface of semiconductor photocatalysts, of the reductive and oxidative power of photogenerated electrons and holes, respectively. Alternatively, due to the kinetic constraints of water oxidation, hydrogen can be produced using organic sacrificial agents, ideally derived from biomass feedstock, in the process called photoreforming $[116,117]$. In the last decades, a vast amount of semiconductors has been tested as photocatalysts for photocatalytic or photoelectrochemical water splitting [114, 118, 119], among which iron-based oxides and particularly ferrites have been less explored than other types of materials. This is generally related to low charge carrier mobilities and hence short exciton lifetimes, which nevertheless can be improved by doping or by other chemical, structural or surface modifications [120, 121]. Some ferrites have indeed the adequate band positions for at least one of the halfreactions (proton reduction and water oxidation) involved in water splitting and, furthermore, these positions can be tuned by means of the inclusion of different metals into the ferrite structure [121]. As described below, some ferrites have been reported active for photocatalytic hydrogen evolution. Selected examples are summarized in Table 5.

Regarding photoelectrochemical hydrogen production, varied chemical composition, multiple valence states and choice of metal cation, narrow band gaps and both n-type and p-type 
behaviour convert ferrites into attractive candidates as electrodes for photoelectrochemical cells (PEC). However, even if they are considered as promising earth abundant and non-toxic alternative photoactive materials for PECs, only a few works have been published using ferrites as photocathodes and photoanodes [121, 122]. Actually, the measured photocurrents of PECs with ferrite photoelectrodes are still low, which is mainly related to the charge mobility limitations mentioned above. Similarly to the case of photocatalysis, different strategies proved that higher photocurrents can be achieved, including nanostructuring, heterojunctions, co-catalyst loading and control of the defect chemistry [121, 122]. Pioneer work on the fundamental investigation using ferrites as electrodes in (photo) electrochemical reactions dates back to the late 1970 s and early 1980 s and has continued in the following years, including different compositions. P-type $\mathrm{CaFe}_{2} \mathrm{O}_{4}$ [123-130], $\mathrm{CdFe}_{2} \mathrm{O}_{4}$ [131], p- and ntype $\mathrm{Co}_{x} \mathrm{Fe}_{3-\mathrm{x}} \mathrm{O}_{4}$ and $\mathrm{CoTi}_{x} \mathrm{Fe}_{2-\mathrm{x}} \mathrm{O}_{4}$ [132], p-type $\mathrm{CoFe}_{2} \mathrm{O}_{4}$ [133], p- and n-type $\mathrm{NiFe}_{2} \mathrm{O}_{4}$ [134, 135], $\mathrm{Li}_{0.5} \mathrm{Fe}_{2.5} \mathrm{O}_{4}$ [136], $\mathrm{MgFe}_{2} \mathrm{O}_{4}[137,138], \mathrm{Ti}_{x} \mathrm{Fe}_{3-\mathrm{x}} \mathrm{O}_{4}$ [139] and n-type $\mathrm{ZnFe}_{2} \mathrm{O}_{4}$ [136-142] are remarkable examples.

In turn, $\mathrm{CO}_{2}$ reduction is probably the lowest-TRL application of photocatalysis. In spite of its scientific interest, providing a route for $\mathrm{CO}_{2}$ valorization coupled to solar energy harnessing [143], it still faces a number of issues mainly related to the inherent difficulty associated to the stability and relative inertness of the $\mathrm{CO}_{2}$ molecule and to the complex nature of water oxidation. Indeed, this latter is in principle the preferred reaction to close the electron balance as Nature does in natural photosynthesis [144]. Among the different semiconductors that have been reported as $\mathrm{CO}_{2}$ reduction photocatalysts [145-147], ferrite-based ones do not play a prominent role, even if some of these oxides have adequate band positions for some of the reactions involved in $\mathrm{CO}_{2}$ reduction [148]. Nevertheless, a few works have reported photocatalytic and photoelectrochemical $\mathrm{CO}_{2}$ reduction using ferrite materials, as will be described in the next sections.

\subsection{Ferrite photocatalysts for water splitting and $\mathrm{CO}_{2}$ reduction}

\subsubsection{Single-phase ferrite photocatalysts}


Magnetite, the chemically simplest ferrite $\left(\mathrm{Fe}_{3} \mathrm{O}_{4}\right.$ or $\left.\mathrm{Fe}^{\| \prime} \mathrm{Fe}^{\prime \prime \prime}{ }_{2} \mathrm{O}_{4}\right)$, can be employed for water oxidation in the presence of the appropriate co-catalyst, as shown by Neudeck and coworkers, who prepared $\mathrm{Fe}_{3} \mathrm{O}_{4}$ nanoparticles using xyloglucan as stabilizing agent [149]. This method yields size controllable nanoparticles with narrow size distributions, which are able to oxidize water into oxygen under irradiation with a blue-light LED, with the participation of the $\left(\mathrm{Ru}(\text { bipy })_{3}\right)^{3+}$ complex as sensitizer/co-catalyst and using sodium persulfate as electron scavenger. In the presence of other nanoparticle-stabilizing polymer such as dextran, magnetite also showed oxygen evolution although lower than that attained with the xyloglucan. This reveals an effect of the latter that, according to the authors, is beyond surface area and might be related to the lifetime of the photo-generated excited Ru complex that would favour charge transfer to water molecules.

Sacrificial hydrogen production over magnetite was reported by Mangrulkar and co-workers in the presence of ethanol as sacrificial reagent, with platinum as co-catalyst, and under UVAvis (tungsten filament lamp) irradiation [150]. The material was synthesized in the form of 10$12 \mathrm{~nm}$ nanoparticles, and the band gap was roughly estimated from the UV-vis spectrum as $2.7 \mathrm{eV}$, considerably larger than the value of ca. $1.9 \mathrm{eV}$ determined from photoelectrochemical measurements [151]. The $\mathrm{Pt} / \mathrm{Fe}_{3} \mathrm{O}_{4}$ photocatalytic system was active for hydrogen evolution in the presence of different sacrificial reagents, with ethanol giving the best results over methanol and ethanolamine. Experiments carried out in different conditions revealed that hydrogen evolved only above a certain value of irradiation power, and that, in the dark, there was hydrogen evolution when the temperature was raised. This suggest that the reaction has a thermal component, and indeed experiments in photo-thermal conditions revealed a synergistic effect of the photocatalytic and the thermocatalytic effects, even at temperatures as low as $100{ }^{\circ} \mathrm{C}$. Deactivation of the catalyst was observed in all cases, and photo-thermal conditions also enhanced this deactivation.

Gobara et al. compared the activity of magnetite for hydrogen production from methanol aqueous solutions under simulated solar radiation with those of different ferrites resulting from the substitution of several divalent cations $\left(\mathrm{Zn}^{2+}, \mathrm{Cd}^{2+}\right.$ or $\left.\mathrm{Ni}^{2+}\right)$ for $\mathrm{Fe}^{2+}[152]$. All catalysts were prepared by co-precipitation methods which resulted in nanocrystalline cubic phases except for the cadmium ferrite which was considerably less crystalline and contained a 
segregated $\mathrm{Fe}_{2} \mathrm{O}_{3}$ phase. The band gaps decreased upon metal substitution from $2.8 \mathrm{eV}$ in $\mathrm{Fe}_{3} \mathrm{O}_{4}$ to $1.62,1.90$ and $2.23 \mathrm{eV}$ in $\mathrm{Ni}, \mathrm{Cd}$ and $\mathrm{Zn}$ ferrites, respectively. All samples gave rise to hydrogen evolution without the concourse of any co-catalyst and with stable rates along 72 h. All three ferrites led to higher hydrogen evolution rates than magnetite in the order $\mathrm{Zn}<\mathrm{Cd}$ $<\mathrm{Ni}$, although in the case of the cadmium sample this should be taken cautiously because of the presence of the mentioned iron oxide phase. The superior activity of nickel ferrite was attributed to the affinity of $\mathrm{Ni}$ for hydrogen. Nonetheless, the $\mathrm{NiFe}_{2} \mathrm{O}_{4}$ sample displayed the highest metal surface area as determined by hydrogen chemisorption.

Indeed, $\mathrm{NiFe}_{2} \mathrm{O}_{4}$ is probably the most extensively explored ferrite photocatalyst for water splitting reactions. As summarized in Table 5, some works have reported its activity in different experimental conditions, with a quite wide range of hydrogen production rates. An apparent quantum yield of $0.53 \%$ was obtained by Rekhila et al. with a sol-gel prepared nickel ferrite using thiosulfate as sacrificial reagent without any co-catalyst, under the full spectrum of a halogen lamp [153] and in optimum conditions of $\mathrm{pH}, \mathrm{S}_{2} \mathrm{O}_{3}{ }^{2-}$ concentration and catalyst mass. An electrochemical impedance spectroscopy analysis revealed the p-type semiconductivity of $\mathrm{NiFe}_{2} \mathrm{O}_{4}$, as well as the drastic increase of the lifetime of electrons under illumination in the presence of the sacrificial reagent, emphasizing its crucial role in improving the charge separation by hole scavenging. Peng and co-workers obtained $\mathrm{NiFe}_{2} \mathrm{O}_{4}$ nanoparticles with homogeneous size distribution and high surface area by means of a surfactant-assisted hydrothermal method [154]. These nanoparticles gave rise, under visible light $(\lambda \geq 420 \mathrm{~nm})$ and in the absence of any co-catalyst, to hydrogen evolution from an aqueous methanol solution with an apparent quantum yield of $0.52 \%$, after an optimum calcination temperature of $500{ }^{\circ} \mathrm{C}$ in which a compromise situation between crystallinity and surface area is reached. The effect of particle size and distribution is revealed by the lower efficiency of $\mathrm{NiFe}_{2} \mathrm{O}_{4}$ synthesized without any structure-directing agent, which was formed by inhomogeneous agglomerations of particles. XRD and XPS studies of the solid together with ICP-AES analyses of the liquid reaction medium and consecutive activity runs confirmed the stability of the ferrite in reaction conditions. In the absence of any sacrificial reagent, some hydrogen evolution was observed in water spitting experiments, although without any oxygen production, which suggests the possibility of self-oxidation or the possible role of organic 
matter remaining from the synthesis as hole scavenger. A structure-directing agent, in this case Pluronic F127, was also used by Hong and co-workers to obtain mesoporous $\mathrm{NiFe}_{2} \mathrm{O}_{4}$ photocatalysts with high crystallinity and large surface area by a self-assembly associated aerosol spray pyrolysis method [155], which were tested for methanol photoreforming under visible light irradiation $(\lambda>420 \mathrm{~nm})$. Again, the highest activity of all different catalyst appears as a compromise between crystallinity and surface area, with well-crystallized mesoporous samples resulting in higher $\mathrm{H}_{2}$ evolution rates than amorphous ones with small pore size and high BET values, but also than a non-mesoporous, highly crystalline ferrite with relatively low surface area. The photocatalytic character of the reaction was demonstrated by an action spectrum study that showed that the dependence of hydrogen evolution on the irradiation wavelength closely matched the absorption spectrum of $\mathrm{NiFe}_{2} \mathrm{O}_{4}$ (Figure 11). This mesoporous ferrite was shown to be stable up to three photocatalytic runs without any loss of activity and without structural or morphological modifications.

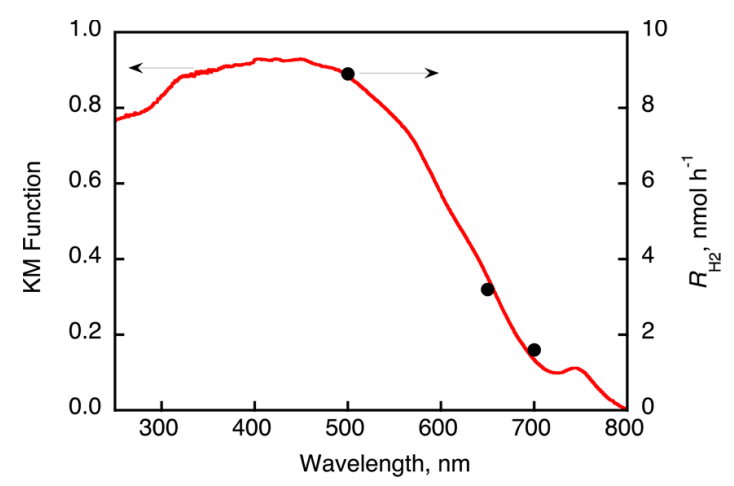

Figure 11. Dependence of $\mathrm{H}_{2}$ evolution rates $\left(\mathrm{R}_{\mathrm{H} 2}\right)$ on the wavelength of monochromatic light irradiation of a 25 vol.\% methanol aqueous solution with a mesoporous $\mathrm{NiFe}_{2} \mathrm{O}_{4}$ photocatalyst. Reproduced with permission from ref. [155]. Copyright American Chemical Society.

A modification of the Pechini method was employed by Domínguez-Arvizu et al. to obtain single-phase nickel ferrite with average crystal size of $25 \mathrm{~nm}$ and $50 \mathrm{~m}^{2} \mathrm{~g}^{-1}$ of BET surface area after calcination temperature of $400{ }^{\circ} \mathrm{C}$, which was determined as the minimum one to remove all the organic matter after the chelation step [156]. The authors studied some optical characteristics such as the absorption spectrum and scattering, absorption and extinction 
coefficients, as a basis for future designs of photoreactors using this catalyst. Under white light and without any co-catalyst present, $\mathrm{NiFe}_{2} \mathrm{O}_{4}$ produced ca. 5 times larger amount of hydrogen than $\mathrm{TiO}_{2} \mathrm{P} 25$ after $8 \mathrm{~h}$ from an aqueous methanol solution.

In photocatalytic hydrogen evolution reactions, the presence of a co-catalyst, most generally a noble metal, improves the hydrogen yield by boosting charge separation and acting as catalytic sites for H-H bond formation [157]. In addition, in the case of some metals with appropriate particle size, the localized surface plasmon resonance effect may enhance light absorption in the visible range [114]. In a recent work, Zeng and co-workers examined the combined effect of plasmonic gold nanoparticles and fluorescein sensitization on the activity of $\mathrm{NiFe}_{2} \mathrm{O}_{4}$ photocatalysts for visible-light hydrogen production from water using triethanolamine as sacrificial reagent [158]. The presence of gold increased the hydrogen yield by a factor of 5 at an optimum metal loading with respect to the pure ferrite, which the authors ascribed to stronger absorption in the visible range and slower recombination on the basis of UV-vis and photoluminescence spectra, respectively. A synergistic effect of fluorescein sensitizer and plasmonic Au co-catalyst further improved the photoactivity by one order of magnitude, with stable hydrogen production throughout 6 photocatalytic cycles.

In contrast to the above-cited work by Gobara et al. [152], Rodríguez-Rodríguez and coworkers obtained a higher hydrogen yield with the spinel zinc ferrite $\mathrm{ZnFe}_{2} \mathrm{O}_{4}$ compared to $\mathrm{NiFe}_{2} \mathrm{O}_{4}$ [159]. The authors prepared nanosized $\mathrm{Ni}, \mathrm{Co}$ and $\mathrm{Zn}$ ferrites in oil-in-water microemulsions and tested them without any co-catalyst for photocatalytic hydrogen evolution from methanol aqueous solutions. The photocatalytic activity followed the order $\mathrm{ZnFe}_{2} \mathrm{O}_{4}>\mathrm{NiFe}_{2} \mathrm{O}_{4}>\mathrm{CoFe}_{2} \mathrm{O}_{4}$, which is mainly attributed to conduction band energies increasing in the reversed order on the basis of UV-vis spectra. A higher conduction band energy would thus imply a stronger driving force for the transfer of electrons to protons. Dom and co-workers used a microwave solid-state synthesis method to improve the activity of zinc ferrite by a factor of 4 with respect to the one obtained by a conventional solid state reaction [160]. Electrochemical measurements together with physicochemical and optical characterizations let the authors conclude that the absence of agglomeration of nanoparticles in the microwave method compared to the conventional one modified the electronic band positions and the electron mobility, resulting in improved photocatalytic behaviour. Doping 
zinc ferrite may also lead to improved photocatalytic hydrogen production, as shown by Boudjemaa and co-workers, who prepared $\mathrm{M}_{0.2} \mathrm{Zn}_{0.8} \mathrm{Fe}_{2} \mathrm{O}_{4}$ spinels by a co-precipitation method, being $\mathrm{M} \mathrm{Co}$, Ni or $\mathrm{Cu}$ [161]. In this work, a considerable improvement of the activity of the zinc ferrite is reported in the case Co- and $\mathrm{Ni}$-doping, with the former giving the best results of the series. In contrast, Cu-doping resulted in a decrease of activity with respect to $\mathrm{ZnFe}_{2} \mathrm{O}_{4}$. On the basis of electrochemical, photoelectrochemical and optical characterization, the authors mainly ascribe the effect of the guest cation on activity to its influence on the electronic structure of the ferrites, with the band gap values of the different samples decreasing in the same order as the obtained hydrogen evolution rates increase.

Ortega López et al. report a significant hydrogen production with the cobalt spinel ferrite $\mathrm{CoFe}_{2} \mathrm{O}_{4}$ [162]. They compared two different synthetic methods, namely co-precipitation, followed by a relatively low temperature crystallization, and ball-milling of a stoichiometric mixture of iron metal and $\mathrm{Co}_{3} \mathrm{O}_{4}$ previously activated y solid-state reaction at $700^{\circ} \mathrm{C}$. The latter method yielded a final $\mathrm{CoFe}_{2} \mathrm{O}_{4}$ cubic spinel with $5 \mathrm{~nm}$ crystal size vs. $20 \mathrm{~nm}$ with the former synthesis. This, however, resulted in a lower surface area of the ball-milled sample than the co-precipitated one and, contrarily to what may be expected from the quantum-size effect, to a considerably lower band gap (1.15 vs. $1.38 \mathrm{eV}$ ). The authors ascribe both results to the differences in the secondary particle size (100-500 vs. $25 \mathrm{~nm}$ ), which is more plausible in the case of the surface area than in that of the electronic structure. In any case, the balled-milled sample exhibited a higher adsorption capacity which the authors relate to oxygen vacancies created by the high-energy mechanochemical process and invoke to explain the higher hydrogen production per surface area unit displayed by this catalyst.

Copper ferrite $\left(\mathrm{CuFe}_{2} \mathrm{O}_{4}\right)$ has also been shown active for photocatalytic hydrogen evolution. Yang et al. obtained $\mathrm{CuFe}_{2} \mathrm{O}_{4}$ nanoparticles by sol-gel, solid-state reaction and coprecipitation methods, among which the first one yielded the highest hydrogen formation rate using oxalic acid as sacrificial reagent [163]. The use of citric acid in the sol-gel method resulted in a relatively homogeneous particle size distribution, which according to the authors had a key influence on the higher activity of the so-obtained photocatalyst, due to the shorter path travelled by photogenerated charges to the surface. The $\mathrm{CuFe}_{2} \mathrm{O}_{4}$ photocatalyst was active in 
four consecutive cycles, although a decline in the hydrogen evolution rate can be observed in each of them.

Regarding ferrites of non-transition metals, some alkaline and alkali earth metal ferrites have been tested for photocatalytic hydrogen evolution. For example, Boudjemaa and co-workers synthesized the $\mathrm{MgFe}_{2} \mathrm{O}_{4}$ spinel ferrite by calcination of a $\mathrm{Mg}$-Fe layered double hydroxide obtained by co-precipitation [138]. This material gave rise to hydrogen evolution under visible light from an aqueous sulphite solution, although production declined after $20 \mathrm{~min}$ of reaction. This deactivation was ascribed by the authors to the saturation of catalytic sites and competitive reduction of the end product $\mathrm{S}_{2} \mathrm{O}_{6}{ }^{2-}$ for conduction band electrons. Dom et al. reported the synthesis of orthorhombic $\mathrm{CaFe}_{2} \mathrm{O}_{4}$ nanoparticles using different preparation methods, namely solid state reaction, polymer complex, microwave sintering and selfpropagating combustion (SPC) [164]. As they already reported for zinc ferrite [160], the microwave-directed method yielded interesting results, outperforming by nearly one order of magnitude the activities obtained with the rest of syntheses, which gave very similar results [164]. The authors ascribed this difference to an optimum combination of high crystallinity with monodispersed morphology, together with efficient visible light absorption, suitable band energetics and relatively low charge transfer resistance. Photodeposition of platinum as a hydrogen evolution co-catalyst resulted in a further improvement of the activity by a factor of ca. 2.5, resulting in an apparent quantum yield of $1.57 \%$ under $420 \mathrm{~nm}$ irradiation. Different strontium ferrites, namely the cubic, hexagonal and orthorhombic $\mathrm{SrFe}_{2} \mathrm{O}_{4}, \mathrm{SrFe}_{12} \mathrm{O}_{19}$ and $\mathrm{Sr}_{7} \mathrm{Fe}_{10} \mathrm{O}_{22}$, respectively, were selectively obtained by Jiménez-Miramontes et al. by modifying the crystallisation conditions in the Pechini synthetic method [165]. Among the three crystalline phases, the activity towards hydrogen production under UV irradiation was maximum for the cubic one, with the hexagonal phase yielding a two orders of magnitude lower amount of hydrogen as a result of unsuitable band positions.

The perovskite-type lanthanum ferrite, $\mathrm{LaFeO}_{3}$, has been studied for photocatalytic hydrogen evolution in a number of articles. It is considered as a promising catalyst for this application by combining adequate band positions, visible light absorption and (photo)chemical stability. Parida and co-workers actually reported that $\mathrm{LaFeO}_{3}$ was active both for hydrogen evolution from water by using an electron donating (methanol) sacrificial agent, and for oxygen 
evolution with an electron scavenging $\left(\mathrm{Ag}^{+}\right)$agent. High productions were obtained in both cases (see table 5 for the case of hydrogen), although no overall water splitting experiments were reported [166]. Using ethanol as sacrificial agent, Tijare and co-workers reported a relatively similar hydrogen evolution rate (even if the usual difficulties to quantitatively compare different works must be considered) that could be further boosted by using platinum as co-catalyst [167]. However, in this case the improvement caused by platinum was considerably low if compared to its effect on other semiconducting catalysts [157]. Indeed, lervolino and co-workers studied $\mathrm{LaFeO}_{3}$ as a promising noble-metal-free hydrogen evolution photocatalyst [168]. Interestingly, they reported stoichiometric overall water splitting (i.e. without any sacrificial reagent) under UV light over $\mathrm{LaFeO}_{3}$ photocatalysts synthesized using the solution combustion synthesis method. The hydrogen yield increased by a factor of 4 when using glucose as sacrificial electron donor. Under purely visible light irradiation (440 $\mathrm{nm}$ ), the activity of the best-performing catalyst, obtained from an optimized synthetic method, for glucose photoreforming was above $70 \%$ of that under UV, revealing the interest of this material as visible-light-active photocatalyst. Using a similar synthetic procedure, Chen et al. obtained a homogeneously nanocrystalline $\mathrm{LaFeO}_{3}$ that was further modified by encapsulation with a conductive polyaniline (PANI) aerogel (Figure 12) as a means to control the hydrophilicity of the surface and to improve charge mobility. An improvement of hydrogen evolution activity of about 4 times with respect to the unmodified ferrite was observed, using in this case platinum as co-catalyst and triethanolamine as electron donor [169]. Doping $\mathrm{Ru}^{3+}$ into the $\mathrm{Fe}^{3+}$ positions of the $\mathrm{LaFeO}_{3}$ structure improved the hydrogen evolution rate in this reaction by a factor of ca. 4.5 under UV irradiation [168], which was ascribed to the role of the dopant cation as electron scavenger, preventing electron-hole recombination. The optimum doped catalyst was also active in glucose photoreforming under visible light and, in an especially interesting result, in the valorization of a real waste water from a brewing company by using it as sacrificial agent for the production of hydrogen. Partial substitution of $\mathrm{Sr}^{2+}$ for $\mathrm{La}^{3+}$ and $\mathrm{Ti}^{4+}$ for $\mathrm{Fe}^{3+}$, using a flux growth synthetic method, was studied by Domen and coworkers as a way of further improving the photocatalytic activity of $\mathrm{LaFeO}_{3}$ for hydrogen evolution by methanol photoreforming, using Pt as co-catalyst [170]. Simultaneous cation substitution led to improvement in photocatalytic activity attributed to the concurrence of modified structural properties by Sr-doping and electronic characteristics due to Ti-doping, as 
well as reduced grain boundaries and lattice defects, which relates to the synthesis method. The combination of the different factors led to an optimal activity in $\mathrm{La}_{0.925} \mathrm{Sr}_{0.075} \mathrm{Fe}_{0.925} \mathrm{Ti}_{0.075} \mathrm{O}_{3}$. Related perovskite lanthanum strontium ferrites in the Ruddlesden-Popper series $\left(\mathrm{SrO}_{(}\left(\mathrm{LaFeO}_{3}\right)_{\mathrm{n}}(\mathrm{n}: 1\right.$ and 2$)$ were reported a hydrogen evolution photocatalysts from $\mathrm{Na}_{2} \mathrm{SO}_{3}$ solutions by Chen and co-workers [171], with the $\mathrm{n}=1$ compound $\left(\mathrm{SrLaFeO}_{4}\right)$ giving rise to a higher hydrogen evolution rate with $\mathrm{Pt}$ as co-catalyst. Anisotropic charge transportation phenomena are invoked to account for the activity of this kind of solids.

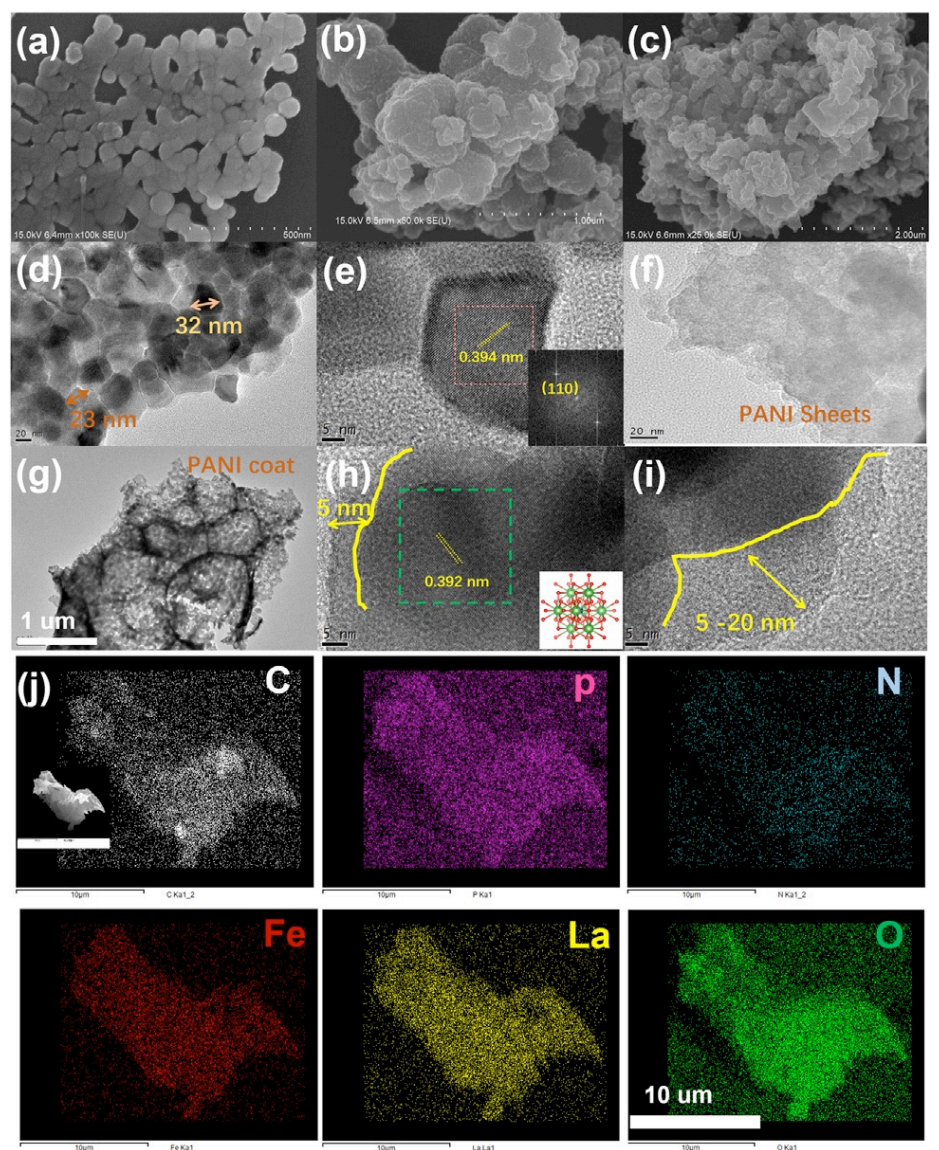

Figure 12. SEM images of (a) $\mathrm{LaFeO}_{3}$, (b) $\mathrm{LaFeO}_{3}-0.75 \mathrm{PANI}$, (c) PANI; TEM image of (d, e) $\mathrm{LaFeO}_{3}$, (f) PANI, (g, h, i) $\mathrm{LaFeO}_{3}-0.75 \mathrm{PANI}$; (j) EDX element mapping of $\mathrm{LaFeO}_{3}-0.75 \mathrm{PANI}$. Reproduced with permission from ref. [169]. Copyright Elsevier.

As mentioned earlier, photocatalytic $\mathrm{CO}_{2}$ reduction studies with ferrite catalysts are much scarcer in the literature than hydrogen production ones. Matsumoto and co-workers reported in 1994 the production of methanol and formaldehyde from a $\mathrm{CO}_{2}$-saturated solution on 
$\mathrm{CaFe}_{2} \mathrm{O}_{4}$ irradiated with light of different wavelengths [172]. The $\mathrm{CH}_{3} \mathrm{OH}$ production followed the same trend against irradiation wavelength than the photocurrent in a $\mathrm{CaFe}_{2} \mathrm{O}_{4}$ photocathode, proving the photocatalytic character of the reaction. However, in spite of the narrow band gap of the ferrite $(1.9 \mathrm{eV})$, both photocurrents and $\mathrm{CO}_{2}$ conversions were significantly higher under UV light. Results with the addition of suspended solid $\mathrm{BaCO}_{3}$ led the authors to propose a mechanism in which $\mathrm{CO}_{3}{ }^{2-} / \mathrm{CO}_{2}$ activation occurs at the interface between the solid catalyst, the solid carbonate and water. Matsumoto reported two years later a screening of photoelectrochemical response and $\mathrm{CO}_{2}$ reduction to methanol with different ferrites [148]. Both properties were not necessarily related, with some ferrites showing electrochemical but not catalytic activity under irradiation and vice versa. Not only the mentioned calcium ferrite was photocatalytically active but also some compositions containing magnesium, strontium, barium, lead and bismuth were. The elements forming the oxides as well as the positions of the band edges were found to determine the photocatalytic activity, with $\mathrm{CaFe}_{2} \mathrm{O}_{4}$ and $(\mathrm{Bi}, \mathrm{Pb})_{2} \mathrm{Sr}_{2} \mathrm{BiFe}_{2} \mathrm{O}_{9+\times}$ giving the best results.

Apparently, as reported by Xiao and co-workers from a combination of UV-vis and XPS spectroscopies, $\mathrm{ZnFe}_{2} \mathrm{O}_{4}$ has adequate band positions to conduct, under visible light, $\mathrm{CO}_{2}$ reduction but not water oxidation [173]. Therefore, triethanolamine was used in that study as a sacrificial agent to scavenge photoproduced holes, while conduction band electrons were utilized to reduce aqueous bicarbonate into mainly acetaldehyde and ethanol. It remains unclear though, whether these products result from the oxidation of triethanolamine.

\subsubsection{Ferrite-based heterojunction photocatalysts}

Either by combining different ferrites or by joining one ferrite another semiconductor like $\mathrm{TiO}_{2}$, $\mathrm{ZnO}$ or $\mathrm{C}_{3} \mathrm{~N}_{4}$, some works have dealt with the improvement of photocatalytic hydrogen production or carbon dioxide reduction by incorporating the materials subject of this review into different kinds of heterostructures.

Regarding the combination of different ferrites, Chen et al. reported the fabrication of a $\mathrm{CaFe}_{2} \mathrm{O}_{4} / \mathrm{MgFe}_{2} \mathrm{O}_{4}$ bulk $\mathrm{p}$ - $\mathrm{n}$ heterojunction for photocatalytic hydrogen evolution from 
aqueous methanol solutions under visible light, with the concourse of two co-catalysts, namely $\mathrm{RuO}_{2}$ and Pt [174]. By bulk heterojunction, the authors mean that there are junctions of the two phases distributed along the whole composite material, as investigated by highresolution transmission electron microscopy, which was obtained by a polymer-complex synthetic method that allowed good crystallinity to be obtained at low temperature as well as an adequate distribution of the composing phases. This heterojunction, which band structure is shown in Figure 13, gave rise to a remarkable hydrogen production activity under light with $\lambda \geq 420 \mathrm{~nm}$, with reported quantum yield of ca. $10 \%$, in contrast with the single phases that showed little activity in the same conditions. Compared to a layered heterojunction, the authors ascribed the improved photocatalytic activity to the higher probability of excitons reaching the interfaces and dissociate, particularly for semiconductor particles with sizes in the same range as the exciton diffusion length. In a related work, Vijayaraghavan and coworkers reported a series of photocatalysts based on magnesium and calcium ferrites composed by single phases and mixed compositions of up to four different crystalline structures $-\mathrm{MgFe}_{2} \mathrm{O}_{4}$, cubic and orthorhombic $\mathrm{CaFe}_{2} \mathrm{O}_{4}$ and $\mathrm{Fe}_{2} \mathrm{O}_{3}$ [175], with activities for hydrogen evolution from glycerol solutions depending mainly on the phase composition of the photocatalyst system, in the absence of co-catalysts. A kind of electron cascade mechanism is proposed by the author to account for the highest activity displayed by a catalyst composed of the four mentioned phases.
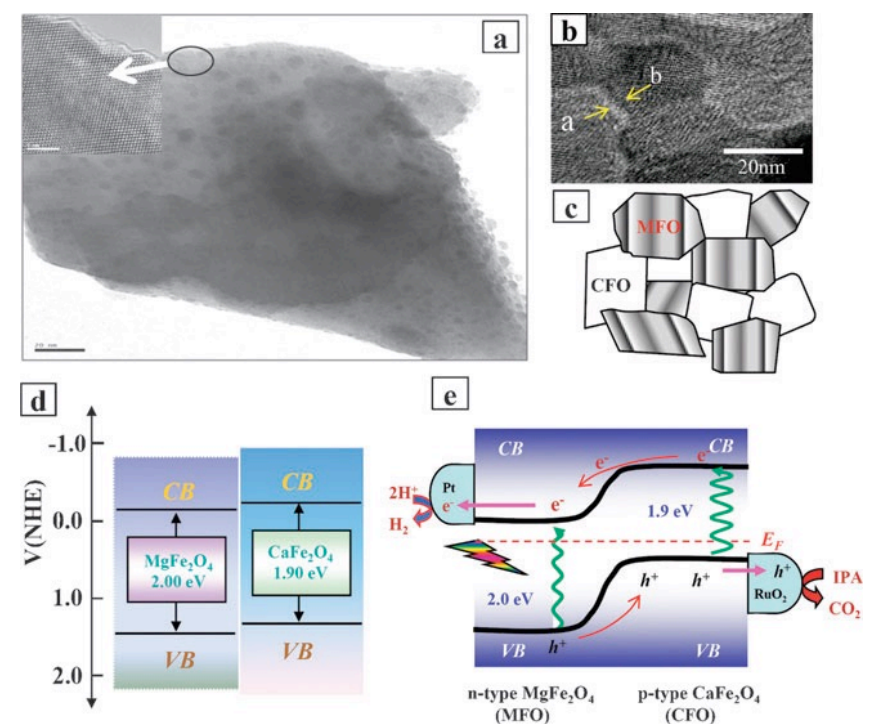

Figure 13. (a) TEM image of a $\mathrm{CaFe}_{2} \mathrm{O}_{4} / \mathrm{MgFe}_{2} \mathrm{O}_{4}$ particle. (b) HRTEM image of interfaces between semiconductor nanoparticles. (c) Schematic model of interpenetrating domains of 
$\mathrm{CaFe}_{2} \mathrm{O}_{4}$ (white) and $\mathrm{MgFe}_{2} \mathrm{O}_{4}$ (gray). (d) Energy band diagram showing band gap energies and band positions of $p-\mathrm{CaFe}_{2} \mathrm{O}_{4}$ and $n-\mathrm{MgFe}_{2} \mathrm{O}_{4}$. (e) Operating principle of the formed heterojunction promoted by co-catalysts. Reproduced with permission from ref. [174]. Copyright Royal Society of Chemistry.

Different ferrites have been combined with $\mathrm{TiO}_{2}$ in coupled photocatalysts for energy applications. An et al. reported the preparation of $\mathrm{Fe}_{3} \mathrm{O}_{4} / \mathrm{TiO}_{2}$ composites with varying magnetite loadings supported on nanofibrilated cellulose, and the activity of the obtained systems for hydrogen production from aqueous methanol solutions [176]. An increase of electron-trapping sites, reducing recombination, is invoked to account for the improved photocatalytic activity of the composite under UV light with respect to cellulose-supported $\mathrm{TiO}_{2}$, although no scheme of the electronic coupling of both phases is reported. According to previous works though, it is feasible that electrons photogenerated in titania are transferred into the lower lying conduction band of magnetite [177], although this would mean that those transferred electrons would lose reduction potential. In addition to electronic features, these composites were reported to be recyclable by means of an external magnetic field. Recyclability tests showed a loss of activity of ca. $8 \%$ after 15 photocatalytic runs [176].

A p-n heterojunction of $\mathrm{CuFe}_{2} \mathrm{O}_{4}$ and $\mathrm{TiO}_{2}$ supported on reduced graphene oxide was reported by Hafeez and co-workers for hydrogen evolution under UV-vis light using glycerol as hole scavenger [178]. Based on optical and electrochemical measurements, a mechanism was proposed in which electrons would flow from the high-energy conduction band of the ferrite phase to the lower-energy one of titania, and from there to the reduced graphene oxide sheets, where they would be transferred to protons to produce hydrogen. In turn, holes would migrate from the valence band of $\mathrm{TiO}_{2} \mathrm{VB}$ to that of $\mathrm{CuFe}_{2} \mathrm{O}_{4}$ and there be trapped by glycerol molecules. Therefore, $\mathrm{CuFe}_{2} \mathrm{O}_{4}$ and $\mathrm{rGO}$ acting as hole traps and electron mediators, respectively, would improve photocatalytic activity with respect to $\mathrm{TiO}_{2}$, as shown by the hydrogen evolution results, by largely inhibiting charge carrier recombination. This inhibition is actually supported by the practical disappearance of photoluminescence at wavelengths associated with $\mathrm{TiO}_{2}$ in the composite system. A similar mechanism, without the concourse of graphene, was proposed by Uddin and co-workers to account for the visible-light ( $\lambda>400 \mathrm{~nm})$ activity of $\mathrm{CuFe}_{2} \mathrm{O}_{4}$ heterojunctions for $\mathrm{CO}_{2}$ reduction into methanol from an aqueous solution 
of potassium bicarbonate, using sodium sulphide as hole scavenger [179]. The ferrite phase would in this case act as a visible-light sensitizer for titania, which would be inactive in those irradiation conditions, and which does, on the other hand improve the activity with respect to the ferrite single phase. Again, photoluminescence spectroscopy measurements under UV excitation suggested recombination to be diminished in the composite, although the difference between $\mathrm{TiO}_{2}$ and the two-phase system was not as dramatic as in the previous case. As is common in photocatalytic $\mathrm{CO}_{2}$ reduction experiments [144], deactivation of the catalyst was observed in all cases, which the authors associated to the depletion of active sites.

A Z-scheme electronic mechanism was proposed by Son et al. in the photocatalytic reduction of $\mathrm{CO}_{2}$ in cyclohexanol solution by $\mathrm{ZnFe}_{2} \mathrm{O}_{4} / \mathrm{TiO}_{2}$ composites [180]. With a similar relative band position arrangement to that of the previous heterojunction, $\mathrm{ZnFe}_{2} \mathrm{O}_{4}$ and $\mathrm{TiO}_{2}$ may couple in such a way that electrons from the conduction band of the latter are transferred into the valence band of the former, while electrons in the ferrite conduction bands reduce $\mathrm{CO}_{2}$ and holes in titania VB oxidize the sacrificial agent, in a kind of all-solid Z-scheme without an electron mediator between the distinct phases. This heterojunction, formed by $\mathrm{TiO}_{2}$ nanobelts decorated with ferrite nanoparticles, showed higher photocatalytic activity than either of the two single phases. Cyclohexyl formate and cyclohexanone were detected as the main products, together with lower amounts of formic acid. This led the authors to propose a mechanism in which cyclohexane is oxidized to cyclohexanol, while $\mathrm{CO}_{2}$ is reduced into formic acid. Esterification between these two intermediates would form cyclohexyl formate, while part of the alcohol would be further oxidized to the ketone (Figure 14). This research group has also reported the combination of the zinc ferrite with bismuth oxychloride, $\mathrm{BiOCl}$, for the same reaction $[181,182]$. Apparently, the same type of heterojunction as in the case of the $\mathrm{ZnFe} \mathrm{O}_{4} / \mathrm{TiO}_{2}$ can be formed with the oxychloride instead of titania, leading to improved photocatalytic activity with respect to the separate semiconductors. The preparation method and the resulting morphology of the particles affected the final photocatalytic activity, in such a way that hydrothermally obtained samples displayed a better performance than physical mixtures of the semiconductors, probably due to a more extended interphase contact [182]. In addition, systems with hierarchical microsphere microstructure showed higher 
photocatalytic activities, apparently due to a better charge carrier separation, than those with non- hierarchical nanosheet morphology [182]. Furthermore, photocatalytic activity in the $\mathrm{ZnFe}_{2} \mathrm{O}_{4} / \mathrm{BiOCl}$ system is also influenced by the exposed facets of $\mathrm{BiOCl}$. Thus, the yields of cyclohexyl formate and cyclohexanone were higher for the samples with more exposed (001) facets than for the samples with more exposed (010) facets, which the authors attribute to the higher density of oxygen atoms on the (001) facets which enriches the production of electrons under UV irradiation [181]

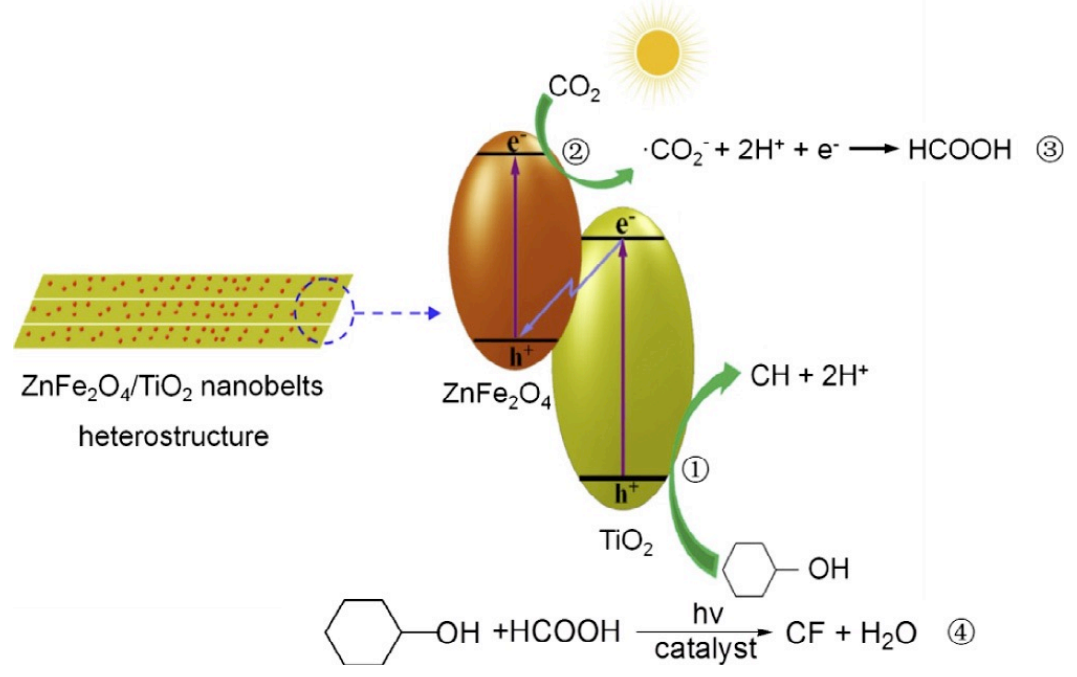

Figure 14. Schematic diagram for photocatalytic reduction of $\mathrm{CO}_{2}$ in cyclohexanol over a Zscheme $\mathrm{ZnFe}_{2} \mathrm{O}_{4} / \mathrm{TiO}_{2}$ heterostructure photocatalyst under UV light irradiation. " $\mathrm{CH}^{\prime}$ stands for cyclohexanone and "CF" for cyclohexyl formate. Reproduced with permission from ref. [180]. Copyright Elsevier.

Soto-Arreola and co-workers combined $\mathrm{ZnO}$ with either $\mathrm{CuFe}_{2} \mathrm{O}_{4}$ or $\mathrm{NiFe}_{2} \mathrm{O}_{4}$ to form type-II heterojunctions aimed at improved photocatalytic activity for water splitting without any sacrificial reagent under UV light [183]. With an optimum amount of $3 \mathrm{wt}$.\% ZnO, both composites, obtained by physical mixture of the single phases, surpassed the activity of the corresponding single-phase ferrites and that of $\mathrm{ZnO}$ under the same reaction conditions. In spite of the absence of any sacrificial agent, the reported results are in the same order of magnitude as other works with similar materials that make use of organic hole scavengers. Based of fluorescence spectroscopy and (photo)electrochemical measurements, the 
improvement in the photocatalytic activity of the heterostructures was attributed to a reduced recombination of the charge carriers, due to the transfer of electrons from the conduction band of the metal ferrite to the conduction band of the $\mathrm{ZnO}$. Therefore, the authors proposed a mechanism in which electrons accumulated in the conduction band of $\mathrm{ZnO}$ reduce protons to produce hydrogen, while holes remaining in the valence band of the ferrite phase would oxidize water to oxygen. However, no oxygen evolution was reported in the work to account for the electron balance and, as shown by the authors in their electronic scheme, holes in the valence band of both copper and nickel ferrites do not have enough reduction potential to oxidize water. A similar charge transfer mechanism was proposed by Karamian and Sharifnia to account for the visible-light activity of $\mathrm{BiFeO}_{3}-\mathrm{ZnO} \mathrm{p}-\mathrm{n}$ junctions for photocatalytic $\mathrm{CO}_{2}$ reduction using methane as hole scavenger [184], although in this case only the ferrite component is activated by the used irradiation source, thereby acting as an inorganic visible-light sensitizer of the otherwise inactive, wide-band-gap ZnO phase. The charge separation was supported by photoluminescence spectroscopy results, which suggested a hindered recombination in the mixed phases. With an optimized 1:1 molar ratio between the components, ca. $20 \% \mathrm{CO}_{2}$ conversion was reached, which declined to ca. $14 \%$ after four runs. However, no other efficiency measure than conversion is given to make the results comparable to other works, nor is it clear what products are obtained.

Regarding other oxides that have been coupled to ferrites, Guo and co-workers [185] reported the preparation of $\mathrm{Ce}$-doped $\mathrm{ZnFe}_{2} \mathrm{O}_{4}$ via a sol-gel method that actually gave rise to bi-phasic samples composed of a $\mathrm{Ce}^{3+}$-doped $\mathrm{ZnFe}_{2} \mathrm{O}_{4}$ spinel phase together with an additional $\mathrm{CeO}_{2}$ phase with fluorite structure. These composites displayed higher activity than the pristine zinc ferrite for photocatalytic $\mathrm{CO}_{2}$ reduction under visible light, with $\mathrm{CH}_{4}$ and $\mathrm{CO}$ as main products, together with hydrogen from the competing reduction of water and oxygen from water oxidation (not shown though). The formation of a $p-n$ junction between the two phases induced the establishment of a type-II heterojunction that promoted charge separation and reduced recombination, as suggested by a combined study of photoluminescence and UV-Vis absorption spectroscopies with (photo)electrochemical measurements. In addition, TPD and FTIR studies revealed that the alkalinity of cerium oxide favours the chemical interaction 
between $\mathrm{CO}_{2}$ and photocatalyst surfaces, which occurs via the formation of monodentate and bidentate carbonate and bidentate bicarbonate as the main surface species.

In a similar approach, Khan et al. reported the use of another wide-band gap alkaline oxide like $\mathrm{SrO}$ to promote both charge separation and $\mathrm{CO}_{2}$ adsorption [186]. However, the electronic matching here is slightly different from those in the previous examples, with the conduction band of SrO lying considerably above that of the ferrite, so that it is only able to extract hot electrons generated in the latter by absorption of relatively high-energy (although still visible) photons. Charge separation is demonstrated by increased signals in the surface photovoltage spectra upon the addition of the strontium oxide phase, as well as by the increased generation of hydroxyl radicals followed by the formation of the fluorescent 7-hydroxycoumarin from coumarin solutions. On the other hand, TPD studies reveal that the alkaline oxide promotes the adsorption of $\mathrm{CO}_{2}$ via carbonate species, increasing not only the amount of $\mathrm{CO}_{2}$ adsorbed but also the strength of the interaction. In this case, carbon monoxide is the main product of $\mathrm{CO}_{2}$ reduction. According to previous theoretical studies on $\mathrm{MO}-\mathrm{TiO}_{2}$ systems ( $\mathrm{M}: \mathrm{Mg}, \mathrm{Ca}, \mathrm{Sr}$, Ba) [187], the improvement of $\mathrm{CO}_{2}$ adsorption and activation on alkaline earth metal oxide modifications should facilitate the activity for photocatalytic $\mathrm{CO}_{2}$ reduction, $\mathrm{SrO}$ being particularly interesting to that aim since it promotes $\mathrm{CO}_{2}$ activation and $\mathrm{CO}$ desorption.

$\mathrm{C}_{3} \mathrm{~N}_{4}$ has been extensively studied in the last years as a metal-free and visible-light-responsive photocatalyst [188], and some works have extended this studies to its combination with ferrites for photocatalytic water splitting. Thus, Chen and co-workers enhanced the photocatalytic activity of graphitic carbon nitride for hydrogen evolution from triethanolamine solutions through the incorporation of $\mathrm{MgFe}_{2} \mathrm{O}_{4}$ by annealing a mixture of ferrite particles obtained by the sol-gel method and melamine as the $\mathrm{C}_{3} \mathrm{~N}_{4}$ precursor [189]. According to static photoluminescence spectra and time-resolved fluorescence decay curves, the ferrite is able extract photoinduced electrons and holes from carbon nitride, which per se leads to a poor activity for hydrogen production due to the low energy of the conduction band of $\mathrm{MgFe}_{2} \mathrm{O}_{4}$. However, if the nitride is modified with both ferrite and platinum, the latter can extract electrons more efficiently, according to the greatly improved activity with respect to both bare $\mathrm{C}_{3} \mathrm{~N}_{4}$ and $\mathrm{MgFeO}_{4} / \mathrm{C}_{3} \mathrm{~N}_{4}$. In turn, electrochemical measurements revealed the ferrite to be a good oxidation catalyst, which led the authors to propose a dual effect of $\mathrm{MgFe}_{2} \mathrm{O}_{4}$ in 
the photocatalytic system as hole extractor and oxidation co-catalyst, with platinum acting as the reduction co-catalyst. The situation is different with nickel and copper ferrites, since both have conduction band levels above that of $C_{3} N_{4}$, according to the same authors [190]. Therefore, under visible irradiation both ferrites can donate electrons from their conduction bands to that of the nitride, while holes can be move from the valence band of the latter to that of the ferrite. In this line, steady-state photoluminescence spectra and fluorescence decay curves suggest in both cases $\left(\mathrm{CuFe}_{2} \mathrm{O}_{4} / \mathrm{C}_{3} \mathrm{~N}_{4}\right.$ and $\left.\mathrm{NiFe}_{2} \mathrm{O}_{4} / \mathrm{C}_{3} \mathrm{~N}_{4}\right)$ an inhibited electronhole recombination, while electrochemical impedance spectroscopy shows a greatly enhanced internal conductivity in the composites compared to the bare nitride. As a result, the activity of the heterojunctions for $\mathrm{H}_{2}$ production from aqueous triethanolamine increases with respect to the single phases, and is further enhanced in the presence of platinum as reduction co-catalyst. As in the previous work, the authors highlight the dual role of the ferrite as charge separation promoter and oxidation co-catalyst.

The junction of $\mathrm{C}_{3} \mathrm{~N}_{4}$ with the perovskite-structured lanthanum ferrite $\mathrm{LaFeO}_{3}$ has been studied in a few works for photocatalytic hydrogen production. In principle, the relative band positions of both phases would be adequate for the formation of a type-II heterojunction. However, as previously described for the zinc ferrite heterojunctions, an all-solid Z-scheme without any electronic mediator seems to occur in the case of $\mathrm{LaFeO}_{3} / \mathrm{C}_{3} \mathrm{~N}_{4}$ photocatalysts. Acharya et al. proposed this kind of junction based on thermodynamic considerations [191], given that, in the case of a type-Il heterojunction, electrons would fall into a conduction band (that of $\mathrm{LaFeO}_{3}$ in this case) with reduction potential slightly below that of the $\mathrm{H}^{+} / \mathrm{H}_{2}$ redox couple. Even if the presence of Pt as co-catalyst is able to overcome this limitation in the single-phase ferrite, the observed improvement in hydrogen evolution with respect both to the ferrite and to $\mathrm{C}_{3} \mathrm{~N}_{4}$ would not occur. This mechanism is, according to the authors, supported by the observed increase in photoluminescence in the heterojunction due to the recombination of the electrons in the conduction band of $\mathrm{C}_{3} \mathrm{~N}_{4}$ with the holes in the valence band of the ferrite. However, this evidence does not seem so obvious from the photophysics point of view. The same kind of heterojunction between these two components was proposed by Xu and co-workers [192], by which they surpassed the activity of both single phases for hydrogen evolution from triethanolamine solutions under visible light, using platinum (3 wt.\%) 
as co-catalyst. The introduction of $2 \mathrm{wt} . \%$ of $\mathrm{Ni}_{2} \mathrm{~S}$ improved the photocatalytic activity of the $\mathrm{LaFeO}_{3} / \mathrm{C}_{3} \mathrm{~N}_{4}$ heterojunction in the same conditions by a factor of 60 , with an apparent quantum yield of $2 \%$ at $420 \mathrm{~nm}$ [193], although the activity was still lower than that obtained in the previous work with platinum as co-catalyst.

\subsection{Ferrite-based photoelectrode materials for solar fuels production}

\subsubsection{Ferrite photocathodes}

One of the most investigated ferrite photocathodes is p-type calcium ferrite $\left(\mathrm{CaFe}_{2} \mathrm{O}_{4}\right)$, which has a band gap of $1.9 \mathrm{eV}$ and suitable band edge positions for water reduction. The first paper using this material was published by Matsumoto et al. [127] using pressed pelletized electrodes sintered at $1200{ }^{\circ} \mathrm{C}$ and oxidized under $\mathrm{O}_{2}$ at $1000{ }^{\circ} \mathrm{C}$. $\mathrm{CaFe}_{2} \mathrm{O}_{4}$ was studied in a $\mathrm{N}_{2}$ saturated $\mathrm{K}_{2} \mathrm{SO}_{4}$ solution $(0.25 \mathrm{M}, \mathrm{pH}=6.0)$, combined in the cell combined with an n-type $\mathrm{Zn}_{1.2} \mathrm{Fe}_{1.8} \mathrm{O}_{4}$. Photoelectrolysis of water without external bias resulted in a solar-to-hydrogen (STH) conversion efficiency lower than $0.01 \%$. This limited efficiency was ascribed to a low electron concentration in the surface. In addition, Fermi level pinning (FLP) arises due to the presence of surface states associated to the redox pair $\mathrm{Fe}^{3+} / \mathrm{Fe}^{2+}$. To improve contact and subsequently the photocurrent, authors propose the use of noble metal nanoparticles (Au, Pt$\mathrm{Pd}$ alloy) in the semiconductor/metal interface. Cao et al. [123] have investigated the use of p- $\mathrm{CaFe}_{2} \mathrm{O}_{4}$ as photocathode by depositing $\mathrm{CaFe}_{2} \mathrm{O}_{4}$ thin films on fluorine-doped tin oxide (FTO) by pulsed laser deposition method. A photocurrent density of $-0.117 \mathrm{~mA} \mathrm{~cm}^{-2}$ at $-0.06 \mathrm{~V}$ was reported which is significantly larger than the values reported by Matsumoto and co-workers $[127,128]$, probably due to shorter electron transfer distances in the thinner films and higher electrical conductivity. The $\mathrm{H}_{2}$ evolution rate under visible light irradiation, using a Pt counter electrode without applying any additional bias, was $\sim 4.8 \mu \mathrm{mol} \mathrm{m}{ }^{-2} \mathrm{~h}^{-1}$. Sekizawa et al. have reported several metal-doped $\mathrm{CaFe}_{2} \mathrm{O}_{4}$ electrodes prepared by radio frequency magnetron cosputtering over antimony-doped tin oxide (ATO) [130]. The doping with Au and Ag leads to an increase in the photocurrent. Particularly, Ag doping triggered an improvement in the symmetry around the Fe atom, which induces high mobility and an increase in activity of 23 times with respect to the undoped ferrite. 
Ye et al. have compared the photoelectrochemical properties of $p-\mathrm{CaFe}_{2} \mathrm{O}_{4}, n-\mathrm{ZnFe}_{2} \mathrm{O}_{4}, \mathrm{p}$ $\mathrm{CaFe}_{2} \mathrm{O}_{4} / \mathrm{n}-\mathrm{ZnFe}_{2} \mathrm{O}_{4}$, and multiple $\mathrm{p}$ - $\mathrm{n}$ junction $\mathrm{CaFe}_{2} \mathrm{O}_{4} / \mathrm{ZnFe}_{2} \mathrm{O}_{4}$ photoelectrodes [129]. All electrodes were prepared by a pulsed laser deposition. In the $\mathrm{FTO} / \mathrm{ZnFe} \mathrm{O}_{4} / \mathrm{CaFe}_{2} \mathrm{O}_{4}$ photoelectrode configuration, a negative photocurrent and a positive open circuit photovoltage $\left(+0.025 \mathrm{~V}, \lambda=430 \mathrm{~nm}, 118 \mu \mathrm{Wcm}^{-2}\right)$ was described, indicating that $\mathrm{p}-\mathrm{CaFe}_{2} \mathrm{O}_{4}$ layer acts as photocathode. In the case of four multiple-junction $\mathrm{FTO} /\left(\mathrm{ZnFe}_{2} \mathrm{O}_{4} / \mathrm{CaFe}_{2} \mathrm{O}_{4}\right)_{x}$ photoelectrodes with the same single-layer thickness of 10 to $15 \mathrm{~nm}$, an improvement in the photocurrent density and the onset potential was observed with increasing number of layers $x(x=10,15,20$, and 25). The 20-junction photoelectrode showed the highest photocurrent density $\left(-0.025 \mathrm{mAcm}^{-2}\right.$ at $\left.+0.4 \mathrm{~V}\right)$ and the most positive onset potential $(+1.3 \mathrm{~V})$ of all four samples.

Ida et al. developed a tandem cell (Figure 15a) without applying an external voltage using (hk0)-oriented p-type $\mathrm{CaFe}_{2} \mathrm{O}_{4}$ deposited over FTO (100 nm thick) by pulse layer deposition (PLD) as photocathode and $\mathrm{TiO}_{2}$ as photoanode with an onset potential of $-0.75 \mathrm{~V}$ (Figure 15b) [124]. The open-circuit voltage was $0.97 \mathrm{~V}$ and the short-circuit current was about $200 \mu \mathrm{A} / \mathrm{cm}^{2}$ (Figure $15 \mathrm{c}$ ), and $\mathrm{a}_{2}$ and $\mathrm{O}_{2}$ evolution of 70 and $4 \mu \mathrm{mol}$, respectively, in $48 \mathrm{~h}$ was attained (Figure 15d). After this time, many cracks were observed on the $\mathrm{CaFe}_{2} \mathrm{O}_{4}$ surface as shown in Figure $15 \mathrm{e}$ and the solution contained $2.3 \mu \mathrm{mol}$ of $\mathrm{Fe}$, indicating a slight corrosion of the $\mathrm{CaFe}_{2} \mathrm{O}_{4}$ electrode. Later, the same authors, described the use of $\mathrm{n}$ - $\mathrm{ZnO}$ as photocathode generating a photovoltage of $0.82 \mathrm{~V}$ [125]. In this case, only $\mathrm{H}_{2}$ was detected and $\mathrm{Zn}$ was partially dissolved, which accounted for the absence of $\mathrm{O}_{2}$. In a following work, they also described a modification of p-type $\mathrm{CaFe}_{2} \mathrm{O}_{4}$ with the presence of a $\mathrm{Ca}_{2} \mathrm{Fe}_{2} \mathrm{O}_{5}$ impurity enhancing the short circuit photocurrent density $\left(0.55 \mathrm{mAcm}^{-2}\right)$ and slightly increasing the photovoltage (1.09 V) [126]. During the reaction a $\mathrm{H}_{2} / \mathrm{O}_{2}$ ratio of 3.7 was observed which is lower than in the previous paper. In addition, $\mathrm{O}_{2}$ formation was improved. 

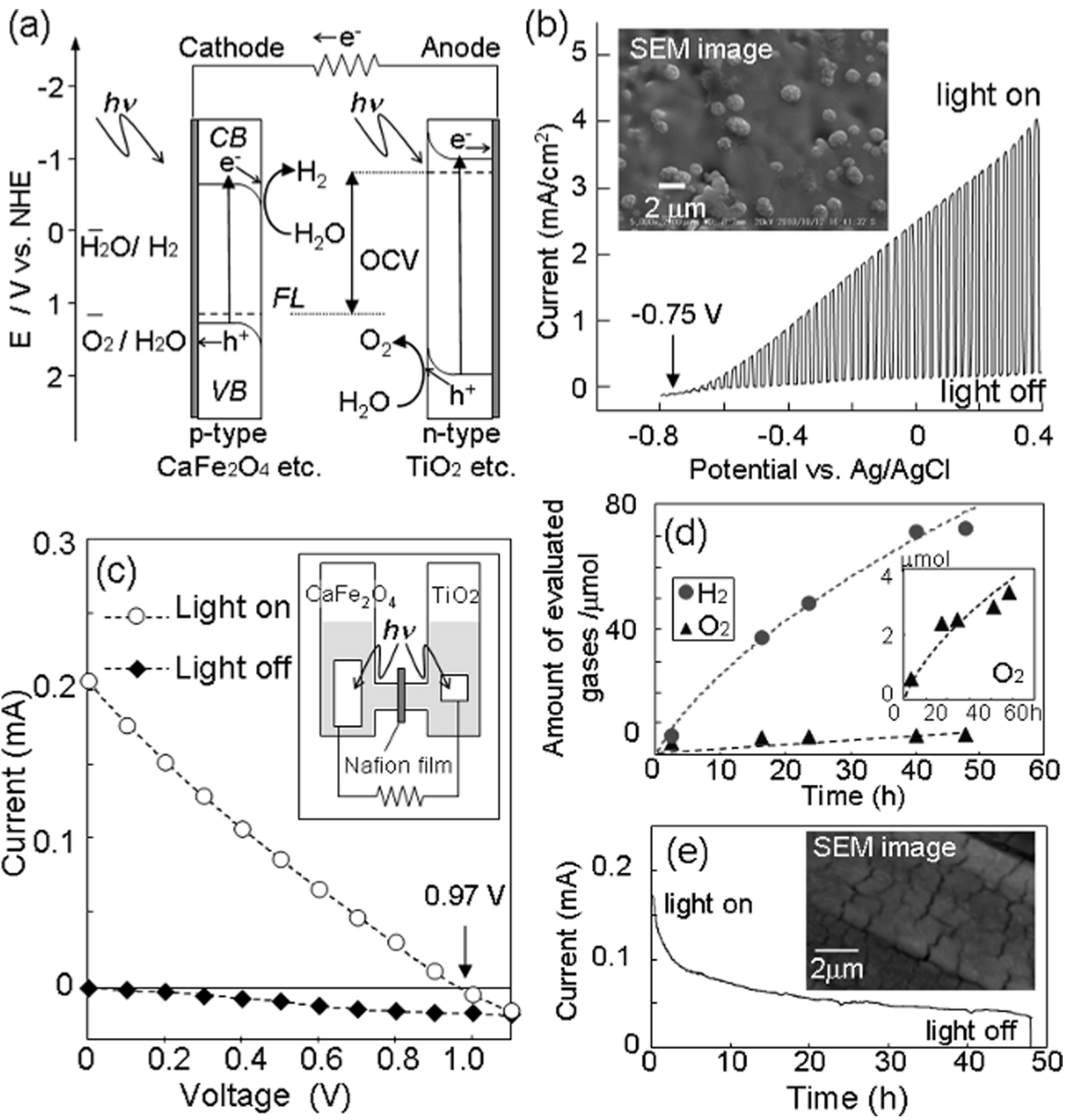

Figure 15. (a) Reaction and band model in photovoltaic cells using p-type and n-type semiconductor electrodes. (b) Current-potential curve and SEM image of the $\mathrm{TiO}_{2}$ electrode. (c) Current-potential curve of a photocell with $\mathrm{CaFe}_{2} \mathrm{O}_{4}\left(2 \mathrm{~cm}^{2}\right)$ and $\mathrm{TiO}_{2}\left(0.5 \mathrm{~cm}^{2}\right)$ electrodes and model structure of measurement cell. (d) Amount of hydrogen and oxygen gases generated from the photocell short-circuited by connecting the $\mathrm{CaFe}_{2} \mathrm{O}_{4}$ and $\mathrm{TiO}_{2}$ electrodes as a function of illumination time. (e) Current-time evolution for the photocell short-circuited by connecting the $\mathrm{CaFe}_{2} \mathrm{O}_{4}$ and $\mathrm{TiO}_{2}$ electrodes and $\mathrm{SEM}$ image of $\mathrm{CaFe}_{2} \mathrm{O}_{4}$ after $48 \mathrm{~h}$ reaction. All reactions were carried out in $0.1 \mathrm{M} \mathrm{NaOH}$ (aq) under illumination (500 W Xe lamp). Reproduced with permission from [124]. Copyright American Chemical Society. 
One strategy to improve the low quantum efficiency of a pristine $\mathrm{p}-\mathrm{CaFe}_{2} \mathrm{O}_{4}$ electrode due to the poor mobility of the photogenerated charge carriers is to dope it with different elements. In this way, Matsumoto et al. used $\mathrm{Na}$ and $\mathrm{Mg}$ which have similar ionic radii than $\mathrm{Ca}$ and $\mathrm{Fe}$ respectively to prepare type $\mathrm{Ca}_{1-x} \mathrm{Na}_{x} \mathrm{Fe}_{2-y} \mathrm{Mg}_{y} \mathrm{O}_{4}$ photocathodes [128]. This led to the formation of acceptor levels within the bandgap and to higher electronic conductivity but still low photocurrents.

Rekhila et al proposed the use of $\mathrm{p}-\mathrm{NiFe}_{2} \mathrm{O}_{4}$ pellets prepared by sintering sol-gel synthesized particles at $850^{\circ} \mathrm{C}$ [134]. The open-circuit voltage, short-circuit current and efficiency were reported to be, respectively, $0.43 \mathrm{~V}, 0.71 \mathrm{~mA} \mathrm{~cm}^{-2}$ and 0.28 under irradiation with visible light $\left(50 \mathrm{~mW} \mathrm{~cm}^{-2}\right)$ with Pt as counter electrode.

Yang et al. prepared porous $\mathrm{CoFe}_{2} \mathrm{O}_{4}$ nanosheets on FTO from aqueous solutions of $\mathrm{Co}$ and $\mathrm{Fe}$ nitrate using a template-free electrochemical deposition followed by a heat treatment at 933 $\mathrm{K}$ [133]. The photocathodes exhibit a small photocurrent of $\sim 0.3 \mu \mathrm{Acm}-2$ in $0.1 \mathrm{M}$ aqueous $\mathrm{Na}_{2} \mathrm{~S}$ at zero bias voltage under wavelength $\geq 390 \mathrm{~nm}\left(30 \mathrm{mWcm}^{-2}\right)$.

Fan and co-workers reported the preparation of $\mathrm{MgFe}_{2} \mathrm{O}_{4}$ nanofibers and nanowires by electrospinning [194, 195]. By CVD-coating with $\mathrm{MoS}_{2}$, a 1D heterostructure with enhanced charge carrier mobility was created, which showed $92 \%$ photoelectrochemical tetracycline degradation after two hours. A photoelectrochemical hydrogen evolution rate of $5.8 \mathrm{mmol} \mathrm{h}^{-}$ ${ }^{1} \mathrm{~g}^{-1}$ was found at $0.5 \mathrm{~V}$ bias under Xe arc lamp irradiation.

Guijarro et al. [196] used a $\beta-\mathrm{FeOOH}$ nanostructure as a solid precursor for $\mathrm{MgFe}_{2} \mathrm{O}_{4}, \mathrm{CuFe}_{2} \mathrm{O}_{4}$ and $\mathrm{ZnFe}_{2} \mathrm{O}_{4}$ thin films. The infiltration with metal nitrate solutions and subsequent calcination at $800{ }^{\circ} \mathrm{C}$ led to the formation of $\mathrm{MgO}, \mathrm{CuO}$ and $\mathrm{ZnO}$ impurities, which were etched under highly acidic ( $7 \mathrm{M} \mathrm{HNO}_{3}$ for $\mathrm{CuFe}_{2} \mathrm{O}_{4}, \mathrm{MgFe}_{2} \mathrm{O}_{4}$ ) or alkaline (5 $\mathrm{M} \mathrm{NaOH}$ for $\mathrm{ZnFe}_{2} \mathrm{O}_{4}$ ) conditions. They were able to improve the performance by $\mathrm{NiFe}_{2} \mathrm{O}_{x}$ deposition and post-synthetic calcination in $\mathrm{H}_{2}$ atmosphere. Promising faradaic efficiencies (97\%), but also a high degree of bulk recombination and Fermi level pinning at $0.9 \mathrm{~V}$ vs. RHE, were reported.

In the case of $\mathrm{CO}_{2}$ photoreduction, the use of ferrites as photoelectrodes is scarcer. Rezaul Karim et al. [197] developed a p-type $\mathrm{CuFe}_{2} \mathrm{O}_{4}$ photocathode, synthesized by the sol-gel method, for $\mathrm{CO}_{2}$ photoelectroreduction in a $\mathrm{CO}_{2}$ saturated $\mathrm{NaHCO}_{3}$ solution under visible light 
irradiation (470 nm). Methanol was found as the only product in the liquid phase with a faradaic efficiency of $62 \%$ of and a quantum efficiency of $14.4 \%$, using a bias potential of 0.5 $\mathrm{V}$ (vs RHE). The relatively lower quantum efficiency was ascribed to the formation of competitive gas products during $\mathrm{CO}_{2}$ reduction.

\subsubsection{Ferrite photoanodes}

Ferrites can also act as n-type semiconductors being suitable candidates as photoanodes for PEC. Among them, $\mathrm{ZnFe}_{2} \mathrm{O}_{4}$ is a remarkable example. Tahir et al., for instance [141, 142], propose the use of $\mathrm{ZnFe}_{2} \mathrm{O}_{4}$ prepared by aerosol-assisted chemical vapour deposition (AACVD) over FTO as photoanode for water splitting. The obtained photocurrents have a high dependence with the synthesis conditions, with a maximum photocurrent density of $0.35 \mathrm{~mA}$ $\mathrm{cm}^{-2}$ at $1.23 \mathrm{~V}$ versus RHE using ethanol as solvent and a calcination temperature of $450{ }^{\circ} \mathrm{C}$. An incident photon-to-current conversion efficiency of $13.5 \%$ at $350 \mathrm{~nm}$ at an applied potential of $1.23 \mathrm{~V}$ versus RHE was observed [141]. The authors attributed this behaviour to the improved collection of the photogenerated minority carriers at the $\mathrm{ZnFe}_{2} \mathrm{O}_{4} /$ electrolyte interface as the average feature size gradually decreased with the solvent from $\sim 500 \mathrm{~nm}$ (methanol) to $\sim 100 \mathrm{~nm}$ (ethanol) [142].

To decrease the synthesis temperature, Kim et al. propose the use of hybrid microwave annealing (HMA) post-synthetic heat treatment with graphite powder as the susceptor. The synthesis is based on the treatment of $\beta-\mathrm{FeOOH}$ nanorods with a zinc nitrate solution with a thermal treatment at $550{ }^{\circ} \mathrm{C}$ for $3 \mathrm{~h}$. After that, $\mathrm{ZnFe}_{2} \mathrm{O}_{4}$ nanorods were calcined at $800{ }^{\circ} \mathrm{C}(20$ $\mathrm{min}$ ) or subjected to $\mathrm{HMA}\left(5 \mathrm{~min}\right.$ ) to increase the crystallinity. The $\mathrm{ZnFe}_{2} \mathrm{O}_{4}$ nanorods from HMA treatment show a 10 - to 15 -fold increase in activity compared to conventional thermally treated electrodes and an enhancement of the stability, which is attributed to a higher crystallinity and lower amount of surface defects [198]. In a later work, these authors modified the synthesis atmosphere (vacuum, air, or hydrogen) after the first thermal stage $\left(800{ }^{\circ} \mathrm{C}\right)$ [199]. In both $\mathrm{H}_{2}$ and vacuum an increase of the photoactivity about 20-fold is observed.

Hufnagel et al. [200] prepared mesoporous $\mathrm{ZnFe}_{2} \mathrm{O}_{4}$ thin films on a macroporous ATO scaffold using atomic layer deposition (ALD). These photoanodes show a more negative photocurrent 
onset ( $0.9 \mathrm{~V}$ versus $\mathrm{RHE}$ ) compared to reported values. In addition, these electrodes exhibit a photoresponse 4 to 5 fold higher than the same material in film conformation.

In order to improve the diffusion length of minority carriers, several strategies have been developed. One of them is the use of structured transparent conductive oxide current collectors to capture and tunnel the photogenerated electrons readily while the large interfacial area allows efficient transfer of the holes to the solution. In this way, Fu et al. propose the use developed a $\mathrm{ZnFe}_{2} \mathrm{O}_{4}$ decorated Al-doped $\mathrm{ZnO}$ (AZO) nanowire films [100]. In a first stage the Al:ZnO nanowires were grown on the FTO using hydrothermal synthesis and subsequently treated with $\mathrm{FeCl}_{3}$ and calcined at $550{ }^{\circ} \mathrm{C}$. The remarkable photoelectrochemical performance (photocurrent density of $1.72 \mathrm{mAcm}^{-2}$ at $1.23 \mathrm{~V}$ versus RHE) was attributed to the synergy of the visible light absorption of $\mathrm{ZnFe}_{2} \mathrm{O}_{4}$ and the of high conductivity of Al: $\mathrm{ZnO}$.

$\mathrm{Fe}_{2} \mathrm{O}_{3}$ is one of the most studied photoanode materials. There are a number of research works and review articles dealing with the modification strategies of hematite such as morphology control, doping, and heterojunction formation to improve the charge transfer efficiency [201, 202]. Regarding the last strategy, ferrites have been also investigated forming heterojunctions with hematite for photoanodes. The most studied one is the $\mathrm{ZnFe}_{2} \mathrm{O}_{4} / \mathrm{Fe}_{2} \mathrm{O}_{3}$ heterojunction prepared by different synthesis methods. McDonald and Choi employed the electrodeposition route to develop core-shell photoelectrodes composed by $\alpha-\mathrm{Fe}_{2} \mathrm{O}_{3}$ (core) and $\mathrm{ZnFe}_{2} \mathrm{O}_{4}$ (shell) [203]. In a first stage, $\beta$-FeOOH films were electrodeposited on FTO being transformed into $\alpha-$ $\mathrm{Fe}_{2} \mathrm{O}_{3}$ by a thermal treatment and a subsequent treatment with a $\mathrm{Zn}$-containing solution covering the iron oxide and annealing to produce the $\mathrm{ZnFe}_{2} \mathrm{O}_{4}$ shell. The best photoelectrochemical performance was obtained for a $\mathrm{ZnFe}_{2} \mathrm{O}_{4} / \mathrm{Fe}_{2} \mathrm{O}_{3}$ ratio of 1 . The synergy between $\mathrm{ZnFe}_{2} \mathrm{O}_{4}$ and $\mathrm{Fe}_{2} \mathrm{O}_{3}$ led to an improved electron hole separation in the heterojunction interface that is responsible for the increase on the photoelectrochemical performance comparing with bare iron oxide. In addition, the incorporation of $\mathrm{Al}^{3+}$ leads to a thin layer solid solution $\left(\mathrm{ZnFe}_{2-x} \mathrm{Al}_{x} \mathrm{O}_{4}\right.$ or $\left.\mathrm{Fe}_{2-x} \mathrm{Al}_{x} \mathrm{O}_{3}\right)$ after heat treatment. This reduces the electron-hole recombination centres, but decreases the catalytic activity for the oxygen evolution reaction (OER). Guo et al. also use the hydrothermal synthesis growing the $\mathrm{FeOOH}$ nanorods and subsequent treatment with different concentrations of $\mathrm{Zn}$ precursor leading to $\mathrm{ZnFe} \mathrm{O}_{4} / \mathrm{Fe}_{2} \mathrm{O}_{3}$ nanorod [204]. The photocurrent density for the composite electrode was $0.44 \mathrm{mAcm}^{-2}$ at 
1.2 $\mathrm{V}$ versus $\mathrm{RHE}$, which was almost twice as high as that for a $\mathrm{Fe}_{2} \mathrm{O}_{3}$ electrode $(0.24$ $\mathrm{mAcm}^{-2}$ ). On the other hand, Borse et al. used plasma spray method to deposited an aqueous solution of $\mathrm{Zn}$ and Fe salts over stainless steel leading to a $\mathrm{ZnFe} 2 \mathrm{O}_{4} / \mathrm{Fe}_{2} \mathrm{O}_{3}$ electrode obtaining a photocurrent five-fold higher than for bare Zinc ferrite. In addition, the rates for HER were determined to be $46.3 \mu \mathrm{mol} \cdot \mathrm{cm}^{-2}($ STH conversion $=0.06)$ and $99.0 \mu \mathrm{mol} \cdot \mathrm{cm}^{-2}($ STH conversion $=0.0125)$ for $\mathrm{ZnFe}_{2} \mathrm{O}_{4}$ and the $\mathrm{ZnFe}_{2} \mathrm{O}_{4} / \mathrm{Fe}_{2} \mathrm{O}_{3}$ photoanode respectively [205].

Kim et al. [206, 207] reported the preparation of heterojunction photoanodes using p-CaFe $\mathrm{O}_{4}$ with $\mathrm{TaON}$ and $\mathrm{BiVO}_{4}$. The selection of these oxides is due to their staggered relative band positions with the ferrite leading to an effective heterojunction for water oxidation reactions. The $\mathrm{CaFe}_{2} \mathrm{O}_{4}$ layer on the surface of a TaON lead to an increase of in the photocurrent density $\left(1.26 \mathrm{mAcm}^{-2}\right)$ it is about 5.5 times greater than bare TaON. This enhancement in the photoelectrochemical performance is due to a reduction of the resistance of the charge carrier transport and, therefore, an improved electron-hole separation [206]. In the case of $\mathrm{CaFe}_{2} \mathrm{O}_{4} / \mathrm{BiVO}_{4}$ an increase of $65 \%$ over that measured at the $\mathrm{BiVO}_{4}$ electrode was observed [207]. In order to improve the photoelectrochemical performance, an OER co-catalyst (cobalt phosphate, $\mathrm{Co}-\mathrm{Pi}$ ) was deposited on $\mathrm{CaFe}_{2} \mathrm{O}_{4} / \mathrm{TaON}$. After deposition of $\mathrm{Co}-\mathrm{Pi}, \mathrm{H}_{2}$ and $\mathrm{O}_{2}$ were generated with a nearly stoichiometric ratio of $2.1\left(123 \mu \mathrm{mol} \mathrm{H}_{2}\right.$ and $\left.59 \mu \mathrm{mol} \mathrm{O}_{2}\right)$ applying a bias of $1.23 \mathrm{~V}$ versus RHE under $3 \mathrm{~h}$ of illumination with $\lambda \geq 400 \mathrm{~nm}$. The STH efficiency was $0.053 \%$ at $1.0 \mathrm{~V}$ versus $\mathrm{RHE}$, but reached $0.55 \%$ when a PV device is coupled in a tandem configuration (assuming the applied voltage is zero). However, the initial current decreased within $3 \mathrm{~h}$ to about $50 \%$. Similar results have been obtained with $\mathrm{CaFe}_{2} \mathrm{O}_{4} / \mathrm{BiVO}_{4}$ composite photoanodes, but with a lower photocurrent and a higher stability. $\mathrm{H}_{2}$ and $\mathrm{O}_{2}$ production were 297 and $140 \mu \mathrm{mol}$, respectively (within $2 \mathrm{~h}$ of illumination with visible light, $\lambda \geq 400 \mathrm{~nm}$ ), with a faradic efficiency around $80 \%$.

Another example with a calcium ferrite was reported by Ahmed and co-workers, who prepared a $\mathrm{p}-\mathrm{CaFe}_{2} \mathrm{O}_{4} / \mathrm{n}-\mathrm{Fe}_{2} \mathrm{O}_{3}$ heterojunction photoanode by anisotropic growth of a $\beta$ FeOOH film on FTO from an aqueous solution containing Fe and $\mathrm{Ca}$ ions followed by two-step thermal annealing at $550{ }^{\circ} \mathrm{C}$ and $800{ }^{\circ} \mathrm{C}$ [208]. This heterojunction showed a photocurrent density of $0.53 \mathrm{mAcm}^{-2}$ at $1.23 \mathrm{~V}$ versus $\mathrm{RHE}$, being $100 \%$ higher than that obtained with $\mathrm{Fe}_{2} \mathrm{O}_{3}$. This behaviour is explained by a reduction of the resistance of the interfacial charge 
transfer between the electrolyte and the electrode and an improvement of the charge separation. 
Table 5. Photocatalytic hydrogen production with selected single-phase ferrite photocatalysts

\begin{tabular}{|c|c|c|c|c|c|c|c|}
\hline Catalyst & $\begin{array}{l}\text { Band } \\
\text { gap } \\
\text { (eV) }\end{array}$ & $\begin{array}{l}\text { Co- } \\
\text { catalyst }\end{array}$ & Sacrificial agent & Light source & $\begin{array}{l}\mathrm{H}_{2} \text { evolution rate } \\
\left(\mathrm{mmol} \mathrm{h}^{-1} \mathrm{gcat}^{-1}\right)\end{array}$ & $\begin{array}{l}\text { Apparent } \\
\text { quantum yield } \\
\text { (\%) }\end{array}$ & Reference \\
\hline $\mathrm{Fe}_{3} \mathrm{O}_{4}$ & 2.7 & $\mathrm{Pt}$ & Ethanol & $\begin{array}{l}2 \times 200 \mathrm{~W} \\
\text { tungsten lamp }\end{array}$ & 8.275 & - & $\begin{array}{l}\text { Mangrulkar et } \\
\text { al. [150] }\end{array}$ \\
\hline $\mathrm{Fe}_{3} \mathrm{O}_{4}$ & 2.84 & - & Methanol & $\begin{array}{l}\text { Simulated } \\
\text { solar }\end{array}$ & 1.25 & - & $\begin{array}{l}\text { Gobara et al. } \\
{[152]}\end{array}$ \\
\hline $\mathrm{NiFe}_{2} \mathrm{O}_{4}$ & 1.7 & - & Methanol & $\begin{array}{l}250 \text { W Xe } \\
\text { lamp } \\
\lambda \geq 420 \mathrm{~nm}\end{array}$ & 0.155 & $\begin{array}{l}0.52 \\
\mathrm{~nm})\end{array} \quad(\lambda \geq 420$ & Peng et al. [154] \\
\hline $\mathrm{NiFe}_{2} \mathrm{O}_{4}$ & 1.56 & - & $\mathrm{S}_{2} \mathrm{O}_{3}{ }^{2-}$ & $\begin{array}{l}500 \quad W \\
\text { halogen lamp }\end{array}$ & 1.529 & $\begin{array}{ll}0.53 & \text { (full } \\
\text { spectrum) } & \end{array}$ & $\begin{array}{l}\text { Rekhila et al. } \\
{[134]}\end{array}$ \\
\hline $\mathrm{NiFe}_{2} \mathrm{O}_{4}$ & 1.7 & - & Methanol & $\begin{array}{l}\text { Xe lamp } \\
\lambda \geq 420 \mathrm{~nm}\end{array}$ & 0.045 & $\begin{array}{l}7.5 \times 10^{-3} \quad(\lambda= \\
450 \pm 10 \mathrm{~nm})\end{array}$ & $\begin{array}{l}\text { Hong et al. } \\
{[155]}\end{array}$ \\
\hline $\mathrm{NiFe}_{2} \mathrm{O}_{4}$ & 1.73 & $\mathrm{Au}$ & Triethanolamine & $\begin{array}{l}300 \text { W Xe } \\
\text { lamp } \\
\lambda \geq 420 \mathrm{~nm}\end{array}$ & 3.162 & - & Zeng et al. [158] \\
\hline $\mathrm{NiFe}_{2} \mathrm{O}_{4}$ & 1.62 & - & Methanol & $\begin{array}{l}\text { Simulated } \\
\text { solar }\end{array}$ & 4.95 & - & $\begin{array}{l}\text { Gobara et al. } \\
\text { [152] }\end{array}$ \\
\hline $\mathrm{NiFe}_{2} \mathrm{O}_{4}$ & 1.6 & - & Methanol & $\begin{array}{l}250 \mathrm{~W} \text { metal } \\
\text { halide lamp }\end{array}$ & 0.040 & - & \begin{tabular}{l}
\multicolumn{3}{l}{ Domínguez- } \\
Arvizu et al. \\
{$[156]$}
\end{tabular} \\
\hline
\end{tabular}




\begin{tabular}{|c|c|c|c|c|c|c|c|}
\hline $\mathrm{NiFe}_{2} \mathrm{O}_{4}$ & 1.79 & - & Methanol & $\begin{array}{l}250 \mathrm{~W} \text { metal } \\
\text { halide lamp }\end{array}$ & 0.016 & - & $\begin{array}{l}\text { Rodríguez- } \\
\text { Rodríguez et al. } \\
\text { [159] }\end{array}$ \\
\hline $\mathrm{ZnFe}_{2} \mathrm{O}_{4}$ & 2.23 & - & Methanol & $\begin{array}{l}\text { Simulated } \\
\text { solar }\end{array}$ & 4.37 & - & $\begin{array}{l}\text { Gobara et al. } \\
{[152]}\end{array}$ \\
\hline $\mathrm{ZnFe}_{2} \mathrm{O}_{4}$ & 1.90 & - & Methanol & $\begin{array}{l}250 \mathrm{~W} \text { metal } \\
\text { halide lamp }\end{array}$ & 0.044 & - & $\begin{array}{l}\text { Rodríguez- } \\
\text { Rodríguez et al. } \\
{[159]}\end{array}$ \\
\hline $\mathrm{ZnFe}_{2} \mathrm{O}_{4}$ & 1.93 & - & Methanol & $\begin{array}{l}500 \quad W \quad \mathrm{Hg} \\
\text { lamp } \\
\lambda \geq 420 \mathrm{~nm}\end{array}$ & 0.134 & $\begin{array}{l}0.19 \quad(\lambda \geq 420 \\
\mathrm{nm})\end{array}$ & Dom et al. [160] \\
\hline $\mathrm{CoFe}_{2} \mathrm{O}_{4}$ & 1.39 & - & Methanol & $\begin{array}{l}250 \mathrm{~W} \text { metal } \\
\text { halide lamp }\end{array}$ & 0.016 & - & $\begin{array}{l}\text { Rodríguez- } \\
\text { Rodríguez et al. } \\
\text { [159] }\end{array}$ \\
\hline $\mathrm{CoFe}_{2} \mathrm{O}_{4}$ & 1.15 & - & Methanol & 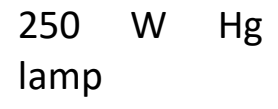 & 0.436 & - & $\begin{array}{l}\text { Ortega López et } \\
\text { al. [162] }\end{array}$ \\
\hline $\mathrm{CuFe}_{2} \mathrm{O}_{4}$ & - & - & Oxalic acid & $\begin{array}{l}250 \\
\text { lamp }\end{array}$ & 1.72 & - & Yang et al. [163] \\
\hline $\mathrm{CaFe}_{2} \mathrm{O}_{4}$ & 1.83 & $\mathrm{Pt}$ & Methanol & $\begin{array}{l}\text { Hg arc lamp } \\
\lambda=420 \pm 10 \\
\mathrm{~nm}\end{array}$ & 1.09 & $\begin{array}{l}1.57(\lambda=420 \pm \\
10 \mathrm{~nm})\end{array}$ & Dom et al. [164] \\
\hline $\mathrm{SrFe}_{2} \mathrm{O}_{4}$ & 1.77 & - & Methanol & $\begin{array}{lll}250 & W & H g \\
\text { lamp } & & \end{array}$ & 0.730 & - & $\begin{array}{l}\text { Jiménez- } \\
\text { Miramontes et } \\
\text { al. [165] }\end{array}$ \\
\hline
\end{tabular}




\begin{tabular}{|c|c|c|c|c|c|c|c|}
\hline $\mathrm{LaFeO}_{3}$ & 2.11 & - & Methanol & $\begin{array}{l}125 \mathrm{~W} \quad \mathrm{Hg} \\
\text { lamp } \\
\lambda \geq 420 \mathrm{~nm}\end{array}$ & 8.6 & $\begin{array}{l}8.07 \\
\mathrm{~nm})\end{array}(\lambda \geq 420$ & $\begin{array}{l}\text { Parida et al. } \\
\text { [84] }\end{array}$ \\
\hline $\mathrm{LaFeO}_{3}$ & 2.07 & $\mathrm{Pt}$ & Ethanol & $\begin{array}{l}2 \times 200 \mathrm{~W} \\
\text { tungsten lamp }\end{array}$ & 3.315 & - & $\begin{array}{l}\text { Tijare et al. } \\
{[167]}\end{array}$ \\
\hline $\mathrm{LaFeO}_{3}$ & 2.0 & - & Glucose & $\begin{array}{l}10 \mathrm{~W} \text { LED } 440 \\
\mathrm{~nm}\end{array}$ & 0.292 & - & $\begin{array}{l}\text { lervolino et al. } \\
\text { [168] }\end{array}$ \\
\hline Ru-doped $\mathrm{LaFeO}_{3}$ & 1.98 & - & $\begin{array}{l}\text { Waste water } \\
\text { from brewing }\end{array}$ & $\begin{array}{l}10 \mathrm{~W} \text { LED } 460 \\
\mathrm{~nm}\end{array}$ & 0.532 & - & $\begin{array}{l}\text { lervolino et al. } \\
{[209]}\end{array}$ \\
\hline $\mathrm{LaFeO}_{3}$ & 2.22 & $\mathrm{Pt}$ & Triethanolamine & $\begin{array}{l}300 \quad W \quad X e \\
\text { lamp } \\
\lambda \geq 420 \mathrm{~nm}\end{array}$ & 0.707 & - & Chen et al. [169] \\
\hline $\mathrm{La}_{0.925} \mathrm{Sr}_{0.075} \mathrm{Fe}_{0.925} \mathrm{Ti}_{0.075} \mathrm{O}_{3}$ & 2.1 & $\mathrm{Pt}$ & Methanol & $\begin{array}{l}300 \text { W Xe } \\
\text { lamp } \\
\lambda \geq 420 \mathrm{~nm}\end{array}$ & 0.555 & - & $\begin{array}{l}\text { Hojamberdiev } \\
\text { et al. [170] }\end{array}$ \\
\hline $\mathrm{LaSrFeO}_{4}$ & 2.16 & $\mathrm{Pt}$ & $\mathrm{Na}_{2} \mathrm{SO}_{3}$ & $\begin{array}{l}500 \quad W \quad \mathrm{Hg} \\
\operatorname{lamp} \\
\lambda \geq 400 \mathrm{~nm}\end{array}$ & 0.158 & $\begin{array}{l}0.19 \\
\mathrm{~nm})\end{array} \quad(\lambda \geq 420$ & $\begin{array}{l}\text { Chen et al. } \\
{[210]}\end{array}$ \\
\hline
\end{tabular}




\section{Conclusions}

Even if ferrites have displayed some appealing properties that make them promising materials for light-activated applications for energy and environment like photocatalysis, photo-Fenton and photoelectrochemistry, the amount of scientific literature dealing with such materials is still lower compared to other types of catalysts or semiconductors. Nevertheless, as we have tried to point out here, some works have reported interesting results in the above-mentioned processes. However, there is still room for advancement in the way towards the full understanding of the relationships between the physico-chemical properties of these materials and their performance in photoassisted reactions. The possibilities that they display for the modification of their chemical composition, crystalline structure and optoelectronic properties, as well as their versatility for the creation of heterojunction and doped systems, are in our opinion the most relevant characteristics of ferrites for their further development in photoassisted environmental and solar fuels applications.

\section{Acknowledgements.}

The authors want to thank the European Fund for regional development (EFRE/FEDER) for the financial support of the PHOTOPUR project which is performed within the framework of Interreg $V$ and the Sciences Offensive. Financial support from project SOLPAC: ENE201789170-R, MCIU/AEI/FEDER, EU from the Spanish Ministry of Science, Innovation and Universities is also gratefully acknowledged. 


\section{REFERENCES}

[1]Helaïli N, Bessekhouad Y, Bachari K, Trari M (2014) Synthesis and physical properties of the CuFe2-xMnxO4 (0 $\leq x \leq 2)$ solid solution. Materials Chemistry and Physics 148:734-743

[2]Sickafus KE, Wills JM, Grimes NW (1999) Structure of Spinel. J Am Ceram Soc 82:3279-3292

[3]Levy D, Diella V, Dapiaggi M, Sani A, Gemmi M, Pavese A (2004) Equation of state, structural behaviour and phase diagram of synthetic MgFe2O4, as a function of pressure and temperature. Physics and Chemistry of Minerals 31:122-129

[4]Candeia RA, Bernardi MIB, Longo E, Santos IMG, Souza AG (2004) Synthesis and characterization of spinel pigment $\mathrm{CaFe} 2 \mathrm{O} 4$ obtained by the polymeric precursor method. Materials Letters 58:569-572

[5]Candeia RA, Souza MAF, Bernardi MIB, Maestrelli SC, Santos IMG, Souza AG, Longo E (2007) Monoferrite BaFe2O4 applied as ceramic pigment. Ceramics International 33:521-525

[6]Valenzuela, R. (2012) Novel Applications of Ferrites 2012:ID 591839

[7]Pullar RC (2012) Hexagonal ferrites: A review of the synthesis, properties and applications of hexaferrite ceramics. Progress in Materials Science 57:1191-1334

[8]Structure Type 063: $\mathrm{BaFe}_{12} \mathrm{O}_{19}$ (magnetoplumbite). In: http://som.web.cmu.edu/structures/S063-BaFe12019.html 2019

[9]Dereje H. Taffa, Dillert R, Ulpe AC, Katharina C. L. Bauerfeind, Bredow T, Bahnemann DW, Wark M (2009) Photoelectrochemical and theoretical investigations of spinel type ferrites $\left(\mathrm{M}_{x} \mathrm{Fe}_{3 \hat{a}{ }^{\wedge} \times} \mathrm{O}_{4}\right)$ for water splitting: a mini-review. Journal of Photonics for Energy 7:1-25

[10]Goodenough JB, Longo JM, Hellwege KH (1970) Crystallographic and Magnetic Properties of Perovskite and Perovskite-Related Compounds. Springer-Verlag, Berlin, Landolt-Bornstein Tabellen 
[11]Dixon CAL, Kavanagh CM, Knight KS, Kockelmann W, Morrison FD, Lightfoot P (2015) Thermal evolution of the crystal structure of the orthorhombic perovskite LaFeO3. Journal of Solid State Chemistry 230:337-342

[12]Yuan SJ, Cao YM, Li L, Qi TF, Cao SX, Zhang JC, DeLong LE, Cao G (2013) First-order spin reorientation transition and specific-heat anomaly in CeFeO3. J Appl Phys 114:113909

[13]Kefeni KK, Mamba BB, Msagati TAM (2017) Application of spinel ferrite nanoparticles in water and wastewater treatment: A review. Separation and Purification Technology 188:399422

[14]Kefeni KK, Msagati TAM, Mamba BB (2017) Ferrite nanoparticles: Synthesis, characterisation and applications in electronic device. Materials Science and Engineering: B 215:37-55

[15]Tatarchuk T, Bououdina M, Judith Vijaya J, John Kennedy L (2017) Spinel Ferrite Nanoparticles: Synthesis, Crystal Structure, Properties, and Perspective Applications:305-325

[16]Masunga N, Mmelesi OK, Kefeni KK, Mamba BB (2019) Recent advances in copper ferrite nanoparticles and nanocomposites synthesis, magnetic properties and application in water treatment: Review. Journal of Environmental Chemical Engineering 7:103179

[17]Dhand C, Dwivedi N, Loh XJ, Jie Ying AN, Verma NK, Beuerman RW, Lakshminarayanan R, Ramakrishna S (2015) Methods and strategies for the synthesis of diverse nanoparticles and their applications: a comprehensive overview. RSC Adv 5:105003-105037

[18]Amiri S, Shokrollahi H (2013) Magnetic and structural properties of RE doped Co-ferrite (REåNd, Eu, and Gd) nano-particles synthesized by co-precipitation. Journal of Magnetism and Magnetic Materials 345:18-23

[19]Zi Z, Sun Y, Zhu X, Yang Z, Dai J, Song W (2009) Synthesis and magnetic properties of CoFe2O4 ferrite nanoparticles. Journal of Magnetism and Magnetic Materials 321:1251-1255 
[20]Harzali H, Saida F, Marzouki A, Megriche A, Baillon F, Espitalier F, Mgaidi A (2016) Structural and magnetic properties of nano-sized NiCuZn ferrites synthesized by coprecipitation method with ultrasound irradiation. Journal of Magnetism and Magnetic Materials 419:50-56

[21]Rashmi SK, Bhojya Naik HS, Jayadevappa H, Viswanath R, Patil SB, Madhukara Naik M (2017) Solar light responsive Sm-Zn ferrite nanoparticle as efficient photocatalyst. Materials Science and Engineering: B 225:86-97

[22]Annie Vinosha P, Jerome Das S (2018) Investigation on the role of $\mathrm{pH}$ for the structural, optical and magnetic properties of cobalt ferrite nanoparticles and its effect on the photofenton activity. Materials Today: Proceedings 5:8662-8671

[23]Pereira C, Pereira AM, Fernandes C, Rocha M, Mendes R, FernÃindez-GarcÃa MP, Guedes A, Tavares PB, GrenÃ“che J, AraÃojo JP, Freire C (2012) Superparamagnetic MFe2O4 (M = Fe, Co, Mn) Nanoparticles: Tuning the Particle Size and Magnetic Properties through a Novel OneStep Coprecipitation Route. Chem Mater 24:1496-1504

[24]Tatarchuk T, Bououdina M, Vijaya J, John Kennedy L (2017) Chapter 22: Spinel Ferrite Nanoparticles: Synthesis, Crystal Structure, Properties, and Perspective Applications . In: Fesenko O, Yatsenko L (eds) Nanophysics, Nanomaterials, Interface Studies and Applications, Springer Proceedings in Physics 195. Springer

[25]Sharma R, Bansal S, Singhal S (2015) Tailoring the photo-Fenton activity of spinel ferrites (MFe2O4) by incorporating different cations ( $\mathrm{M}=\mathrm{Cu}, \mathrm{Zn}, \mathrm{Ni}$ and $\mathrm{Co}$ ) in the structure. RSC Adv 5:6006-6018

[26]Zielinska-Jurek A, Bielan Z, Dudziak S, Wolak I, Sobczak Z, Klimczuk T, Nowaczyk G, Hupka J (2017) Design and application of magnetic photocatalysts for water treatment. The effect of particle charge on surface functionality. Catalysts 7 
[27]Kurian M, Nair DS (2015) Heterogeneous Fenton behavior of nano nickel zinc ferrite catalysts in the degradation of 4-chlorophenol from water under neutral conditions. Journal of Water Process Engineering 8:e37-e49

[28]Li R, Cai M, Xie Z, Zhang Q, Zeng Y, Liu H, Liu G, Lv W (2019) Construction of heterostructured CuFe2O4/g-C3N4 nanocomposite as an efficient visible light photocatalyst with peroxydisulfate for the organic oxidation. Applied Catalysis B: Environmental 244:974982

[29]Peng K, Fu L, Yang H, Ouyang J (2016) Perovskite LaFeO3/montmorillonite nanocomposites: synthesis, interface characteristics and enhanced photocatalytic activity. Scientific Reports 6:19723

[30]Sannino D, Vaiano V, Ciambelli P, Isupova LA (2011) Structured catalysts for photo-Fenton oxidation of acetic acid. Catalysis Today 161:255-259

[31]Soltani T, Lee B (2016) Improving heterogeneous photo-Fenton catalytic degradation of toluene under visible light irradiation through Ba-doping in BiFeO3 nanoparticles. J Mol Catal A-Chem 425:199-207

[32]Li X, Shi H, Zhu W, Zuo S, Lu X, Luo S, Li Z, Yao C, Chen Y (2018) Nanocomposite LaFe1xNixO3 /Palygorskite catalyst for photo-assisted reduction of NOx: Effect of Ni doping. Appl Catal B Environ 231:92-100

[33]Li X, Shi H, Yan X, Zuo S, Zhang Y, Wang T, Luo S, Yao C, Ni C (2018) Palygorskite Immobilized Direct Z-Scheme Nitrogen-Doped Carbon Quantum dots/PrFeO3 for Photo-SCR Removal of NOx. ACS Sustainable Chem Eng 6:10616-10627

[34]Ansari F, Soofivand F, Salavati-Niasari M (2019) Eco-friendly synthesis of cobalt hexaferrite and improvement of photocatalytic activity by preparation of carbonic-based nanocomposites for waste-water treatment. Compos Part B: Eng 165:500-509

[35]Pechini MP (1967) Method of preparing lead and alkaline earth titanates and niobates and coating method using the same to form a capacitor. US Patent, 3330697A 
[36]Danks AE, Hall SR, Schnepp Z (2016) The evolution of â€ solâ€“gelâ€ $€^{\mathrm{TM}}$ chemistry as a technique for materials synthesis. Mater Horiz 3:91-112

[37]Garcia-Muñoz P, Lefevre C, Robert D, Keller N (2019) Ti-substituted LaFeO3 perovskite as photoassisted CWPO catalyst for water treatment. Applied Catalysis B: Environmental 248:120-128

[38]Jamil TS, Abbas HA, Nasr RA, Vannier R- (2018) Visible light activity of BaFe1-xCuxO3-d as photocatalyst for atrazine degradation. Ecotoxicol Environ Saf 163:620-628

[39]Danks AE, Hall SR, Schnepp Z (2016) The evolution of â€ solâ€"gelâ€ $€^{\mathrm{TM}}$ chemistry as a technique for materials synthesis. Mater Horiz 3:91-112

[40]Yin J, Liao G, Zhou J, Huang C, Ling Y, Lu P, Li L (2016) High performance of magnetic BiFeO3 nanoparticle-mediated photocatalytic ozonation for wastewater decontamination. Sep Purif Technol 168:134-140

[41]Luo J, Li R, Chen Y, Zhou X, Ning X, Zhan L, Ma L, Xu X, Xu L, Zhang L (2019) Rational design of Z-scheme LaFeO3/SnS2 hybrid with boosted visible light photocatalytic activity towards tetracycline degradation. Separation and Purification Technology 210:417-430

[42]Liu Q, Xu Y, Wang J, Xie M, Wei W, Huang L, Xu H, Song Y, Li H (2018) Fabrication of $\mathrm{Ag} / \mathrm{AgCl} / \mathrm{ZnFe} 2 \mathrm{O} 4$ composites with enhanced photocatalytic activity for pollutant degradation and E. coli disinfection. Colloids Surf A Physicochem Eng Asp 553:114-124

[43]Liu Z, Feng H, Xue S, Xie P, Li L, Hou X, Gong J, Wei X, Huang J, Wu D (2018) The triplecomponent Ag 3 PO 4 -CoFe 204 -GO synthesis and visible light photocatalytic performance. Appl Surf Sci 458:880-892

[44]Diao Y, Yan Z, Guo M, Wang X (2018) Magnetic multi-metal co-doped magnesium ferrite nanoparticles: An efficient visible light-assisted heterogeneous Fenton-like catalyst synthesized from saprolite laterite ore. Journal of Hazardous Materials 344:829-838 
[45]Casbeer E, Sharma VK, Li X (2012) Synthesis and photocatalytic activity of ferrites under visible light: A review. Separation and Purification Technology 87:1-14

[46]Ameer S, Gul IH, Mujahid M (2015) Ultra low permittivity/loss CoFe2O4 and CoFe2O4rGO nanohybrids by novel 1-hexanol assisted solvothermal process. Journal of Alloys and Compounds 642:78-82

[47]Marinca TF, Chicinaş I, Isnard O (2013) Structural and magnetic properties of the copper ferrite obtained by reactive milling and heat treatment. Ceramics International 39:4179-4186

[48]Zhang Z, Yao G, Zhang X, Ma J, Lin H (2015) Synthesis and characterization of nickel ferrite nanoparticles via planetary ball milling assisted solid-state reaction. Ceramics International $41: 4523-4530$

[49]Manova E, Kunev B, Paneva D, Mitov I, Petrov L, EstournÃ “s C, D'Orlã@an C, Rehspringer J, Kurmoo M (2004) Mechano-Synthesis, Characterization, and Magnetic Properties of Nanoparticles of Cobalt Ferrite, CoFe2O4. Chem Mater 16:5689-5696

[50]Yan Z, Gao J, Li Y, Zhang M, Guo M (2015) Hydrothermal synthesis and structure evolution of metal-doped magnesium ferrite from saprolite laterite. RSC Adv 5:92778-92787

[51]Thomson WT (2011) Uhlig's Corrosion Handbook. John Wiley \& Sons, Inc, Hoboken, New Jersey

[52]HEMMI Y, ICHIKAWA N, SAITO N, MASUDA T (1994) Electrochemical Considerations Regarding General Corrosion of Materials in a BWR Primary Circuit. J Nucl Sci Technol 31:12021213

[53]Ramankutty CG, Sugunan S (2001) Surface properties and catalytic activity of ferrospinels of nickel, cobalt and copper, prepared by soft chemical methods. Applied Catalysis A: General 218:39-51 
[54]Reddy GK, Gunasekara K, Boolchand P, Smirniotis PG (2011) Cr- and Ce-Doped Ferrite Catalysts for the High Temperature Waterâ^'Gas Shift Reaction: TPR and Mossbauer Spectroscopic Study. J Phys Chem C 115:920-930

[55]Šimša Z, Široký P, Koláček J, Brabers VAM (1980) Optical and magneto-optical properties of magnetite and manganese ferrites. Journal of Magnetism and Magnetic Materials 1518:775-776

[56]Balaji S, Kalai Selvan R, John Berchmans L, Angappan S, Subramanian K, Augustin CO (2005) Combustion synthesis and characterization of Sn4+ substituted nanocrystalline NiFe2O4. Materials Science \& Engineering B 119:119-124

[57]Harish KN, Bhojya Naik HS, Prashanth kumar PN, Viswanath R (2012) Synthesis, enhanced optical and photocatalytic study of Cdâ€"Zn ferrites under sunlight. Catal Sci Technol 2:10331039

[58]Archer MD, Morris GC, Yim GK (1981) Electrochemical approaches to solar energy conversion: A brief overview and preliminary results obtained with $\mathrm{n}$-type cobalt ferrite. Journal of Electroanalytical Chemistry and Interfacial Electrochemistry 118:89-100

[59]Antonious MS, Etman M, Guyot M, Merceron $T$ (1986) Photoelectrochemical characteristics of $\mathrm{p}$ - and $\mathrm{n}$ - type polycrystalline $\mathrm{Ni}$-ferrite electrodes in aqueous solutions. Materials Research Bulletin 21:1515-1523

[60]Vinodgopal K, Kamat PV (1995) Enhanced Rates of Photocatalytic Degradation of an Azo Dye Using SnO2/TiO2 Coupled Semiconductor Thin Films. Environ Sci Technol 29:841-845

[61]Ranjit KT, Viswanathan B (1997) Synthesis, characterization and photocatalytic properties of iron-doped TiO2 catalysts. Journal of Photochemistry and Photobiology A: Chemistry 108:79-84

[62]Bard AJ (1979) Photoelectrochemistry and heterogeneous photo-catalysis at semiconductors. Journal of Photochemistry 10:59-75 
[63]Low J, Yu J, Jaroniec M, Wageh S, Al-Ghamdi A (2017) Heterojunction Photocatalysts. Adv Mater 29:1601694

[64]Jang JS, Kim HG, Lee JS (2012) Heterojunction semiconductors: A strategy to develop efficient photocatalytic materials for visible light water splitting. Catalysis Today 185:270-277

[65]Jang JS, Choi SH, Kim HG, Lee JS (2008) Location and State of Pt in Platinized CdS/TiO2 Photocatalysts for Hydrogen Production from Water under Visible Light. J Phys Chem C $112: 17200-17205$

[66]Jang JS, Yoon KY, Xiao X, Fan FF, Bard AJ (2009) Development of a Potential Fe2O3-Based Photocatalyst Thin Film for Water Oxidation by Scanning Electrochemical Microscopy: Effects of Agâ^’Fe2O3 Nanocomposite and Sn Doping. Chem Mater 21:4803-4810

[67]Tu Y, You C, Chang C, Wang S, Chan T (2013) Adsorption behavior of As(III) onto a copper ferrite generated from printed circuit board industry. Chemical Engineering Journal 225:433439

[68]Tu Y, You C, Chang C, Wang S, Chan T (2012) Arsenate adsorption from water using a novel fabricated copper ferrite. Chemical Engineering Journal 198-199:440-448

[69]Tu Y, You C (2014) Phosphorus adsorption onto green synthesized nano-bimetal ferrites: Equilibrium, kinetic and thermodynamic investigation. Chemical Engineering Journal 251:285292

[70]Rehman MA, Yusoff I, Alias Y (2015) Fluoride adsorption by doped and un-doped magnetic ferrites CuCexFe2-xO4: Preparation, characterization, optimization and modeling for effectual remediation technologies. Journal of Hazardous Materials 299:316-324

[71]Sun W, Pan W, Wang F, Xu N (2015) Removal of Se(IV) and Se(VI) by MFe2O4 nanoparticles from aqueous solution. Chemical Engineering Journal 273:353-362

[72]Duan S, Tang R, Xue Z, Zhang X, Zhao Y, Zhang W, Zhang J, Wang B, Zeng S, Sun D (2015) Effective removal of $\mathrm{Pb}(\mathrm{II})$ using magnetic $\mathrm{Co0} .6 \mathrm{Fe} 2.4 \mathrm{O} 4$ micro-particles as the adsorbent: 
Synthesis and study on the kinetic and thermodynamic behaviors for its adsorption. Colloids and Surfaces A: Physicochemical and Engineering Aspects 469:211-223

[73]Li J, Ng DHL, Song P, Song Y, Kong C (2015) Bio-inspired synthesis and characterization of mesoporous $\mathrm{ZnFe2O4}$ hollow fibers with enhancement of adsorption capacity for acid dye. Journal of Industrial and Engineering Chemistry 23:290-298

[74]Srivastava V, Sharma YC, Sillanpää M (2015) Application of nano-magnesso ferrite (n$\mathrm{MgFe} 2 \mathrm{O} 4)$ for the removal of $\mathrm{Co} 2+$ ions from synthetic wastewater: Kinetic, equilibrium and thermodynamic studies. Applied Surface Science 338:42-54

[75]Yang L, Zhang Y, Liu X, Jiang X, Zhang Z, Zhang T, Zhang L (2014) The investigation of synergistic and competitive interaction between dye Congo red and methyl blue on magnetic MnFe204. Chemical Engineering Journal 246:88-96

[76]Zhang S, Niu H, Cai Y, Zhao X, Shi Y (2010) Arsenite and arsenate adsorption on coprecipitated bimetal oxide magnetic nanomaterials: MnFe2O4 and CoFe2O4. Chemical Engineering Journal 158:599-607

[77]An S, Liu X, Yang L, Zhang L (2015) Enhancement removal of crystal violet dye using magnetic calcium ferrite nanoparticle: Study in single- and binary-solute systems. Chemical Engineering Research and Design 94:726-735

[78]Zeng S, Duan S, Tang R, Li L, Liu C, Sun D (2014) Magnetically separable Ni0.6Fe2.4O4 nanoparticles as an effective adsorbent for dye removal: Synthesis and study on the kinetic and thermodynamic behaviors for dye adsorption. Chemical Engineering Journal 258:218-228

[79]Liu R, Fu H, Yin H, Wang P, Lu L, Tao Y (2015) A facile sol combustion and calcination process for the preparation of magnetic Ni0.5Zn0.5Fe2O4 nanopowders and their adsorption behaviors of Congo red. Powder Technology 274:418-425

[80]Gao F, Chen X, Yin K, Dong S, Ren Z, Yuan F, Yu T, Zou Z, Liu J- (2007) Visible-Light Photocatalytic Properties of Weak Magnetic BiFeO3 Nanoparticles. Adv Mater 19:2889-2892 
[81]Li S, Jing L, Fu W, Yang L, Xin B, Fu H (2007) Photoinduced charge property of nanosized perovskite-type $\mathrm{LaFeO} 3$ and its relationships with photocatalytic activity under visible irradiation. Materials Research Bulletin 42:203-212

[82]Thirumalairajan S, Girija K, Ganesh V, Mangalaraj D, Viswanathan C, Ponpandian N (2013) Novel Synthesis of LaFeO3 Nanostructure Dendrites: A Systematic Investigation of Growth Mechanism, Properties, and Biosensing for Highly Selective Determination of Neurotransmitter Compounds. Crystal Growth \& Design 13:291-302

[83]Ismael M, Wark M (2019) Perovskite-type $\mathrm{LaFeO}_{3}$ : Photoelectrochemical Properties and Photocatalytic Degradation of Organic Pollutants Under Visible Light Irradiation. Catalysts $9: 4$

[84]Parida KM, Reddy KH, Martha S, Das DP, Biswal N (2010) Fabrication of nanocrystalline LaFeO3: An efficient sol-gel auto-combustion assisted visible light responsive photocatalyst for water decomposition. International Journal of Hydrogen Energy 35:12161-12168

[85]Gong S, Xie Z, Li W, Wu X, Han N, Chen Y (2019) Highly active and humidity resistive perovskite LaFeO3 based catalysts for efficient ozone decomposition. Applied Catalysis B: Environmental 241:578-587

[86]Zaharieva K, Rives V, Tsvetkov M, Cherkezova-Zheleva Z, Kunev B, Trujillano R, Mitov I, Milanova M (2015) Preparation, characterization and application of nanosized copper ferrite photocatalysts for dye degradation under UV irradiation. Mater Chem Phys 160:271-278

[87]Mahto TK, Roy A, Sahoo B, Sahu SK (2015) Citric acid fuctionalized magnetic ferrite nanoparticles for photocatalytic degradation of azo dye. J Nanosci Nanotechnol 15:273-280

[88]EL-Rafei AM, El-Kalliny AS, Gad-Allah TA (2017) Electrospun magnetically separable calcium ferrite nanofibers for photocatalytic water purification. Journal of Magnetism and Magnetic Materials 428:92-98

[89]Patil SB, Bhojya Naik HS, Nagaraju G, Viswanath R, Rashmi SK, Vijay kumar M (2018) Sugarcane juice mediated eco-friendly synthesis of visible light active zinc ferrite 
nanoparticles: Application to degradation of mixed dyes and antibacterial activities. Mater Chem Phys 212:351-362

[90]Roonasi P, Mazinani M (2017) Synthesis and application of barium ferrite/activated carbon composite as an effective solar photocatalyst for discoloration of organic dye contaminants in wastewater. J Environ Chem Eng 5:3822-3827

[91]Song Y, Xue S, Wang G, Jin J, Liang Q, Li Z, Xu S (2018) Enhanced photocatalytic decomposition of an organic dye under visible light with a stable $\mathrm{LaFeO} / \mathrm{AgBr}$ heterostructured photocatalyst. Journal of Physics and Chemistry of Solids 121:329-338

[92]Malathi A, Arunachalam P, Kirankumar VS, Madhavan J, Al-Mayouf AM (2018) An efficient visible light driven bismuth ferrite incorporated bismuth oxyiodide (BiFeO3/BiOI) composite photocatalytic material for degradation of pollutants. Opt Mater 84:227-235

[93]Bhoi YP, Mishra BG (2018) Photocatalytic degradation of alachlor using type-II CuS/BiFeO3 heterojunctions as novel photocatalyst under visible light irradiation. Chemical Engineering Journal 344:391-401

[94]Luo J, Li R, Chen Y, Zhou X, Ning X, Zhan L, Ma L, Xu X, Xu L, Zhang L (2019) Rational design of Z-scheme LaFeO3/SnS2 hybrid with boosted visible light photocatalytic activity towards tetracycline degradation. Separation and Purification Technology 210:417-430

[95]Zhu K, Wang J, Wang Y, Jin C, Ganeshraja AS (2016) Visible-light-induced photocatalysis and peroxymonosulfate activation over $\mathrm{ZnFe2O}$ fine nanoparticles for degradation of Orange II. Catal Sci Technol 6:2296-2304

[96]Li C, Wang J, Wang B, Gong J, Lin Z (2012) Direct Formation of Reusable TiO2/CoFe2O4 Heterogeneous Photocatalytic Fibers via Two-Spinneret Electrospinning. Journal of Nanoscience and Nanotechnology 12:2496-2502

[97]Mandal S, Natarajan S, Tamilselvi A, Mayadevi S (2016) Photocatalytic and antimicrobial activities of zinc ferrite nanoparticles synthesized through soft chemical route: A magnetically 
recyclable catalyst for water/wastewater treatment. Journal of Environmental Chemical Engineering 4:2706-2712

[98]Chen C, Butler E, Ahmad MA, Hung Y, Fu Y (2014) Characterizations of TiO2@Mn-Zn ferrite powders for magnetic photocatalyst prepared from used alkaline batteries and waste steel pickling liquor. Materials Research Bulletin 50:178-182

[99]Meng W, Hu R, Yang J, Du Y, Li J, Wang H (2016) Influence of lanthanum-doping on photocatalytic properties of $\mathrm{BiFeO} 3$ for phenol degradation. Cuihua Xuebao Chin J Catalysis $37: 1283-1292$

[100]Xu Y-, Rao H-, Wang X-, Chen H-, Kuang D-, Su C- (2016) In situ formation of zinc ferrite modified Al-doped ZnO nanowire arrays for solar water splitting. J Mater Chem A 4:5124-5129

[101]Li R, Cai M, Xie Z, Zhang Q, Zeng Y, Liu H, Liu G, Lv W (2019) Construction of heterostructured CuFe2O4/g-C3N4 nanocomposite as an efficient visible light photocatalyst with peroxydisulfate for the organic oxidation. Appl Catal B Environ:974-982

[102]Dumitru R, Ianculescu A, Păcurariu C, Lupa L, Pop A, Vasile B, Surdu A, Manea F (2019) BiFeO3-synthesis, characterization and its photocatalytic activity towards doxorubicin degradation from water. Ceramics International 45:2789-2802

[103]Jamil TS, Abbas HA, Nasr RA, Vannier R- (2018) Visible light activity of BaFe1-xCuxO3-d as photocatalyst for atrazine degradation. Ecotoxicol Environ Saf 163:620-628

[104]Aghdam TR, Mehrizadeh H, Salari D, Tseng H-, Niaei A, Amini A (2018) Photocatalytic removal of $\mathrm{NOx}$ over immobilized $\mathrm{BiFeO} 3$ nanoparticles and effect of operational parameters. Korean J Chem Eng 35:994-999

[105]Gao J, Wu S, Han Y, Tan F, Shi Y, Liu M, Li X (2018) 3D mesoporous CuFe2O4 as a catalyst for photo-Fenton removal of sulfonamide antibiotics at near neutral pH. Journal of Colloid and Interface Science 524:409-416 
[106]Samoila P, Cojocaru C, Sacarescu L, Dorneanu PP, Domocos A, Rotaru A (2017) Remarkable catalytic properties of rare-earth doped nickel ferrites synthesized by sol-gel auto-combustion with maleic acid as fuel for CWPO of dyes. Applied Catalysis B: Environmental 202:21-32

[107]Phan TTN, Nikoloski AN, Bahri PA, Li D (2018) Heterogeneous photo-Fenton degradation of organics using highly efficient Cu-doped LaFeO3 under visible light. Journal of Industrial and Engineering Chemistry 61:53-64

[108]Li Y, Chen D, Fan S, Yang T (2019) Enhanced visible light assisted Fenton-like degradation of dye via metal-doped zinc ferrite nanosphere prepared from metal-rich industrial wastewater. J Taiwan Inst Chem Eng 96:185-192

[109]Garcia-Muñoz P, Fresno F, Lefevre C, Robert D, Keller N (2020) Highly robust La1xTixFeO3 dual catalyst with combined photocatalytic and photo-CWPO activity under visible light for 4-chlorophenol removal in water. Applied Catalysis B: Environmental 262:118310

[110]Phan TTN, Nikoloski AN, Bahri PA, Li D (2018) Heterogeneous photo-Fenton degradation of organics using highly efficient Cu-doped LaFeO3 under visible light. Journal of Industrial and Engineering Chemistry 61:53-64

[111]Annie Vinosha P, Jerome Das S (2018) Investigation on the role of $\mathrm{pH}$ for the structural, optical and magnetic properties of cobalt ferrite nanoparticles and its effect on the photofenton activity. Materials Today: Proceedings 5:8662-8671

[112]Gao J, Wu S, Han Y, Tan F, Shi Y, Liu M, Li X (2018) 3D mesoporous CuFe2O4 as a catalyst for photo-Fenton removal of sulfonamide antibiotics at near neutral pH. Journal of Colloid and Interface Science 524:409-416

[113]Samoila P, Cojocaru C, Sacarescu L, Dorneanu PP, Domocos A, Rotaru A (2017) Remarkable catalytic properties of rare-earth doped nickel ferrites synthesized by sol-gel auto-combustion with maleic acid as fuel for CWPO of dyes. Applied Catalysis B: Environmental 202:21-32 
[114]Yang X, Wang D (2018) Photocatalysis: From Fundamental Principles to Materials and Applications. ACS Appl Energy Mater 1:6657-6693

[115]Armaroli N, Balzani V (2011) The hydrogen issue. ChemSusChem 4:21-36

[116]Christoforidis KC, Fornasiero P (2017) Photocatalytic Hydrogen Production: A Rift into the Future Energy Supply. ChemCatChem 9:1523-1544

[117]Colmenares JC (2019) Selective redox photocatalysis: Is there any chance for solar biorefineries?. Current Opinion in Green and Sustainable Chemistry 15:38-46

[118]Kudo A, Miseki Y (2009) Heterogeneous photocatalyst materials for water splitting. Chem Soc Rev 38:253-278

[119]Coronado JM, Fresno F, Hernández-Alonso MD, Portela R (2013) Design of advanced photocatalytic materials for energy and environmental applications. Green Energy and Technology 71

[120]Osterloh FE (2008) Inorganic materials as catalysts for photochemical splitting of water. Chem Mater 20:35-54

[121]Dillert R, Taffa DH, Wark M, Bredow T, Bahnemann DW (2015) Research Update: Photoelectrochemical water splitting and photocatalytic hydrogen production using ferrites (MFe2O4) under visible light irradiation. APL Mater 3

[122]Taffa DH, Dillert R, Ulpe AC, Bauerfeind KCL, Bredow T, Bahnemann DW, Wark M (2017) Photoelectrochemical and theoretical investigations of spinel type ferrites (MxFe3-xO4) for water splitting: A mini-review. J Photonics Energy 7

[123]Cao J, Kako T, Li P, Ouyang S, Ye J (2011) Fabrication of p-type CaFe2O4 nanofilms for photoelectrochemical hydrogen generation. Electrochem Commun 13:275-278 
[124]Ida S, Yamada K, Matsunaga T, Hagiwara H, Matsumoto Y, Ishihara T (2010) Preparation of p-type CaFe 204 photocathodes for producing hydrogen from water. J Am Chem Soc 132:17343-17345

[125]Ida S, Yamada K, Matsunaga T, Hagiwara H, Ishihara T, Taniguchi T, Koinuma M, Matsumoto $Y$ (2011) Photoelectrochemical hydrogen production from water using p-type CaFe 204 and n-type ZnO. Electrochem 79:797-800

[126]Ida S, Yamada K, Matsuka M, Hagiwara H, Ishihara T (2012) Photoelectrochemical hydrogen production from water using $\mathrm{p}$-type and $\mathrm{n}$-type oxide semiconductor electrodes. Electrochim Acta 82:397-401

[127]Matsumoto Y, Omae M, Sugiyama K, Sato E- (1987) New photocathode materials for hydrogen evolution: CaFe2O4 and Sr7Fe10022. J Phys Chem 91:577-581

[128]Matsumoto Y, Sugiyama K, Sato E- (1988) Improvement of CaFe2O4 photocathode by doping with $\mathrm{Na}$ and Mg. J Solid State Chem 74:117-125

[129]Cao J, Xing J, Zhang Y, Tong H, Bi Y, Kako T, Takeguchi M, Ye J (2013) Photoelectrochemical properties of nanomultiple CaFe 204 /ZnFe 204 pn junction photoelectrodes. Langmuir 29:3116-3124

[130]Sekizawa K, Nonaka T, Arai T, Morikawa T (2014) Structural improvement of CaFe2O4 by metal doping toward enhanced cathodic photocurrent. ACS Appl Mater Interfaces 6:1096910973

[131]Kung HH, Jarrett HS, Sleight AW, Ferretti A (1977) Semiconducting oxide anodes in photoassisted electrolysis of water. J Appl Phys 48:2463-2469

[132]Archer MD, Morris GC, Yim GK (1981) Electrochemical approaches to solar energy conversion: A brief overview and preliminary results obtained with $n$-type cobalt ferrite. J Electroanal Chem 118:89-100 
[133]Yang H, Mao Y, Li M, Liu P, Tong Y (2013) Electrochemical synthesis of CoFe2O4 porous nanosheets for visible light driven photoelectrochemical applications. New J Chem 37:29652968

[134]Rekhila G, Bessekhouad Y, Trari M (2013) Visible light hydrogen production on the novel ferrite NiFe 204. Int J Hydrogen Energy 38:6335-6343

[135]Antonious MS, Etman M, Guyot M, Merceron T (1986) Photoelectrochemical characteristics of $\mathrm{p}$ - and $\mathrm{n}$ - type polycrystalline Ni-ferrite electrodes in aqueous solutions. Mater Res Bull 21:1515-1523

[136]de Haart LGJ, Blasse G (1985) Photoelectrochemical Properties of Ferrites with the Spinel Structure. J Electrochem Soc 132:2933-2938

[137]Benko FA, Koffyberg FP (1986) The effect of defects on some photoelectrochemical properties of semiconducting MgFe2O4. Mater Res Bull 21:1183-1188

[138]Zazoua H, Boudjemaa A, Chebout R, Bachari K (2014) Enhanced photocatalytic hydrogen production under visible light over a material based on magnesium ferrite derived from layered double hydroxides (LDHs). Int J Energy Res 38:2010-2018

[139]Chang BT, Jakani M, Campet G, Claverie J (1988) Photoelectrochemical study of a spineltype titanomagnetite. J Solid State Chem 72:201-208

[140]Matsumoto Y, Omae M, Watanabe I, Sato E- (1986) Photoelectrochemical properties of the Zn-Ti-Fe spinel oxides. J Electrochem Soc 133:711-716

[141]Tahir AA, Wijayantha KGU (2010) Photoelectrochemical water splitting at nanostructured ZnFe 204 electrodes. J Photochem Photobiol A Chem 216:119-125

[142]Tahir AA, Burch HA, Wijayantha KGU, Pollet BG (2013) A new route to control texture of materials: Nanostructured ZnFe 204 photoelectrodes. Int J Hydrogen Energy 38:4315-4323 
[143]Senftle TP, Carter EA (2017) The holy grail: Chemistry enabling an economically viable CO2 capture, utilization, and storage strategy. Acc Chem Res 50:472-475

[144]Fresno F, Villar-García IJ, Collado L, Alfonso-González E, Renones P, Barawi M, De La Pena O'Shea VA (2018) Mechanistic View of the Main Current Issues in Photocatalytic CO 2 Reduction. J Phys Chem Lett 9:7192-7204

[145]Mota FM, Kim DH (2019) From CO2 methanation to ambitious long-chain hydrocarbons: Alternative fuels paving the path to sustainability. Chem Soc Rev 48:205-259

[146]Ran J, Jaroniec M, Qiao S- (2018) Cocatalysts in Semiconductor-based Photocatalytic CO2 Reduction: Achievements, Challenges, and Opportunities. Adv Mater 30

[147]Lais A, Gondal MA, Dastageer MA (2018) Semiconducting oxide photocatalysts for reduction of CO2 to methanol. Environ Chem Lett 16:183-210

[148]Matsumoto Y (1996) Energy positions of oxide semiconductors and photocatalysis with iron complex oxides. J Solid State Chem 126:227-234

[149]Neudeck C, Kim Y-, Ogasawara W, Shida Y, Meldrum F, Walsh D (2011) General route to functional metal oxide nanosuspensions, enzymatically deshelled nanoparticles, and their application in photocatalytic water splitting. Small 7:869-873

[150]Mangrulkar PA, Joshi MM, Tijare SN, Polshettiwar V, Labhsetwar NK, Rayalu SS (2012) Nano cobalt oxides for photocatalytic hydrogen production. Int J Hydrogen Energy 37:1046210466

[151]Büchler M, Schmuki P, Böhni H, Stenberg T, Mäntylä T (1998) Comparison of the semiconductive properties of sputter-deposited iron oxides with the passive film on iron. J Electrochem Soc 145:378-385

[152] Gobara HM, Nassar IM, El Naggar AMA, Eshaq G (2017) Nanocrystalline spinel ferrite for an enriched production of hydrogen through a solar energy stimulated water splitting process. Energy 118:1234-1242 
[153]Rekhila G, Bessekhouad Y, Trari M (2013) Visible light hydrogen production on the novel ferrite NiFe 204. Int J Hydrogen Energy 38:6335-6343

[154]Peng T, Zhang X, Lv H, Zan L (2012) Preparation of NiFe2O4 nanoparticles and its visiblelight-driven photoactivity for hydrogen production. Catalysis Communications 28:116-119

[155]Hong D, Yamada Y, Sheehan M, Shikano S, Kuo C-, Tian M, Tsung C-, Fukuzumi S (2014) Mesoporous nickel ferrites with spinel structure prepared by an aerosol spray pyrolysis method for photocatalytic hydrogen evolution. ACS Sustainable Chem Eng 2:2588-2594

[156]Domínguez-Arvizu JL, Jiménez-Miramontes JA, Salinas-Gutiérrez JM, Meléndez-Zaragoza MJ, López-Ortiz A, Collins-Martínez V (2017) Optical properties determination of NiFe2O4 nanoparticles and their photocatalytic evaluation towards hydrogen production. Int J Hydrogen Energy 42:30242-30248

[157]Núñez J, Fresno F, Platero-Prats AE, Jana P, Fierro JLG, Coronado JM, Serrano DP, De La Peña O'Shea VA (2016) Ga-Promoted Photocatalytic H2 Production over Pt/ZnO Nanostructures. ACS Appl Mater Interfaces 8:23729-23738

[158]Zeng J, Zeng W, Zeng H (2017) In situ plasmonic Au nanoparticle anchored nickel ferrite: An efficient plasmonic photocatalyst for fluorescein-sensitized hydrogen evolution under visible light irradiation. J Solid State Chem 253:294-304

[159]Rodríguez-Rodríguez AA, Moreno-Trejo MB, Meléndez-Zaragoza MJ, Collins-Martínez V, López-Ortiz A, Martínez-Guerra E, Sánchez-Domínguez M (2018) Spinel-type ferrite nanoparticles: Synthesis by the oil-in-water microemulsion reaction method and photocatalytic water-splitting evaluation. Int J Hydrogen Energy

[160]Dom R, Subasri R, Hebalkar NY, Chary AS, Borse PH (2012) Synthesis of a hydrogen producing nanocrystalline $\mathrm{ZnFe2O} 4$ visible light photocatalyst using a rapid microwave irradiation method. RSC Adv 2:12782-12791 
[161]Boudjemaa A, Popescu I, Juzsakova T, Kebir M, Helaili N, Bachari K, Marcu I- (2016) Msubstituted $(\mathrm{M}=\mathrm{Co}, \mathrm{Ni}$ and $\mathrm{Cu}$ ) zinc ferrite photo-catalysts for hydrogen production by water photo-reduction. Int J Hydrogen Energy 41:11108-11118

[162] Ortega López Y, Medina Vázquez H, Salinas Gutiérrez J, Guzmán Velderrain V, López Ortiz A, Collins Martínez V (2015) Synthesis method effect of CoFe2O4 on its photocatalytic properties for $\mathrm{H} 2$ production from water and visible light. J Nanomater 2015

[163]Yang H, Yan J, Lu Z, Cheng X, Tang Y (2009) Photocatalytic activity evaluation of tetragonal CuFe2O4 nanoparticles for the $\mathrm{H} 2$ evolution under visible light irradiation. J Alloys Compd 476:715-719

[164]Dom R, Kim HG, Borse PH (2017) Photo Chemical Hydrogen Generation from Orthorhombic CaFe2O4 Nanoparticles Synthesized by Different Methods. ChemistrySelect 2:2556-2564

[165]Jiménez-Miramontes JA, Domínguez-Arvizu JL, Salinas-Gutiérrez JM, Meléndez-Zaragoza MJ, López-Ortiz A, Collins-Martínez V (2017) Synthesis, characterization and photocatalytic evaluation of strontium ferrites towards $\mathrm{H} 2$ production by water splitting under visible light irradiation. Int J Hydrogen Energy 42:30257-30266

[166]Parida KM, Reddy KH, Martha S, Das DP, Biswal N (2010) Fabrication of nanocrystalline LaFeO3: An efficient sol-gel auto-combustion assisted visible light responsive photocatalyst for water decomposition. Int J Hydrogen Energy 35:12161-12168

[167]Tijare SN, Joshi MV, Padole PS, Mangrulkar PA, Rayalu SS, Labhsetwar NK (2012) Photocatalytic hydrogen generation through water splitting on nano-crystalline LaFeO3 perovskite. Int J Hydrogen Energy 37:10451-10456

[168]lervolino G, Vaiano V, Sannino D, Rizzo L, Ciambelli P (2016) Production of hydrogen from glucose by LaFeO3 based photocatalytic process during water treatment. Int J Hydrogen Energy 41:959-966 
[169]Chen Z, Fan T, Zhang Q, He J, Fan H, Sun Y, Yi X, Li J (2019) Interface engineering: Surface hydrophilic regulation of $\mathrm{LaFeO} 3$ towards enhanced visible light photocatalytic hydrogen evolution. J Colloid Interface Sci 536:105-111

[170]Hojamberdiev M, Kawashima K, Kumar M, Yamakata A, Yubuta K, Gurlo A, Hasegawa M, Domen K, Teshima K (2017) Engaging the flux-grown La1-xSrxFe1-yTiyO3 crystals in visiblelight-driven photocatalytic hydrogen generation. Int J Hydrogen Energy 42:27024-27033

[171]Chen D, Zhang F, Li Q, Wang W, Qian G, Jin Y, Xu Z (2017) A promising synergistic effect of nickel ferrite loaded on the layered double hydroxide-derived carrier for enhanced photocatalytic hydrogen evolution. Int J Hydrogen Energy 42:867-875

[172]Matsumoto Y, Obata M, Hombo J (1994) Photocatalytic reduction of carbon dioxide on p-type CaFe2O4 powder. J Phys Chem 98:2950-2951

[173]Xiao J, Yang W, Gao S, Sun C, Li Q (2018) Fabrication of ultrafine ZnFe2O4 nanoparticles for efficient photocatalytic reduction $\mathrm{CO} 2$ under visible light illumination. J Mater Sci Technol $34: 2331-2336$

[174]Kim HG, Borse PH, Jang JS, Jeong ED, Jung O-, Suh YJ, Lee JS (2009) Fabrication of CaFe2O4/MgFe2O4 bulk heterojunction for enhanced visible light photocatalysis. Chem Commun:5889-5891

[175]Vijayaraghavan T, Lakshmana Reddy N, Shankar MV, Vadivel S, Ashok A (2018) A cocatalyst free, eco-friendly, novel visible light absorbing iron based complex oxide nanocomposites for enhanced photocatalytic hydrogen evolution. Int J Hydrogen Energy 43:14417-14426

[176]An X, Cheng D, Dai L, Wang B, Ocampo HJ, Nasrallah J, Jia X, Zou J, Long Y, Ni Y (2017) Synthesis of nano-fibrillated cellulose/magnetite/titanium dioxide (NFC@Fe304@TNP) nanocomposites and their application in the photocatalytic hydrogen generation. Appl Catal B Environ 206:53-64 
[177]Beydoun D, Amal R, Low GK-, McEvoy S (2000) Novel Photocatalyst: Titania-Coated Magnetite. Activity and Photodissolution. J Phys Chem B 104:4387-4396

[178] Hafeez HY, Lakhera SK, Karthik P, Anpo M, Neppolian B (2018) Facile construction of ternary CuFe2O4-TiO2 nanocomposite supported reduced graphene oxide (rGO) photocatalysts for the efficient hydrogen production. Appl Surf Sci 449:772-779

[179]Uddin MR, Khan MR, Rahman MW, Yousuf A, Cheng CK (2015) Photocatalytic reduction of $\mathrm{CO} 2$ into methanol over CuFe2O4/TiO2 under visible light irradiation. React Kinet Mech Catal 116:589-604

[180]Song G, Xin F, Yin X (2015) Photocatalytic reduction of carbon dioxide over ZnFe2O4/TiO2 nanobelts heterostructure in cyclohexanol. J Colloid Interface Sci 442:60-66

[181]Song G, Wu X, Xin F, Yin X (2017) ZnFe2O4 deposited on BiOCl with exposed (001) and (010) facets for photocatalytic reduction of CO2 in cyclohexanol. Front Chem Sci Eng 11:197204

[182]Song G, Wu X, Xin F, Yin X (2017) Synthesis of different shapes ZnFe2O4-BiOCl nanocomposites for photocatalytic reduction of $\mathrm{CO} 2$ in cyclohexanol. J Nanosci Nanotechnol $17: 2438-2446$

[183]Soto-Arreola A, Huerta-Flores AM, Mora-Hernández JM, Torres-Martínez LM (2018) Improved photocatalytic activity for water splitting over MFe2O4-ZnO ( $\mathrm{M}=\mathrm{Cu}$ and Ni) type-II heterostructures. J Photochem Photobiol A Chem 364:433-442

[184]Karamian E, Sharifnia S (2018) Enhanced visible light photocatalytic activity of BiFeO3ZnO p-n heterojunction for $\mathrm{CO} 2$ reduction. Mater Sci Eng B Solid State Adv Technol 238239:142-148

[185]Guo J, Wang K, Wang X (2017) Photocatalytic reduction of CO2 with $\mathrm{H} 2 \mathrm{O}$ vapor under visible light over Ce doped ZnFe2O4. Catal Sci Technolog 7:6013-6025 
[186]Khan I, Sun N, Zhang Z, Li Z, Humayun M, Ali S, Qu Y, Jing L (2019) Improved visible-light photoactivities of porous LaFeO3 by coupling with nanosized alkaline earth metal oxides and mechanism insight. Catal Sci Technolog 9:3149-3157

[187]Kwon S, Liao P, Stair PC, Snurr RQ (2016) Alkaline-earth metal-oxide overlayers on TiO2: Application toward CO2 photoreduction. Catal Sci Technolog 6:7885-7895

[188]Ong W-, Tan L-, Ng YH, Yong S-, Chai S- (2016) Graphitic Carbon Nitride (g-C3N4)-Based Photocatalysts for Artificial Photosynthesis and Environmental Remediation: Are We a Step Closer to Achieving Sustainability?. Chem Rev 116:7159-7329

[189]Chen J, Zhao D, Diao Z, Wang M, Guo L, Shen S (2015) Bifunctional Modification of Graphitic Carbon Nitride with MgFe2O4 for Enhanced Photocatalytic Hydrogen Generation. ACS Appl Mater Interfaces 7:18843-18848

[190]Chen J, Zhao D, Diao Z, Wang M, Shen S (2016) Ferrites boosting photocatalytic hydrogen evolution over graphitic carbon nitride: a case study of (Co, Ni)Fe2O4 modification. Sci Bull 61:292-301

[191]Acharya S, Mansingh S, Parida KM (2017) The enhanced photocatalytic activity of gC3N4-LaFeO3 for the water reduction reaction through a mediator free Z-scheme mechanism. Inorg Chem Front 4:1022-1032

[192]Xu K, Feng J (2017) Superior photocatalytic performance of LaFeO3/g-C3N4 heterojunction nanocomposites under visible light irradiation. RSC Adv 7:45369-45376

[193]Xu K, Xu H, Feng G, Feng J (2017) Photocatalytic hydrogen evolution performance of NiS cocatalyst modified LaFeO3/g-C3N4 heterojunctions. New J Chem 41:14602-14609

[194]Fan W, Li M, Bai H, Xu D, Chen C, Li C, Ge Y, Shi W (2016) Fabrication of MgFe2O4/MoS2 Heterostructure Nanowires for Photoelectrochemical Catalysis. Langmuir 32:1629-1636 
[195]Jiang J, Fan W, Zhang X, Bai H, Liu Y, Huang S, Mao B, Yuan S, Liu C, Shi W (2016) Rod-intube nanostructure of MgFe 204 : electrospinning synthesis and photocatalytic activities of tetracycline. New J Chem 40:538-544

[196]Guijarro N, Bornoz P, Prévot M, Yu X, Zhu X, Johnson M, Jeanbourquin X, Le Formal F, Sivula K (2018) Evaluating spinel ferrites MFe $204(\mathrm{M}=\mathrm{Cu}, \mathrm{Mg}, \mathrm{Zn})$ as photoanodes for solar water oxidation: Prospects and limitations. Sustain Energy Fuels 2:103-117

[197]Rezaul Karim KM, Ong HR, Abdullah H, Yousuf A, Cheng CK, Rahman Khan MM (2018) Photoelectrochemical reduction of carbon dioxide to methanol on p-type CuFe2O4 under visible light irradiation. Int J Hydrogen Energy 43:18185-18193

[198]Kim JH, Kim JH, Jang J-, Kim JY, Choi SH, Magesh G, Lee J, Lee JS (2015) Awakening solar water-splitting activity of ZnFe2O4 nanorods by hybrid microwave annealing. Adv Energy Mater 5

[199]Kim JH, Jang YJ, Kim JH, Jang J-, Choi SH, Lee JS (2015) Defective ZnFe2O4nanorods with oxygen vacancy for photoelectrochemical water splitting. Nanoscale 7:19144-19151

[200]Hufnagel AG, Peters K, Müller A, Scheu C, Fattakhova-Rohlfing D, Bein T (2016) Zinc Ferrite Photoanode Nanomorphologies with Favorable Kinetics for Water-Splitting. Adv Funct Mater 26:4435-4443

[201]Sharma P, Jang J, Lee JS (2019) Key Strategies to Advance the Photoelectrochemical Water Splitting Performance of Ît-Fe2O3 Photoanode. ChemCatChem 11:157-179

[202]Sivula K (2013) Metal Oxide Photoelectrodes for Solar Fuel Production, Surface Traps, and Catalysis. J Phys Chem Lett 4:1624-1633

[203]McDonald KJ, Choi K- (2011) Synthesis and photoelectrochemical properties of Fe2O 3/ZnFe2O4 composite photoanodes for use in solar water oxidation. Chem Mater 23:48634869 
[204]Guo Y, Fu Y, Liu Y, Shen S (2014) Photoelectrochemical activity of ZnFe2O4 modified aFe2O3 nanorod array films. RSC Adv 4:36967-36972

[205]Dom R, Kumar GS, Hebalkar NY, Joshi SV, Borse PH (2013) Eco-friendly ferrite nanocomposite photoelectrode for improved solar hydrogen generation. RSC Adv 3:1521715224

[206]Kim JY, Magesh G, Youn DH, Jang J-, Kubota J, Domen K, Lee JS (2013) Single-crystalline, wormlike hematite photoanodes for efficient solar water splitting. Sci Rep 3

[207]Kim ES, Kang HJ, Magesh G, Kim JY, Jang J-, Lee JS (2014) Improved photoelectrochemical activity of CaFe2O4/BiVO4 heterojunction photoanode by reduced surface recombination in solar water oxidation. ACS Appl Mater Interfaces 6:17762-17769

[208]Ahmed MG, Kandiel TA, Ahmed AY, Kretschmer I, Rashwan F, Bahnemann D (2015) Enhanced photoelectrochemical water oxidation on nanostructured hematite photoanodes via p-CaFe2O4/n-Fe2O3 heterojunction formation. J Phys Chem C 119:5864-5871

[209]Iervolino G, Vaiano V, Sannino D, Rizzo L, Palma V (2017) Enhanced photocatalytic hydrogen production from glucose aqueous matrices on Ru-doped LaFeO3. Applied Catalysis B: Environmental 207:182-194

[210]Chen H, Sun X, Xu X (2017) Ruddlesden-Popper compounds (SrO)(LaFeO3)n ( $n=1$ and 2) as p-type semiconductors for photocatalytic hydrogen production. Electrochimica Acta 252:138-146 